\title{
Surgical implications of sacrococcygeal teratoma and its consequences
}

Citation for published version (APA):

Kremer, M. E. B. (2017). Surgical implications of sacrococcygeal teratoma and its consequences.

[Doctoral Thesis, Maastricht University]. Maastricht University. https://doi.org/10.26481/dis.20170609mk

Document status and date:

Published: 01/01/2017

DOI:

10.26481/dis.20170609mk

Document Version:

Publisher's PDF, also known as Version of record

\section{Please check the document version of this publication:}

- A submitted manuscript is the version of the article upon submission and before peer-review. There can be important differences between the submitted version and the official published version of record.

People interested in the research are advised to contact the author for the final version of the publication, or visit the DOI to the publisher's website.

- The final author version and the galley proof are versions of the publication after peer review.

- The final published version features the final layout of the paper including the volume, issue and page numbers.

Link to publication

\footnotetext{
General rights rights.

- You may freely distribute the URL identifying the publication in the public portal. please follow below link for the End User Agreement:

www.umlib.nl/taverne-license

Take down policy

If you believe that this document breaches copyright please contact us at:

repository@maastrichtuniversity.nl

providing details and we will investigate your claim.
}

Copyright and moral rights for the publications made accessible in the public portal are retained by the authors and/or other copyright owners and it is a condition of accessing publications that users recognise and abide by the legal requirements associated with these

- Users may download and print one copy of any publication from the public portal for the purpose of private study or research.

- You may not further distribute the material or use it for any profit-making activity or commercial gain

If the publication is distributed under the terms of Article $25 \mathrm{fa}$ of the Dutch Copyright Act, indicated by the "Taverne" license above, 


\section{Surgical Implications of Sacrococcygeal Teratoma and Its Consequences}

Marijke Kremer 



\section{Surgical Implications of Sacrococcygeal Teratoma and Its Consequences}

\section{PROEFSCHRIFT}

Ter verkrijging van de graad van doctor aan de Universiteit Maastricht, op gezag van de Rector Magnificus,

Prof. dr. Rianne M. Letschert, volgens het besluit van het College van Decanen,

in het openbaar te verdedigen op vrijdag 9 juni 2017 om 14.00 uur

door

Marijke Elena Barbara Kremer

geboren op 6 mei 1985 te Aken, Duitsland 


\section{Promotiecommissie}

\section{Promotor}

Prof. dr. L.W.E. van Heurn

\section{Copromotor}

Dr. J.P.M. Derikx (AMC \& VU Medical Centre Amsterdam)

\section{Beoordelingscommissie}

Prof. dr. L.J.I. Zimmermann (Voorzitter)

Prof. dr. A. De Backer (Universitair Ziekenhuis Brussel, België)

Prof. dr. U.P. Neumann

Prof. dr. J.G. Nijhuis

Prof. dr. R.J. Rintala (University Hospital Helsinki, Finland) 
Für Mama und Papa 


\section{Print:}

Schrijen-Lippertz

Design and layout:

Topic-art - Eric Lemmens

D\&L graphics - www.dlgraphics.nl

ISBN/EAN: 978-90-824909-2-3

Printing of this thesis was financially supported by Stöpler and Edustitch.

Copyright: No part of this book may be reproduced, stored in a retrieval system or transmitted in any form or by any means, without written permission of the author or, when appropriate, of the scientific journal in which parts of this book have been published. 


\section{CONTENTS}

Chapter 1 General introduction

Chapter 2 The incidence of associated congenital abnormalities in patients with sacrococcygeal teratoma

Chapter 3 Haemorrhage is the most common cause of neonatal mortality in patients with sacrococcygeal teratoma

Chapter 4 Patient reported defecation and micturition complaints in adults treated for sacrococcygeal teratoma during childhood - the need for new surveillance strategies

Chapter 5 Sexual function after treatment for sacrococcygeal teratoma 73 during childhood

Chapter 6 Evaluation of pregnancy and delivery in 13 women who 93 underwent resection of a sacrococcygeal teratoma during early childhood

Chapter 7 Quality of life in adulthood after resection of a sacrococcygeal teratoma in childhood - a Dutch multicentre study

Chapter 8 Evaluation of chemotherapeutic sequelae and quality of life in survivors of malignant sacrococcygeal teratoma

Chapter 9 General discussion and summary

Dankwoord 


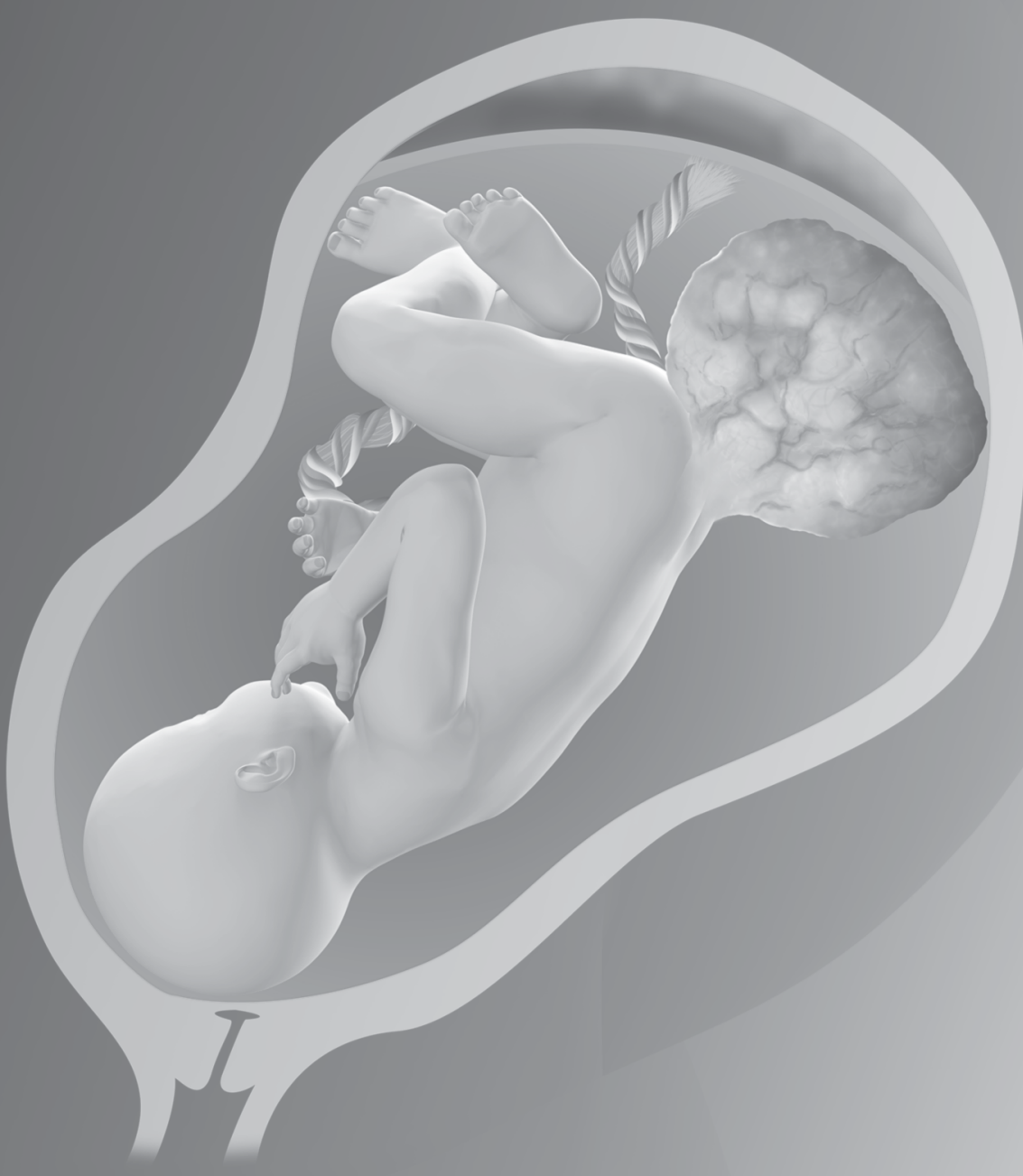




\section{CHAPTER 1}

General introduction 
Chapter 1 


\section{General introduction}

Sacrococcygeal teratoma (SCT) is the most common congenital tumour in neonates and belongs to the group of extra gonadal germ cell tumours. ${ }^{1,2}$ With an incidence of one in 15,000 - 40,000 live births it remains a rare condition. Based on a national study, the incidence of SCT in the Netherlands has been calculated to be at least one in 28,500 newborns; thus approximately six children are born with this disease in the Netherlands annually. Sacrococcygeal teratoma is more often seen in females than in males with a known female predominance of $4: 1 .^{3-5}$

Sacrococcygeal teratoma has been described for the first time approximately $2500 \mathrm{BC}$ by Egyptian foetoscopists. ${ }^{6}$ The term teratoma is derived from the Greek word "teras", meaning wonder if used in a positive sense or monster if used in a negative sense. The suffix "-om" designates a tumour. In the Dutch vernacular this tumour therefore is also called "wondergezwel", whereby the term "sacrococcygeal" specifies the localization of the tumour as it emerges from the coccygeal bone and spreads along the sacral bone and pelvic floor. ${ }^{7}$

\section{Embryonic germ line development as the origin of sacrococcygeal teratoma}

As mentioned above, SCT belongs to the group of what are called germ cell tumours, implying that these tumours arise from a cell line that is predetermined to give rise to gametes. Germ cell tumours can arise in extra gonadal locations (e.g. the sacrococcygeal region) or in the gonads in both sexes and may develop at any age. Extra gonadal tumours are predominantly found during infancy and gonadal tumours (e.g. testicular or ovarian germ cell tumours) are mainly found during puberty and thereafter. ${ }^{2,8}$

To understand the development of sacrococcygeal teratoma some basic knowledge on embryonic germ line development is required. Germ cells become separated from the somatic cells early in embryogenesis to form the sex cells (i.e. the gametes) in both males and females at a later stage. ${ }^{9}$ The precursors of the embryonic germ line development are the primordial germ cells (PGCs). One of the most important properties of these cells is their pluripotency giving these cells the ability to produce differentiated cell types arising from the three different germ layers ectoderm, mesoderm and endoderm. ${ }^{10}$ These three germ layers form the origin for the later formation of internal organs and glands (arising from endoderm) or muscles, 


\section{Chapter 1}

bones, connective- and supporting tissues (arising from mesoderm) as well as brain, nerve tissue and skin cells (arising from ectoderm). ${ }^{11}$ This explains why PGCs can give rise to a broad panel of organ-like tissues including cerebral tissue, connective tissue and cartilage but also full-differentiated anatomical structures like teeth and hair, which are often found in teratomas in general. , $^{911,12}$

Primordial germ cells develop around the fourth to sixth week of embryogenesis when the three-laminar disc embryo begins to fold to form a three-dimensional tube body with various embryonic cavities. (Figure 1) During this period PGCs are identified for the first time in the wall of a cavity adherent to the embryo, the yolk sac, which is responsible for its haematopoiesis and primary nutrition. Before birth the yolk sac normally recedes completely; if not it remains as a so-called Meckel's diverticulum. ${ }^{9,11}$ Normally, PGCs migrate straight out of the yolk sac through the gut mesentery to arrive around the sixth foetal week at the dorsal body wall in the gonadal ridges. These are the primitive gonads where gametogenesis will take place at a later stage through interactions of PGCs with somatic cells (Figure 1). ${ }^{9,13}$

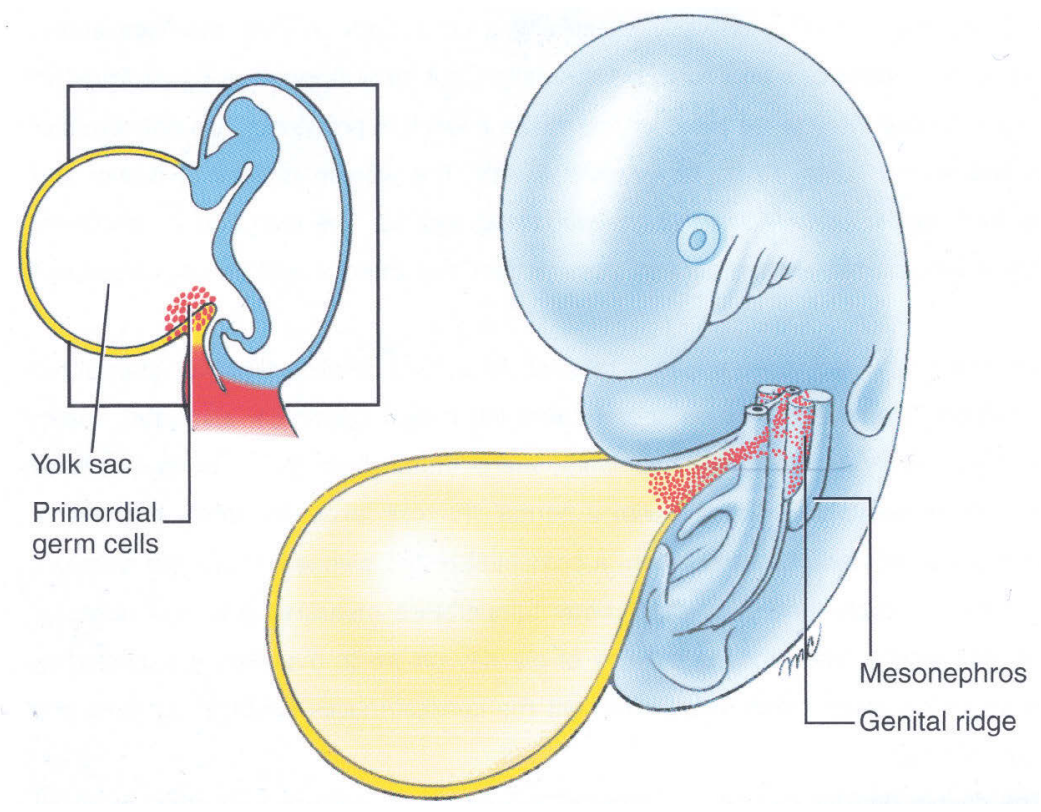

Figure 1. Migration of the primordial germ cells from the yolk sac to the genital ridge at the dorsal body wall ${ }^{11 *}$ 
The predetermined migration route of PGCs explains why extra gonadal germ cell tumours occur in the midline of the body, i.e. the ventral midline of the brain, mediastinal or sacrococcygeal. ${ }^{14}$ During their migration PGCs are normally guided to their final destination by interaction of several factors expressed by somatic cells along the route, including the Steel ligand with the receptor tyrosine kinase c-KIT expressed by PGCs. ${ }^{2,9,11}$ Sacrococcygeal teratomas therefore originate from an aberrant PGC migration pattern when stranded PGCs do not degenerate but continue to proliferate and differentiate through pregnancy. ${ }^{9,13}$ Normally, PGCs that fail to reach their final destination are eliminated by apoptosis. The KIT/KIT-ligand signal pathway, however, seems to be responsible for the suppression of apoptosis during migration of PGCs, as failure of a proper migration would lead to failure of the gonad formation. . $^{11,13}$

In contrast to e.g. the testicular germ cell tumours there is no gross genetic cause for the development of SCT as yet no uniform chromosomal aberrations have been identified in patients with SCT even though molecular research showed increased chromosomal aberrations in yolk sac tumour development. ${ }^{8}$ In addition, still there is no explanation of the female predominance of SCT.

Despite the absence of an underlying general gene defect, about $12-30 \%$ of patients diagnosed with SCT present with associated anomalies of various organs and body systems, most commonly urological and musculoskeletal anomalies.,12,15 As most of the studies reporting on SCT incidence had small sample sizes, risk factors and consequences of associated anomalies have been rarely studied and the implications of these anomalies for the surgical treatment and the functional outcomes are unknown.

\section{Histopathological classification and malignant degeneration of SCT}

Sacrococcygeal teratomas are histopathologically classified as mature, immature or malignant, referring to the degree of differentiation of the various tissues that the tumour contains. Mature teratomas are benign tumours principally consisting of well-differentiated tissue elements representing the three germ cell layers and in general have a more cystic appearance. Immature teratomas are more solid and in contrast contain incomplete differentiated components of embryonic tissues - or at least foci of these tissues - and often contain primitive neuroepithelium. ${ }^{12,16}$ 


\section{Chapter 1}

Malignant teratomas contain any kind of malignant elements and in most of the cases yolk sac component and far fewer embryonal carcinoma cells are found. Foci of these malignant cells have also been detected in immature teratomas and therefore even principally benign, immature teratomas are often designated as potentially malignant tumours. ${ }^{17}$

The clinical behaviour of germ cell tumours in general varies between the different tumour subtypes. Patient- and tumour-related factors such as age, sex and the histological composition determine their carcinogenic potential. ${ }^{18}$ The majority of SCT diagnosed in neonates are benign tumours. Malignant disease at initial diagnosis of SCT is rare, affecting $7-17 \%$ of the infants. ${ }^{5,13,14,19}$ In spite of the female predominance, the rate of malignant SCT does not differ between both sexes. ${ }^{9}$ Sacrococcygeal teratoma tends to undergo malignant degeneration in a short time, which would explain the increased malignancy rate of up to $40-70 \%$ in the first month to years, with yolk sac tumour as the most common histological classification. 5,14,20 At cellular level, there are some indications that a higher frequency of wnt-pathway activation in immature teratomas through beta-catenin accumulations might be responsible for this degeneration from immature teratoma to malignant yolk sac tumour, but further research needs to be performed in this field.

Besides the local infiltrative growth pattern, malignant SCT has the potential of metastatic spread, either lymphogenous or haematogenous to primarily the lungs and liver. ${ }^{21}$ Therefore, complete surgical resection is performed in all patients diagnosed with SCT as soon as the infant's condition permits. ${ }^{22}$

\section{Clinical features of sacrococcygeal teratoma}

The SCT develops around the sixth week of gestation and continues to grow through pregnancy. During embryonic development it spreads along the coccygeal bone with possible intra- end extrapelvic extension of the tumour. Based on localization and extension of the tumour, Altman and colleagues developed a classification system that distinguishes four types of SCT. In type I the tumour extends mainly extrapelvic with only a small intrapelvic component; in type II the proportion of the intrapelvic component is greater while in type III the tumour is located mainly intrapelvically and has only a small external extent. In type IV the tumour is located completely intrapelvically and no external tumour mass is visible (Figure 2). ${ }^{5}$ 

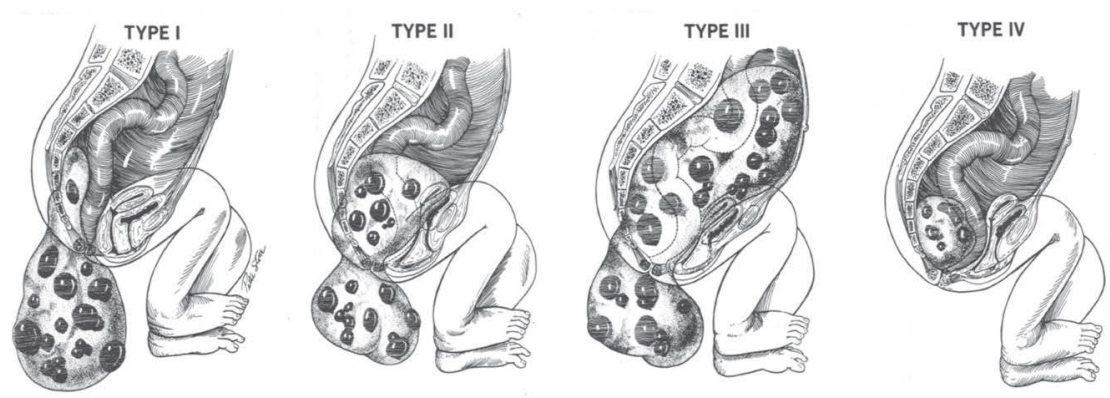

Figure 2. Classification of sacrococcygeal teratomas according to Altman ${ }^{5+}$

Nowadays the antenatal detection rate of SCT is up to $72 \%$ due to advanced ultrasound techniques and more structured pregnancy surveillance with regular ultrasonography screenings. ${ }^{3}$ In general SCT clinically presents in either of two ways: one, as Altman type I or II, predominantly diagnosed antenatally or during delivery with a benign tumour in most of the cases; two, no visible external tumour but more often a malignant SCT at older age. Both a higher Altman type and older age at diagnosis are risk factors for malignant SCT. 5,13,20

\section{Management and course of sacrococcygeal teratoma}

As indicated above, early surgical resection is the cornerstone of treatment for SCT to prevent malignant transformation and haemorrhagic complications of these often well vascularized tumours. Additional chemotherapy containing platinum might be necessary in patients with malignant SCT or disseminated disease. With this approach survival rates of up to $90 \%$ have been achieved. ${ }^{23-25}$

Most of the SCTs with a large extrapelvic tumour mass are resected with a sacral approach. The child is then placed in the jack-knife position and typically a chevron incision (an inverted " $\mathrm{V}$ " incision) is made. The tumour is removed en bloc together with the adherent coccygeal bone. The levator ani muscles and the pelvic floor are restored and the skin is closed (Figure 3). During this procedure, vital organs such as the rectum and the bladder as well as much tinier structures such as the pelvic nerves must be protected from surgical damage. ${ }^{26}$ For tumours with a greater intra-abdominal extent a combined abdominal-sacral approach might be necessary whereby the tumour is first mobilized with a laparoscopically abdominal 


\section{Chapter 1}

approach with the infant in supine position. In addition, in highly vascularized tumours the median sacral artery forming the main supplying blood vessel can be clipped laparoscopically to achieve early haemorrhagic control and to prevent lifethreatening bleeding from the tumour. ${ }^{9,27,28}$ In all patients the coccygeal bone is resected together with the tumour to achieve tumour free resection margins. ${ }^{22}$
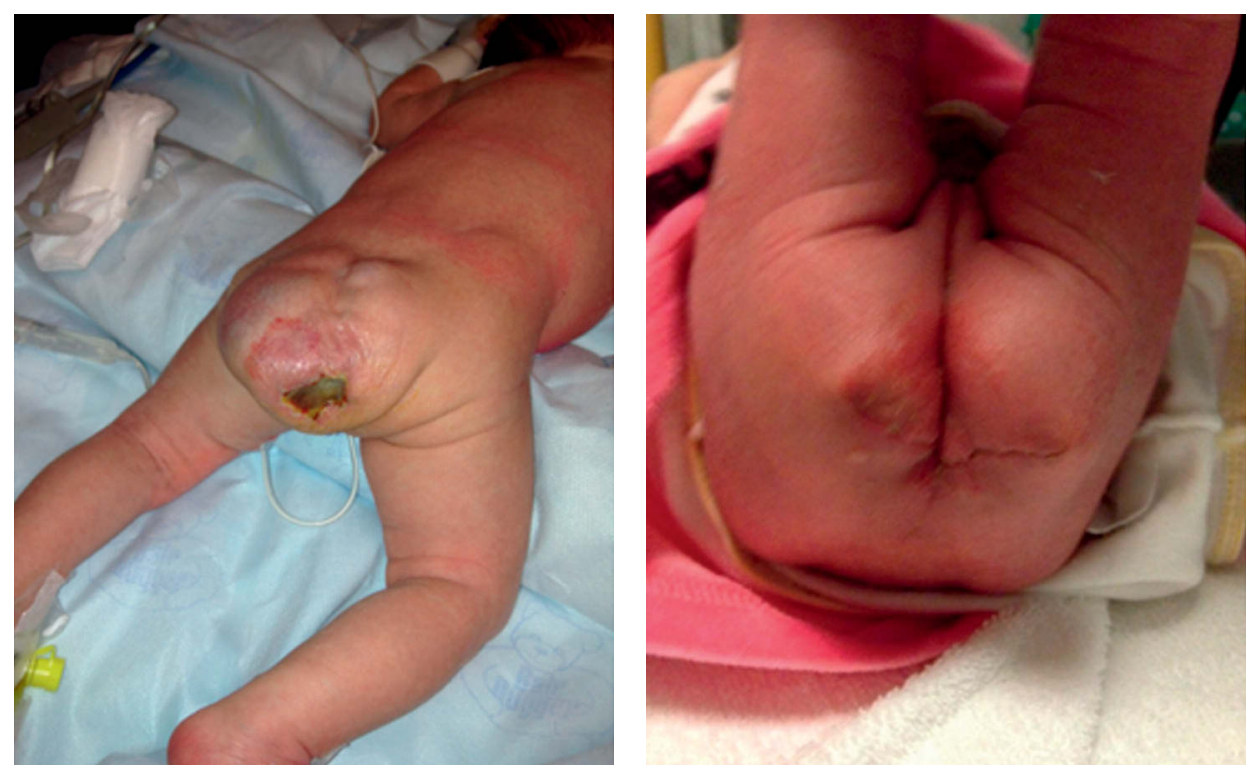

Figure 3. A girl with a small Altman type 2 SCT. Left: the preoperative presentation; Right: the postoperative result

The overall prognosis of early resected SCT is good. However, SCTs are more likely to recur than other germ cell tumours with a relapse rate of $9-20 \% .{ }^{19,20,29}$ Several factors have been held responsible for the relatively large risk of malignant transformation and recurrence. Firstly, achieving complete tumour resection in the vicinity of vital organs is a challenge. Complete tumour resection cannot always be achieved, which would explain the higher relapse rate of SCT compared to other germ cell tumours. Secondly, the risk of tumour spill during operation is higher for SCT than for other germ cell tumours as the tumour is not encapsulated and often contains cystic tissue that may rupture during surgery. In addition, some SCT containing mainly benign 
tissue may also contain micro foci of malignant cells, which can be easily missed during the pathological assessment, which may be more difficult on account of the large volume of tumour tissue. In this case the tumour is erroneously considered benign and chemotherapeutic treatment might be withheld. In addition, incomplete resection in these cases may lead to malignant recurrence. ${ }^{12,30}$

As most of the recurrences of surgically managed SCT occur during the first three years after surgery, oncological follow-up of at least three years after surgery has been recommended. ${ }^{20}$ In addition to the routine clinical examination and radiological imaging the tumour marker alpha-foetoprotein (AFP) plays a particular role in the follow-up of patients treated for SCT. This protein is normally synthetized in the foetal liver and yolk sac and is therefore always elevated in neonates. However, excessively increased values that exceed the age-related norms are highly indicative for malignant yolk sac SCT and might indicate a relapsing tumour or even incomplete surgical resection in treated patients. As the half-life of AFP is 5-7 days, values need to normalize postoperatively and next decline during the first two years. ${ }^{9,21}$

Three types of mortality in patients with SCT can be distinguished. The first group comprises foetuses diagnosed in utero with a great and highly vascularized tumour. These children may die in utero from hydrops foetalis secondary to high output cardiac failure that seems to be the consequence of vascular steal from the tumour, blood shunting within the tumour or tumour haemorrhage. ${ }^{13,31,32}$ If hydrops remains untreated the mortality rate of these children is almost $100 \% .{ }^{33}$ The second group comprises those who die in the neonatal period. The neonatal mortality rate of SCT is approximately $13 \%$ and is mainly determined by haemorrhagic complications before surgical resection or during the surgical procedure. ${ }^{15,34}$ Haemorrhagic control should therefore be achieved during or prior to the operation, e.g. by ligation of the supplying arteries. However, this is not routinely applied. ${ }^{27,35,36}$ The third group comprises those children who die after the neonatal period due to malignant disease progression or malignant recurrence.

\section{Surgical implications of sacrococcygeal teratoma and its consequences}

Sacrococcygeal teratoma develops early during embryogenesis and continues to grow during pregnancy, thereby occupying space and compressing adjacent organs and anatomical structures of the small pelvis. In addition, the extended surgical 


\section{Chapter 1}

resection performed in all patients compromises the pelvic floor muscles and might damage surrounding nerve tissue and accompanying vascularization. This is held responsible for functional sequelae such as dysfunctional defecation and micturition habits that have been reported in up to $40 \%$ of school-aged children treated for SCT during infancy. ${ }^{4,37-41}$ However, the course of these complaints beyond childhood has hardly been studied. Available studies indicate that some functional complaints seem to recede or persist while other complaints present not until adult age. ${ }^{42}$ Despite the knowledge of functional sequelae after surgical treatment for SCT there are no clear guidelines for follow-up of patients treated for SCT during childhood. Notably, possible problems with fertility and sexuality that might present for the first time during puberty and adolescence deserve attention. There are no follow-up recommendations for long-term care for these patients nor are there arrangements about the responsibilities and coordination of long-term care. The current followup scheme only includes the intervals of blood measures and radiological imaging and is designed to early recognize recurrence of disease, whereas functional outcomes are not considered. In addition, little attention is given to screening, diagnosis and follow-up of anomalies associated with SCT.

\section{OUTLINE OF THIS THESIS}

As outlined in this general introduction, diagnosis and treatment of sacrococcygeal teratoma have been standardized with good results. However, the long-term outcomes and functional complaints after childhood treatment are relatively unknown. The central aim of this thesis is to evaluate long-term functional outcome of patients treated for sacrococcygeal teratoma during childhood and to develop standardized follow-up for this patient group, beginning with the preoperative screening for associated anomalies and defining the mortality risk due to haemorrhage preoperatively.

Firstly, in chapter two we evaluate the occurence of congenital abnormalities associated with SCT in a national cohort of neonates born with SCT. Based on these results we give a recommendation for a structured post partum screening. In chapter three we investigate patient- and disease- related risk factors associated with haemorrhaggic mortality shortly after birth in the same cohort. 
Based on these results we give a recommendation for a structured postpartum screening. Next in chapter four we report frequency and severity of dysfunctional bowel- and urinary habits in adults treated for SCT during childhood and evaluate the course of complaints from childhood to adulthood in a subset of the patients. In addition, we set out to identify patient- and disease-related characteristics associated with urinary incontinence, soiling and constipation beyond childhood.

Various domains of sexual function in adult men and women treated for infant sacrococcygeal teratoma are investigated in chapter five and results are compared to healthy controls. As the personal body image has been stated to play an important role in sexual function we additionally investigate the differences in body image of male and female participants and correlate the results to the outcomes on sexual functioning. Chapter six explores the consequences of previous surgical treatment for SCT in females on pregnancy and delivery later in life and evaluates whether routine caesarean section and standard obstetrical pregnancy surveillance are needed in this patient population.

It is often assumed that functional sequelae have a negative impact on quality of life. Thus, after evaluating various long-term functional sequelae of treatment for SCT, in chapter seven we sought to answer the question if quality of life is impaired in patients who underwent treatment for SCT compared to healthy controls. Chapter eight contains a quality of life sub-analysis and compares the results of patients treated for malignant SCT with those treated for benign SCT. The malignant type often requires chemotherapeutic treatment that might lead to oncological chemotherapeutic sequelae, which may require different follow-up strategies. Lastly, in chapter nine the results of the various chapters are discussed and summarized. In addition, the future perspectives for the implementation of our results in clinical practice are given. 


\section{Chapter 1}

\section{REFERENCES}

1 Barson A. Congenital Neoplasia: The Society's experience. Arch Dis Child 1978;53:436.

2 Mosbech $\mathrm{CH}$, Rechnitzer C, Brok JS, et al. Recent advances in understanding the etiology and pathogenesis of pediatric germ cell tumors. J Pediatr Hematol Oncol 2014;36(4):263-270.

3 Pauniaho SL, Heikinheimo O, Vettenranta K, et al. High prevalence of sacrococcygeal teratoma in Finland - a nationwide population-based study. Acta Paediatr 2013;102(6):e251-256.

4 Derikx JP, De Backer A, van de Schoot L, et al. Long-term functional sequelae of sacrococcygeal teratoma: a national study in The Netherlands. J Pediatr Surg 2007;42(6):1122-1126. Altman RP, Randolph JG, Lilly JR. Sacrococcygeal teratoma: American Academy of Pediatrics Surgical Section Survey-1973. J Pediatr Surg 1974;9(3):389-398. Oosterhuis JW, Stoop H, Honecker F, et al. Why human extragonadal germ cell tumours occur in the midline of the body: old concepts, new perspectives. Int J Androl 2007;30(4):256-263

7 van der Staak F, Festen C. Het sacrococcygeale teratoom: een wondergezwel of een monstergezwel? Ned Tijdschr Geneeskd 1984;128(37):1745-1747.

8 Veltman IM, Schepens MT, Looijenga LH, et al. Germ cell tumours in neonates and infants: a distinct subgroup? APMIS 2003:111(1):152-160; discussion 160.

9 Frazier AL, Weldon C, Amatruda J. Fetal and neonatal germ cell tumors. Semin Fetal Neonatal Med 2012;17(4):222-230.

10 Seydoux G, Braun RE. Pathway to totipotency: lessons from germ cells. Cell 2006;127(5):891-904.

11 Schoenwolf GC, Bleyl SB, Brauer PR, et al. Larsen's Human Embryology Churchill Livingstone Elsevier; 2009. Chapter 1.

12 Harms D, Zahn S, Gobel U, et al. Pathology and molecular biology of teratomas in childhood and adolescence. Klin Padiatr 2006;218(6):296-302.

13 Rescorla FJ. Pediatric germ cell tumors. Semin Pediatr Surg 2012:21(1):51-60.

14 Isaacs H, Jr. Perinatal (fetal and neonatal) germ cell tumors. J Pediatr Surg 2004;39(7):1003-1013. 
15 Usui N, Kitano Y, Sago H, et al. Outcomes of prenatally diagnosed sacrococcygeal teratomas: the results of a Japanese nationwide survey. J Pediatr Surg 2012;47(3):441-447.

16 McKenney JK, Heerema-McKenney A, Rouse RV. Extragonadal germ cell tumors:

a review with emphasis on pathologic features, clinical prognostic variables, and differential diagnostic considerations. Adv Anat Pathol 2007;14(2):69-92.

17 Gobel U, Calaminus G, Schneider DT, et al. Management of germ cell tumors in children: approaches to cure. Onkologie 2002;25(1):14-22.

18 Looijenga LH, de Munnik H, Oosterhuis JW. A molecular model for the development of germ cell cancer. Int J Cancer 1999;83(6):809-814.

19 Yoshida M, Matsuoka K, Nakazawa A, et al. Sacrococcygeal yolk sac tumor developing after teratoma: a clinicopathological study of pediatric sacrococcygeal germ cell tumors and a proposal of the pathogenesis of sacrococcygeal yolk sac tumors. J Pediatr Surg 2013;48(4):776-781.

20 Derikx JP, De Backer A, van de Schoot L, et al. Factors associated with recurrence and metastasis in sacrococcygeal teratoma. Br J Surg 2006;93(12):1543-1548.

21 Gobel U, Schneider DT, Calaminus G, et al. Germ-cell tumors in childhood and adolescence. GPOH MAKEI and the MAHO study groups. Ann Oncol 2000;11(3):263-271.

22 Lakhoo K. Neonatal teratomas. Early Hum Dev 2010;86(10):643-647.

23 Gobel U, Calaminus G, Blohm M, et al. Extracranial non-testicular teratoma in childhood and adolescence: introduction of a risk score for stratification of therapy. Klin Padiatr 1997;209(4):228-234.

24 Gobel U, Schneider DT, Calaminus G, et al. Multimodal treatment of malignant sacrococcygeal germ cell tumors: a prospective analysis of 66 patients of the German cooperative protocols MAKEI 83/86 and 89. J CLin Oncol 2001;19(7):1943-1950.

25 De Corti F, Sarnacki S, Patte C, et al. Prognosis of malignant sacrococcygeal germ cell tumours according to their natural history and surgical management. Surg Oncol 2012;21(2):e31-37.

26 Gross RW, Clatworthy HW, Jr., Meeker IA, Jr. Sacrococcygeal teratomas in infants and children; a report of 40 cases. Surg Gynecol Obstet 1951;92(3):341-354.

27 Bax NM, van der Zee DC. Laparoscopic clipping of the median sacral artery in huge sacrococcygeal teratomas. Surg Endosc 1998;12(6):882-883.

28 Lukish JR, Powell DM. Laparoscopic ligation of the median sacral artery before resection of a sacrococcygeal teratoma. J Pediatr Surg 2004;39(8):1288-1290. 


\section{Chapter 1}

29 Bilik R, Shandling B, Pope M, et al. Malignant benign neonatal sacrococcygeal teratoma. J Pediatr Surg 1993;28(9):1158-1160.

30 Gobel U, Calaminus G, Engert J, et al. Teratomas in infancy and childhood. Med Pediatr Oncol 1998;31(1):8-15.

31 Teitelbaum D, Teich S, Cassidy S, et al. Highly vascularized sacrococcygeal teratoma: description of this atypical variant and its operative management. J Pediatr Surg 1994;29(1):98-101.

32 Graf JL, Albanese CT. Fetal sacrococcygeal teratoma. World J Surg 2003;27(1):84-86.

33 Flake AW. Fetal sacrococcygeal teratoma. Semin Pediatr Surg 1993:2(2):113-120.

34 Benachi A, Durin L, Vasseur Maurer S, et al. Prenatally diagnosed sacrococcygeal teratoma: a prognostic classification. J Pediatr Surg 2006;41(9):1517-1521.

35 Angel CA, Murillo C, Mayhew J. Experience with vascular control before excision of giant, highly vascular sacrococcygeal teratomas in neonates. J Pediatr Surg 1998;33(12):18401842.

36 Kaneyama K, Yamataka A, Kobayashi H, et al. Giant, highly vascular sacrococcygeal teratoma: report of its excision using the ligasure vessel sealing system. J Pediatr Surg 2004;39(12):1791-1793.

37 Berger $M$, Heinrich $M$, Lacher $M$, et al. Postoperative bladder and rectal function in children with sacrococcygeal teratoma. Pediatr Blood Cancer 2011;56(3):397-402.

38 Boemers TM, van Gool JD, de Jong TP, et al. Lower urinary tract dysfunction in children with benign sacrococcygeal teratoma. J Urol1994:151(1):174-176.

39 Malone PS, Spitz L, Kiely EM, et al. The functional sequelae of sacrococcygeal teratoma. J Pediatr Surg 1990;25(6):679-680.

40 Schmidt B, Haberlik A, Uray E, et al. Sacrococcygeal teratoma: clinical course and prognosis with a special view to long-term functional results. Pediatr Surg Int 1999;15(8):573-576.

41 Havranek P, Rubenson A, Guth D, et al. Sacrococcygeal teratoma in Sweden: a 10-year national retrospective study. J Pediatr Surg 1992;27(11):1447-1450.

42 Cozzi F, Schiavetti A, Zani A, et al. The functional sequelae of sacrococcygeal teratoma: a longitudinal and cross-sectional follow-up study. J Pediatr Surg 2008;43(4):658-661.

*Figure 1 was reprinted with permission of Elsevier from Larsen's Human Embryology 4th edition, by Schoenwolf GC, Bleyl SB, Brauer PR, et al. Page 18, Copyright Churchill Livingstone, an imprint of Elsevier (Inc. (2009). 
+Figure 2 was reprinted from The Journal of Pediatric Surgery, 9(3), Altman et al. Sacrococcygeal teratoma: American Academy of Pediatrics Surgical Section Survey-1973, Page 391, Copyright (1974), with permission from Elsevier. 


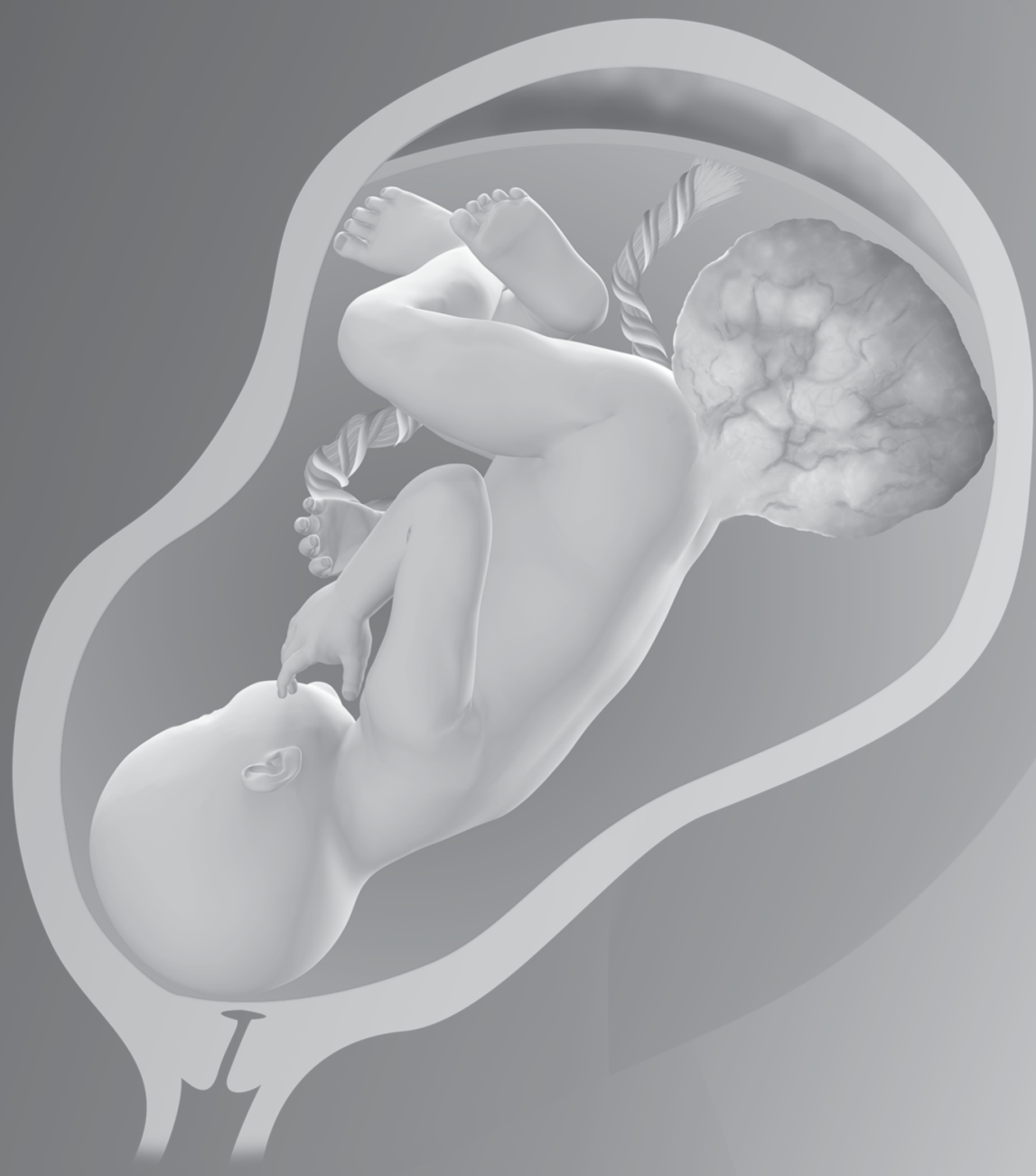




\section{CHAPTER 2}

\section{The incidence of associated abnormalities in patients with sacrococcygeal teratoma}

Marijke E.B. Kremer, Jessica F. Althof, Joep P.M. Derikx, Robertine van Baren, Hugo A. Heij, Marc H.W.A. Wijnen, René M.H. Wijnen, David C. van der Zee, L.W. Ernest van Heurn 


\section{AbSTRACT}

\section{Background}

Sacrococcygeal teratoma (SCT) is a congenital tumour with an incidence of one in 15,000- 40,000 live births. Gross genetic causes for SCT are unknown, but case reports have shown that SCT might be associated with other abnormalities. Therefore, we assessed the incidence of associated abnormalities in a large national cohort of neonates with SCT and aimed to identify predictive risk factors.

\section{Methods}

The medical records were reviewed of 235 consecutive neonates with SCT treated at the six paediatric surgical centres in the Netherlands from January 1970 to December 2010. Potential risk factors for associated abnormalities analysed included sex, gestational age, tumour volume, Altman classification and tumour histology.

\section{Results}

In 76 patients (32.3\%) at least one associated abnormality was diagnosed, with hydronephrosis as the most common (16.2\%) and hip dysplasia in $4.3 \%$. Multiple abnormalities had been documented for 21 patients (9.0\%). Prematurity and Altman type IV SCT were associated with an increased risk of any associated abnormality. No association between increased tumour volume and hydronephrosis or hip dysplasia was found. Patients with type IV Altman SCT had a fourfold risk of suffering from hydronephrosis compared to Altman type I SCT.

\section{Conclusion}

SCT was associated with other abnormalities in one-third of children. Some were tumour-related while others were related to prematurity or occurred sporadically. In contrast to clinically obvious anomalies, hip dysplasia or hydronephrosis might be latently present with more subtle clinical presentation. We therefore suggest renal- and hip ultrasound in all patients, certainly those with Altman type IV SCT. 


\section{INTRODUCTION}

Sacrococcygeal teratoma (SCT) is the most common neoplasm in neonates with a reported female to male predominance of $4: 1$. However, with a live birth incidence of one in 15,000 - 40,000 live births it is still rare. ${ }^{1-4}$ According to the classification by Altman and colleagues four anatomical types are distinguished. Type I is localized predominantly externally; type II also has an intrapelvic tumour component; type III predominantly extends in the abdominal cavity; and type IV is entirely localized presacrally without an obvious external component. ${ }^{5}$

Gross cytogenetic or chromosomal changes have not yet been identified in patients with SCT. The exception is a presacral teratoma as part of the Currarino triad. The Currarino triad is a very rare hereditary disorder characterized by the occurrence of an anorectal malformation in combination with a defect of the sacral bone and a presacral mass that is mostly a meningocele or a presacral teratoma. ${ }^{6,7}$ Other than the stand-alone SCT, the Currarino triad is an autosomal dominant defect apparently linked to mutation of the HLXB9 gene on chromosome $7 q 36 .{ }^{8}$ Presacral teratomas diagnosed as part of the Currarino triad furthermore differ from SCT in their very low risk of malignant transformation even if containing immature tissue. ${ }^{9,10}$

Gross genetic causes for SCT are unknown, but previous studies secondarily mentioned associated abnormalities in $12-30 \%$ of patients with SCT. ${ }^{1,11,12}$ A Finnish study on the prevalence of SCT and pregnancy outcomes in Finland found congenital abnormalities in $30 \%$ of the children. ${ }^{1}$ A Japanese study on outcomes of prenatally diagnosed SCT found various associated abnormalities in $12 \%$ of the 97 children. $^{12}$ However, both studies did not further evaluate risk factors associated with those abnormalities.

Urologic abnormalities such as hydronephrosis or vesicoureteral reflux have been reported in $36-46 \%$ of the postoperative patients treated for SCT with variable degrees of chronic kidney disease. ${ }^{13}$ Urological abnormalities are often seen as tumour-pressure related conditions and a higher Altman type is considered a risk factor for the occurrence of urological abnormalities. ${ }^{13}$ Furthermore, musculoskeletal abnormalities including hip dysplasia and clubfoot as well as cardio-pulmonary defects including ventricular septal defect, pulmonary hypoplasia and thoracic dystrophy have been reported with varying incidences. Some of these associated 


\section{Chapter 2}

abnormalities might have consequences for preoperative screening, surgical treatment and follow-up.

The objective of this nationwide retrospective study was to determine the incidence of abnormalities associated with SCT and to identify possible disease- and patient-related risk factors predicting the occurrence of theses abnormalities.

\section{Methods}

\section{Patients}

We included patients born between January 1970 and December 2010 with a SCT and treated in one of the six paediatric surgical centres in the Netherlands (Emma Children's Hospital University Medical Centre and VU University Medical Centre Amsterdam; University Medical Centre Groningen; Maastricht University Medical Centre; Sophia Children's Hospital Rotterdam; University Medical Centre Nijmegen; and Wilhelmina Children's Hospital Utrecht). The medical records were retrospectively reviewed for patient characteristics (sex, gestational age, birth weight, mode of delivery, comorbidities and time of diagnosis) and disease-related characteristics (Altman classification ${ }^{5}$, tumour histology and tumour volume, age at operation, surgical approach, radical or non-radical resection, complications and metastases). In particular, information on associated abnormalities was retrieved, including genitourinary abnormalities (i.e. hydronephrosis with or without ureteral dilatation, vesicoureteral reflux, strictures, and fistulas), musculoskeletal abnormalities (i.e. hip dysplasia or clubfeet), neural defects (i.e. neurological deficits or paraplegia), pulmonary disorders, cardiovascular anomalies, anorectal malformations and fistulas, chromosomal aberrations and other congenital anomalies (i.e. oesophageal atresia). Patients in whom the teratoma was part of the Currarino triad were excluded. The medical ethical committee of the Maastricht University Medical Centre approved the study.

\section{Statistical analysis}

Statistical analysis was performed using Graph Pad Prism 6 (GraphPad Software, Inc., La Jolla, CA, USA). Normal distribution of data was assessed with the D'Agostino-Pearson omnibus normality test. Logistic regression analysis was used 
to calculate odds ratios with $95 \%$ confidence intervals to determine risk factors (sex, Altman type, tumour volume, tumour histology and prematurity) for associated abnormalities. Statistical significance was defined as $p$-values of $\leq 0.05$. Values are given as mean with standard deviation or as median with interquartile range (IQR).

\section{Results}

\section{Patient characteristics}

In the study period, 235 children (186 girls and 49 boys) were born alive and treated for SCT in the participating centres. Table 1 gives the detailed patient- and diseaserelated characteristics. The majority had been born term by vaginal delivery and had a type I SCT (34.5\%) of mature histology. Fifty-four infants had an Altman type IV SCT, which in 44 was discovered after birth.

A total of 17 patients died due to disease progression, circulatory failure shortly after birth or due to postoperative infectious complications. One neonate died as life-sustaining treatment was discontinued immediately after birth because of multiple anomalies including omphalocele, thoracolumbar spina bifida, anorectal malformation, genital malformation and renal agenesis. Associated abnormalities of all patients were included in the analysis.

At least one associated abnormality had been diagnosed in 76 patients (32.3\%), with more than one in 21 patients (9\%) of the whole cohort. Excluding pulmonary anomalies and a patent ductus arteriosus, still 70 patients had any associated abnormality. The total number of associated abnormalities in the whole cohort was 108. Hydronephrosis was the most frequent one (in $16.2 \%$ of the patients) followed by musculoskeletal anomalies (6.4\%) and neurological defects (6\%) (Table 2). Four of the five patients with pulmonary anomalies as well as the two in whom an open ductus arteriosus was detected were born prematurely. 


\section{Chapter 2}

Table 1. Patient- and disease-related baseline characteristics

$$
\text { n (\%) }
$$

\begin{tabular}{|c|c|}
\hline Gestational age & \\
\hline Mean gestational age in weeks (SD) & 37.5 ( \pm 2.9 weeks $)$ \\
\hline Birth weight & \\
\hline Mean birth weight in kilogram (SD) & $3.2 \mathrm{~kg}( \pm 0.68 \mathrm{~kg})$ \\
\hline Prematurity & \\
\hline Premature ( 37 weeks of gestation) & $43(18.3 \%)$ \\
\hline Term (>37 weeks of gestation) & $143(60.9 \%)$ \\
\hline Unknown & $49(20.9 \%)$ \\
\hline Time of diagnosis & \\
\hline Prenatally & $69(29.4 \%)$ \\
\hline At birth & $90(38.3 \%)$ \\
\hline Post partum & $75(31.9 \%)$ \\
\hline Unknown & $1(0.4 \%)$ \\
\hline Mode of delivery & \\
\hline Vaginal & $118(50.2 \%)$ \\
\hline Caesarean section & $64(27.2 \%)$ \\
\hline Unknown & $53(22.6 \%)$ \\
\hline Age at surgery & \\
\hline Median age in days (IQR) & 8 days (IQR $3-174.5$ days) \\
\hline Surgical approach & \\
\hline Sacral & $172(73.2 \%)$ \\
\hline Abdominal-sacral & $43(18.3 \%)$ \\
\hline Abdominal & $7(3.0 \%)$ \\
\hline Unknown & $13(5.5 \%)$ \\
\hline Altman type & \\
\hline Type I & $81(34.5 \%)$ \\
\hline Type II & $57(24.3 \%)$ \\
\hline Type III & $36(15.3 \%)$ \\
\hline Type IV & $54(23.0 \%)$ \\
\hline Unknown & $7(3.0 \%)$ \\
\hline Tumour histology & \\
\hline Mature & $151(64.3 \%)$ \\
\hline Immature & $42(17.9 \%)$ \\
\hline Malignant & $35(14.9 \%)$ \\
\hline Yolk sac & $30(12.8 \%)$ \\
\hline Embryonic cell carcinoma & $2(0.9 \%)$ \\
\hline Unknown & $7(3.0 \%)$ \\
\hline
\end{tabular}


Table 2. Documented associated abnormalities by category

\begin{tabular}{|c|c|}
\hline Associated abnormalities (categorized) & $\mathrm{n}(\%)$ \\
\hline Genito-urinary system abnormalities & $44(18.7 \%)$ \\
\hline Hydronephrosis & $38(16.2 \%)$ \\
\hline with vesicoureteral reflux (with or without hydro-ureter) & 12 \\
\hline with sclerotic kidney & 1 \\
\hline with horseshoe kidney & 1 \\
\hline Malformations & $6(2.6 \%)$ \\
\hline Ureterovaginal fistula & 2 \\
\hline Vesicointestinal fistula & 1 \\
\hline Renal agenesis & 1 \\
\hline Ectopical kidney at bifurcation of aorta & 1 \\
\hline Hypospadias & 1 \\
\hline Anorectal abnormalities & $7(3.0 \%)$ \\
\hline Rectovaginal fistula & 1 \\
\hline Anorectal abnormalities & 2 \\
\hline Ventral positioned anus & 2 \\
\hline Anal stenosis & 2 \\
\hline Musculoskeletal abnormalities & $15(6.4 \%)$ \\
\hline Hip dysplasia & $10(4.3 \%)$ \\
\hline Clubfeet & 2 \\
\hline Polydactyly & 2 \\
\hline Duchenne muscular dystrophy & 1 \\
\hline Neural abnormalities & $14(6.0 \%)$ \\
\hline Paraplegia & 2 \\
\hline Encephalopathy & 3 \\
\hline Epilepsy & 1 \\
\hline Spina bifida & 2 \\
\hline Loss of strength or sensation in the lower extremities & 7 \\
\hline Facial dysmorphy & $4(1.7 \%)$ \\
\hline Freeman Sheldon syndrome & 1 \\
\hline Not further specified & 3 \\
\hline Cardiovascular anomalies & $9(3.8 \%)$ \\
\hline Ventricle septum defect (with Fallot's Tetralogy in one) & 4 \\
\hline Ventricular anomaly & 2 \\
\hline Persistent ductus arteriosus & 2 \\
\hline Stenosis of pulmonary artery & 1 \\
\hline Pulmonary disorders & $5(2.1 \%)$ \\
\hline Pulmonary hypertension & 1 \\
\hline Infantile respiratory distress syndrome & 3 \\
\hline Bronchopulmonary dysplasia & 1 \\
\hline Other anomalies (not categorized) & $10(4.3 \%)$ \\
\hline Chromosomal aberration & 3 \\
\hline Oesophageal atresia & 1 \\
\hline Congenital hyperthyreosis & 1 \\
\hline Omphalocele & 2 \\
\hline Intraperitoneal testes & 1 \\
\hline Haemangioma & 1 \\
\hline Siamese twin & 1 \\
\hline
\end{tabular}




\section{Chapter 2}

\section{Risk factor analysis}

Patient's sex, Altman type, tumour volume, tumour histology, and prematurity were analysed to determine a possible association of these characteristics with the documented associated abnormalities. Pulmonary disorders and a patent ductus arteriosus were not included as associated abnormalities in this analysis, as they are known to be closely related to prematurity.

Altman type IV SCT was associated with a higher risk of associated abnormalities in general, whereas sex and tumour histology were not of predictive value for the occurrence of associated abnormalities (Table 3).

Table 3. Logistic regression analysis of risk factors for any associated abnormality in patients with SCT

\begin{tabular}{lllll} 
& Level & Rate & Odds ratio [95\% Cl] & $p$-value \\
\hline Sex & Female & 55 of 186 & 1 & \\
& Male & 15 of 49 & $1.05[0.53$ to 2.08] & 0.89 \\
\hline Altman classification & Type I & 18 of 81 & 1 & \\
& Type II & 11 of 57 & $0.84[0.36$ to 1.94$]$ & 0.68 \\
& Type III & 9 of 36 & $1.17[0.47$ to 2.92] & 0.74 \\
& Type IV & 30 of 54 & $4.40[2.07$ to 9.26$]$ & 0.00 \\
\hline Tumour volume & $<150 \mathrm{~cm}^{3}$ & 15 of 61 & 1 & \\
& $>150-500 \mathrm{~cm}^{3}$ & 11 of 32 & $1.60[0.63$ to 4.09$]$ & 0.32 \\
& $>500 \mathrm{~cm}^{3}$ & 11 of 26 & $2.25[0.85$ to 5.94$]$ & 0.10 \\
\hline Tumour histology & Benign & 55 of 193 & 1 & \\
& Malignant & 12 of 35 & $1.31[0.61$ to 2.81$]$ & 0.49 \\
\hline Prematurity & Gestational age $>37$ weeks & 35 of 143 & 1 & \\
& Gestational age $<37$ weeks & 18 of 43 & $0.66[0.08$ to 5.78$]$ & 0.71 \\
\hline
\end{tabular}

While Altman type IV SCT was associated with a fourfold risk to suffer from hydronephrosis, a greater tumour volume was not associated with an increased risk of hydronephrosis (Table 4). 
Table 4. Logistic regression analysis of risk factors for hydronephrosis in patients with SCT

\begin{tabular}{lllll} 
& Level & Rate & Odds ratio $[95 \% \mathrm{Cl}]$ & $p$-value \\
\hline Altman classification & Type I & 9 of 81 & 1 & \\
& Type II & 3 of 57 & $0.44[0.12$ to 1.72$]$ & 0.24 \\
& Type III & 7 of 36 & $1.93[0.66$ to 5.67$]$ & 0.23 \\
& Type IV & 18 of 54 & $4.00[1.64$ to 9.80$]$ & 0.02 \\
\hline Tumour volume & $<150 \mathrm{~cm}^{3}$ & 9 of 61 & 1 & \\
& $>150-500 \mathrm{~cm}^{3}$ & 6 of 32 & $1.33[0.43$ to 4.15$]$ & 0.62 \\
& $>500 \mathrm{~cm}^{3}$ & 6 of 26 & $1.73[0.55$ to 5.50$]$ & 0.35 \\
\hline Prematurity & Gestational age $>37$ weeks & 18 of 143 & 1 & \\
& Gestational age $<37$ weeks & 8 of 43 & $1.58[0.64$ to 3.96] & 0.32 \\
\hline
\end{tabular}

Altman type was not predictive for an increased risk of hip dysplasia (Table 5). Seven children diagnosed with hip dysplasia concomitantly had hydronephrosis.

Table 5. Logistic regression analysis of risk factors for hip dysplasia in patients with SCT

\begin{tabular}{lllll} 
& Level & Rate & Odds ratio [95\% Cl] & $p$-value \\
\hline Altman classification & Type I & 3 of 81 & 1 & \\
& Type II & 1 of 57 & $0.46[0.05$ to 4.58$]$ & 0.51 \\
& Type III & 3 of 36 & $2.36[0.45$ to 12.32] & 0.30 \\
& Type IV & 3 of 54 & $1.53[0.30$ to 7.88$]$ & 0.61 \\
\hline
\end{tabular}




\section{Chapter 2}

\section{DisCUSSION}

The results of the present study show that the spectrum of defects and abnormalities associated with sacrococcygeal teratoma is broad and that various organ systems may be affected. While most of these abnormalities are not life-threatening, some are very severe, in particular when affecting the cardiopulmonary system or central nervous system or if occurring accumulated.

In the studied cohort almost one-third of infants with SCT had at least one associated condition, of which hydronephrosis was the most common, followed by anomalies of the musculoskeletal system. Hip dysplasia accounted for two-thirds of all musculoskeletal abnormalities.

Part of these associated abnormalities may be explained by the tumour extension and are therefore related to the disease itself, while other abnormalities occur independently and are not related to the tumour. Renal anomalies as hydronephrosis and displacement of the anus are tumour-related and are associated with the extent and localisation of the SCT. Hydronephrosis may be the result of a mainly internal tumour causing ureteral compression, which explains the correlation of hydronephrosis with Altman type IV SCT found in the present study. In our study group seven infants had both ureteric obstruction and hip dysplasia. The high incidence of hip dysplasia we found in the present study may be explained by extraabdominal extension of the tumour or reduction the legs of the foetus. In addition, breech presentation of the child and oligohydramnios are risk factors for hip dysplasia. ${ }^{14,15}$ Unfortunately information regarding the amount of amnion fluid and delivery position was not available. The incidence of hip dysplasia in the present study is higher than the previously reported incidence of five in 1000 infants. ${ }^{16}$ The present incidence of hip dysplasia may even be an underestimation, as ultrasonography of the hips was not routinely done, and particularly in the early time period of the study this diagnosis may be missed easily. However, early diagnosis of this anomaly is essential as patients with unrecognised hip dysplasia are prone to arthrosis of the hip at relatively young age in adulthood.

Other reported anomalies, including cardiovascular- and pulmonary anomalies, are probably more related to prematurity than to the tumour itself. The strong association of prematurity and pulmonary problems is well known in literature. ${ }^{17}$ 
However, a relatively large proportion of the infants with SCT are prematurely born as the tumour fills up the uterus leading to distension with induction of preterm labour. ${ }^{18}$ Furthermore, oligohydramnios caused by renal or bladder outlet obstruction may lead to insufficient pulmonary maturation. ${ }^{18,19}$

Chromosomal and congenital anomalies such as omphalocele and oesophageal atresia occur sporadically and association with SCT itself is difficult to prove. The prevalence of this type of abnormalities seems higher compared to the general population: the percentage of these sporadic anomalies in our series exceeds $4 \%$ (as shown in Table 2), which is higher than the known prevalence of $3.6 \%$ for congenital anomalies in the general population. ${ }^{20,21}$ Although there is no common cause explaining this higher prevalence this information deserves a place in the counselling of parents of affected children.

Only few studies have addressed the incidence of associated abnormalities of SCT and most have only included relatively small numbers of patients. In these studies a sub-analysis to identify risk factors was not possible. In 1974, Altman and colleagues reported additional congenital anomalies in $18 \%$ of patients with SCT and found in contrast to our results that musculoskeletal defects were the most common. ${ }^{5}$ Because the diagnostic tools have improved since the seventies and more premature infants survive, it comes not as a surprise that the incidence and number of diagnosed associated abnormalities has increased since then. The incidence of abnormalities in general we found is comparable to the $30 \%$ reported by Pauniaho et al. in a cohort of 124 neonates diagnosed with SCT, of whom $16 \%$ had urinary tract abnormalities. The incidence of hip dysplasia in that study was lower however $(2.8 \%){ }^{1}$ In two other studies the incidence of hip dysplasia was slightly higher with $5.8 \%$ to $6.6 \%$, but the small sample sizes (both studies included fewer than 30 infants) led to a large probability interval. ${ }^{22,23}$

Previous studies reporting on abnormalities associated with SCT did not address disease-related factors predicting the occurrence of anomalies. Cost and colleagues mentioned a relation between the Altman type III tumours and the occurrence of urological comorbidity, but their analysis only considered comorbidities after operative resection. ${ }^{13}$

Differences in the reported incidence of associated abnormalities of SCT between the mentioned studies probably result from varying definitions of associated 


\section{Chapter 2}

abnormalities. Due to the retrospective character of the present study we reported on all anomalies documented in the records and therefore associated conditions were not uniformly defined previously. Moreover, SCT is a relatively rare disorder. Therefore, to study large numbers of patients it is necessary to include patients from a long time period. This may cause a bias that influences the results of the study. In the beginning of our study period, there was no effective ultrasound and a number of patients with hydronephrosis and hip dysplasia may have been undetected. The incidence of associated abnormalities, which is already relatively high in this study, may even be higher. Finally, in the present cohort we reported only on live-born neonates who were surgically treated. Leaving out those whose treatment was terminated or who died in utero may have led to an underestimation of congenital defects in patients with SCT and thereby to an underestimation of the reported abnormalities.

Both hydronephrosis and hip dysplasia were frequent in the studied cohort and sometimes also occurred concomitantly. Both conditions might be latently present with more subtle clinical presentation and missing these anomalies might have serious consequences with possible irreversible damage. Therefore, screening for hip dysplasia and renal impairment should be made part of routine screening in neonates and infants diagnosed with SCT, certainly those with type IV SCT. The high incidence of other, sometimes very serious associated defects justifies careful ultrasonographic screening during pregnancy and adequate counselling of parents of unborn children with SCT. 


\section{References}

1. Pauniaho SL, Heikinheimo $\mathrm{O}$, Vettenranta $\mathrm{K}$, et al. High prevalence of sacrococcygeal teratoma in Finland - a nationwide population-based study. Acta Paediatr 2013;102(6):e251-256.

2. Barksdale EM, Jr., Obokhare I. Teratomas in infants and children. Curr Opin Pediatr 2009;21(3):344-349.

3. Schropp KP, Lobe TE, Rao B, et al. Sacrococcygeal teratoma: the experience of four decades. J Pediatr Surg 1992;27(8):1075-1078

4. Derikx JP, De Backer A, van de Schoot L, et al. Factors associated with recurrence and metastasis in sacrococcygeal teratoma. Br J Surg 2006;93(12):1543-1548.

5. Altman RP, Randolph JG, Lilly JR. Sacrococcygeal teratoma: American Academy of Pediatrics Surgical Section Survey-1973. J Pediatr Surg 1974;9(3):389-398.

6. Currarino G, Coln D, Votteler T. Triad of anorectal, sacral, and presacral anomalies. AJR Am J Roentgenol 1981;137(2):395-398.

7. Emans PJ, Kootstra G, Marcelis CL, et al. The Currarino triad: the variable expression. J Pediatr Surg 2005;40(8):1238-1242.

8. Lynch SA, Bond PM, Copp AJ, et al. A gene for autosomal dominant sacral agenesis maps to the holoprosencephaly region at 7q36. Nat Genet 1995;11(1):93-95.

9. Dirix M, van Becelaere T, Berkenbosch L, et al. Malignant transformation in sacrococcygeal teratoma and in presacral teratoma assosicated with Currarino syndrome: A comperative study. J Pediatr Surg 2015;50:462-464.

10. Lynch SA, Wang Y, Strachan T, et al. Autosomal dominant sacral agenesis: Currarino syndrome. J Med Genet 2000;37(8):561-566.

11. Harms D, Zahn S, Gobel U, et al. Pathology and molecular biology of teratomas in childhood and adolescence. Klin Padiatr 2006;218(6):296-302.

12. Usui N, Kitano Y, Sago H, et al. Outcomes of prenatally diagnosed sacrococcygeal teratomas: the results of a Japanese nationwide survey. J Pediatr Surg 2012;47(3):441-447.

13. Cost NG, Geller JI, Le LD, et al. Urologic co-morbidities associated with sacrococcygeal teratoma and a rational plan for urologic surveillance. Pediatr Blood Cancer 2013;60(10):1626-1629.

14. Chan A, McCaul KA, Cundy PJ, et al. Perinatal risk factors for developmental dysplasia of the hip. Arch Dis Child Fetal Neonatal Ed1997;76(2):F94-100. 


\section{Chapter 2}

15. Akman A, Korkmaz A, Aksoy MC, et al. Evaluation of risk factors in developmental dysplasia of the hip: results of infantile hip ultrasonography. Turk J Pediatr 2007;49(3):290-294.

16. Bialik V, Bialik GM, Blazer S, et al. Developmental dysplasia of the hip: a new approach to incidence. Pediatrics. 1999;103(1):93-99.

17. Jain D, Bancalari E. Bronchopulmonary dysplasia: clinical perspective. Birth defects research Part A, Clin Mol Teratol 2014;100(3):134-144.

18. Adams Waldorf KM, Singh N, Mohan AR, et al. Uterine overdistention induces preterm labor mediated by inflammation: observations in pregnant women and nonhuman primates. Am J Obstet Gynecol 2015;213(6):830 e1- e19.

19. Wilson RD, Hedrick H, Flake AW, et al. Sacrococcygeal teratomas: prenatal surveillance, growth and pregnancy outcome. Fetal Diagn Ther 2009;25(1):15-20.

20. Loane M, Dolk H, Kelly A, et al. Paper 4: EUROCAT statistical monitoring: identification and investigation of ten year trends of congenital anomalies in Europe. Birth defects research Part A, Clinical and molecular teratology 2011;91 Suppl 1:S31-43.

21. Hindori-Mohangoo AD, Schönbeck S, van der Pal-de Bruin KM. Aangeboren afwijkingen in Nederland 2001-2012: Gebaseerd op de landelijke perinatale registraties 2014.

22. Hedrick HL, Flake AW, Crombleholme TM, et al. Sacrococcygeal teratoma: prenatal assessment, fetal intervention, and outcome. J Pediatr Surg 2004;39(3):430-438

23. Ho KO, Soundappan SV, Walker K, et al. Sacrococcygeal teratoma: the 13-year experience of a tertiary paediatric centre. J Paediatr Child Health 2011;47(5):287-291. 


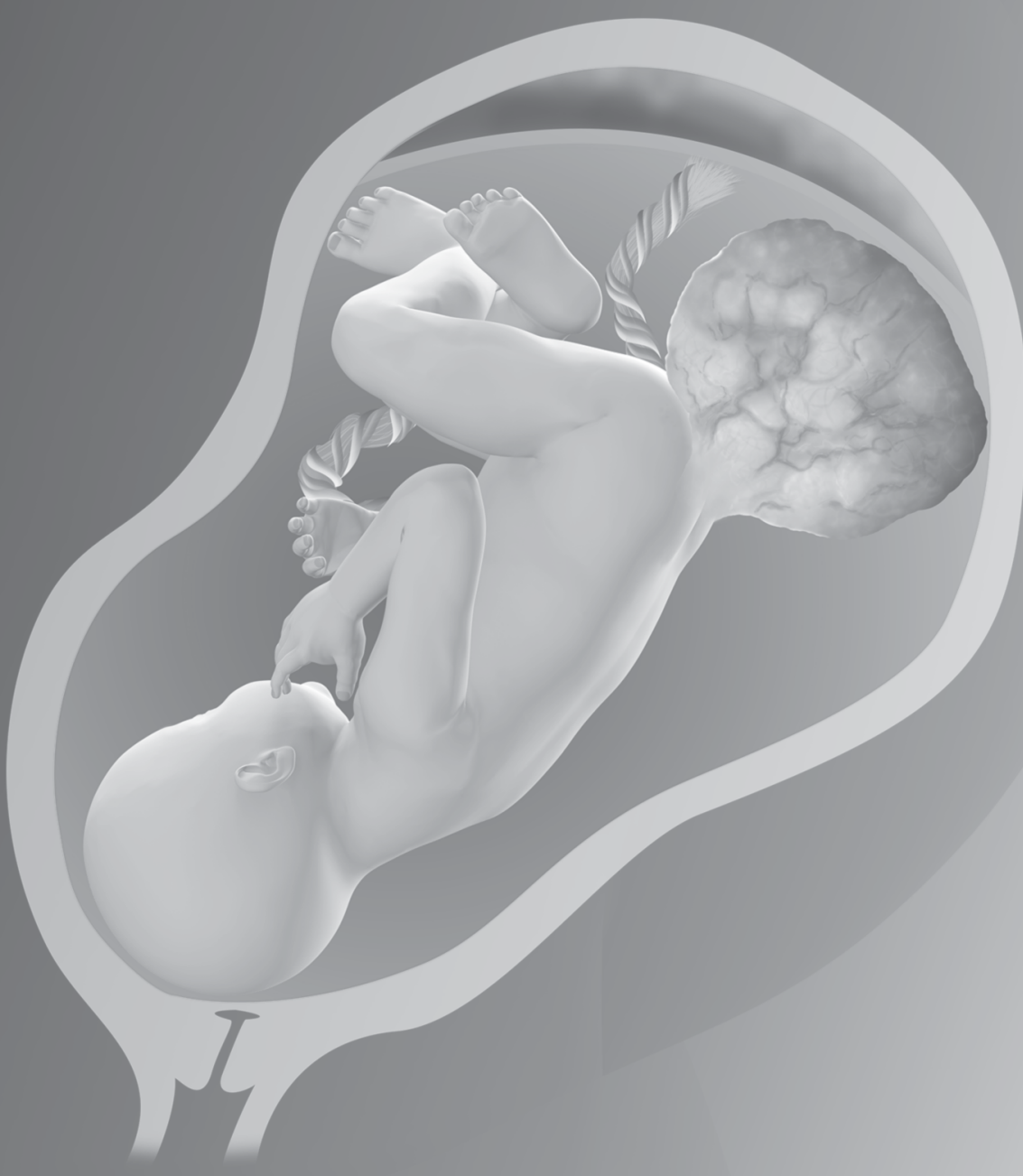




\section{CHAPTER 3}

\section{Haemorrhage is the most common cause of neonatal mortality in patients with sacrococcygeal teratoma}

Marijke E.B. Kremer, Lianne M. Wellens, Joep P.M. Derikx, Robertine van Baren, Hugo A. Heij, Marc H.W.A. Wijnen, René M.H. Wijnen, David C. van der Zee and L.W. Ernest van Heurn

Adapted from: J Pediatr Surg 2016 Nov;51(11):1826-1829. 


\section{AbSTRACT}

\section{Background}

A small percentage of neonates with sacrococcygeal teratoma die shortly after birth from haemorrhagic complications. The incidence of and risk factors associated with haemorrhagic mortality are unknown. In this multicentre study we determined the incidence of early death in neonates born with SCT and evaluated potential risk factors for haemorrhagic mortality.

\section{Methods}

235 children with SCT treated from 1970 to 2010 in the Netherlands were retrospectively included. The following candidate risk factors for haemorrhagic mortality were examined: sex, prematurity, Altman type, tumour volume, tumour histology, necessity of emergency operation and time of diagnosis.

\section{Results}

Eighteen patients $(7.7 \%)$ died at a median age of 163.5 days (range 1.7-973 days). Nine patients died of a malignancy. Nine others (3.8\%) died postnatally (age 1-27 days), six even within two days after birth. In seven of these nine patients death was related to tumour-haemorrhage and/or circulatory failure. Risk factors for haemorrhagic mortality were prematurity, tumour volume $>1000 \mathrm{~cm}^{3}$ and performance of an emergency operation.

\section{Conclusion}

Haemorrhagic mortality of neonates with SCT is relatively high (3.8\%) representing almost $70 \%$ of the overall mortality in the neonatal period. High-output cardiac failure, internal tumour haemorrhage and perioperative bleeding were the most common causes of early death and were all strongly associated with larger tumour sizes 


\section{INTRODUCTION}

Sacrococcygeal teratoma (SCT) is the most common congenital tumour in neonates but is rare considering the low incidence of approximately 1 in 15,000-28,500 live births. ${ }^{1-3}$ The introduction of routine prenatal screening has led to an increase in prenatal diagnosis of SCT with a good chance of survival. ${ }^{1,4-6}$ However, a substantial proportion of the children with SCT die before or soon after birth because of intrauterine or postnatal complications. The perinatal mortality rate of prenatally diagnosed SCT varies between $13 \%$ and $16 \%$ and most of these deaths are attributed to cardiac failure, exsanguinating tumour haemorrhage, or both. ${ }^{7-11}$ Consequently, various strategies to control tumour haemorrhage have been investigated, including intrauterine interventions and ligation of the median sacral artery prior to tumour resection. ${ }^{12-14}$

Factors such as a high tumour-weight to foetal volume ratio (TFR), faster SCT growth rate and predominantly solid and highly vascularized tumour are predictive for poor foetal outcome of prenatally diagnosed SCT. ${ }^{15-18}$ Predictive factors for haemorrhagic mortality shortly after birth have been investigated to a lesser extent. A recent study found a neonatal mortality rate of $12.7 \%$ in patients with prenatal diagnosed SCT. ${ }^{8}$

Massive tumour haemorrhage proved an important cause of death in this study, but patient- and disease-related factors predicting haemorrhage were not analysed. We determined the incidence of early death in a large cohort of Dutch neonates born alive with SCT between January 1970 and December 2010 and evaluated potential risk factors for haemorrhagic mortality.

\section{MethodS}

\section{Patients}

A nationwide retrospective cohort study was conducted at the six paediatric surgical centres in the Netherlands (Emma Children's Hospital University Medical Centre and VU Medical Centre Amsterdam, University Medical Centre Groningen, Maastricht University Medical Centre, St. Radboud University Medical Centre Nijmegen, Sophia Children's Hospital Rotterdam and Wilhelmina Children's 
Hospital Utrecht). The records and surgical reports of all patients treated for SCT in the period from January 1970 to December 2010 were reviewed to retrieve detailed information concerning patient characteristics (sex, gestational age, mode of delivery, age at diagnosis) and disease-related information (Altman classification ${ }^{19}$, tumour histology, metastases, estimated tumour size in $\mathrm{mL}$, age at operation, surgical approach, cause of death). The influence of the following factors associated with perioperative death is analysed: sex, prematurity $(<37$ weeks vs. $>37$ weeks of gestational age), time of diagnosis (prenatal vs. postnatal), mode of delivery (vaginal vs. caesarean section), decade of operation (before 1990 vs. after 1990), the necessity to perform an emergency operation (yes vs. no), Altman type (type I and II vs. type III and IV), tumour histology (benign vs. malignant) and tumour volume $\left(<1000 \mathrm{~cm}^{3}\right.$ vs. $\left.>1000 \mathrm{~cm}^{3}\right)$. The medical ethical committee of the Maastricht University Medical Centre approved the study protocol.

\section{Statistical analysis}

Statistical analysis was performed using Graph Pad Prism 6 (GraphPad Software, Inc., La Jolla, CA, USA). Normal distribution of data was assessed with the D'Agostino-Pearson omnibus normality test. Patient- and disease-related factors associated with haemorrhagic mortality were analysed with the Chi-square test or Fisher's exact test where indicated. Statistical significance was defined as two sided $\mathrm{p}$-values of $\leq 0.05$. Relative risks with corresponding $95 \%$ confidence intervals $(95 \% \mathrm{Cl})$ were calculated.

\section{RESULTS}

\section{Patient characteristics}

From 1970 to 2010, 235 patients were treated for SCT in one of the six Dutch paediatric surgical centres, of whom 49 were male. The mean gestational age was 37.5 weeks ( $\mathrm{SD} \pm 2.9$ weeks), with a mean birth weight of $3.2 \mathrm{~kg}$ ( $\mathrm{SD} \pm 0.68 \mathrm{~kg}$ ). Apart from the seven patients in whom the Altman classification was unknown, most of 228 SCTs were classified as Altman type I $(n=81 ; 35.5 \%)$ or type II SCT $(n=57 ; 23.7 \%)$, followed by Altman type IV SCT $(n=54 ; 23.7 \%)$ and Altman type III 
( $n=36 ; 15.8 \%$ ). Based on the histopathological reports available for 228 patients, 151 SCTs $(66.2 \%)$ were classified as a mature teratoma, $42(18.4 \%)$ as an immature teratoma and $35(15.4 \%)$ as a malignant teratoma, with a yolk sac tumour in 30 cases and embryonal carcinoma in two; for the others the malignant histopathological type was not further specified.

Of 235 patients, 118 were born through vaginal delivery and 64 through caesarean section; for the others the mode of delivery was not described. For only 19/64 patients the reasons for the caesarean section were documented; these included haemorrhagic SCT and great tumour size (each in one case) and preeclampsia, eclampsia or HELLP syndrome (haemolysis-elevated liver enzymeslow platelet count-syndrome), abnormal position of the embryo or deteriorating of the foetal cardiotocography.

The median age at the initial surgical resection was eight days (IQR 3 days174.5 days). A sacral approach was performed in the majority of patients $(77.5 \%$; $n=172)$, an abdominal approach in seven (3.1\%) and a combined approach in 43 $(19.3 \%)$ cases. The surgical approach was unknown for 13 patients. In 207 cases the coccygeal bone was removed, in seven cases, it was not removed and information on this procedure was not available for 21 patients. In two patients the median sacral artery was laparoscopically clipped prior to sacral tumour resection with coccygectomy. Both patients were female and born a term with an Altman type I tumour of unknown size and a type IV tumour of $1200 \mathrm{~cm}^{3}$ respectively; the first was treated in 1996 and the latter in 2008. They survived the operation without complications.

\section{Mortality}

Eighteen of the 235 patients ( $7.7 \%$ ) died, 16 girls and two boys, at a median age of 163.5 days (range 1.7-973 days). The overall mortality can be divided into two groups of causes. First, nine patients died because of malignant transformation caused by disease progression or recurrence during infancy (all girls; median age 2 years, range $0.8-10.6$ years). Second, the other nine patients (3.8\% out of the 235 patients) of whom seven were females and two males, died within 30 days after birth (age 1-27 days). In one patient, the treatment was discontinued shortly after birth because of multiple associated abnormalities (omphalocele, thoracolumbar 


\section{Chapter 3}

spina bifida, anorectal malformation, genital malformation, renal agenesis) and in one death was attributed to meningitis and postoperative sepsis. In the other seven neonates death was caused by circulatory failure and/or tumour haemorrhage. Table 1 shows patient- and disease-related characteristics of the seven patients who died as a consequence of tumour haemorrhage in the perioperative period.

Table 1. Characteristics of patients who died due to tumour haemorrhage during the perioperative period

\begin{tabular}{lllllll} 
Sex & $\begin{array}{l}\text { Year of } \\
\text { treatment }\end{array}$ & $\begin{array}{c}\text { Gestational } \\
\text { age at birth }\end{array}$ & $\begin{array}{l}\text { Moment of } \\
\text { diagnosis }\end{array}$ & Delivery & $\begin{array}{l}\text { Altman } \\
\text { type }\end{array}$ & $\begin{array}{c}\text { Tumour } \\
\text { histology }\end{array}$ \\
\hline Female & 1984 & $296 / 7$ weeks & At birth & Caesarean section & Type I & Mature \\
Female & 1984 & 32 weeks & Prenatally & Caesarean section & Type III & Immature \\
Female & 1987 & 29 weeks & Prenatally & Caesarean section & Type I & Unknown \\
Female & 1992 & $335 / 7$ weeks & At birth & Caesarean section & Type I & Unknown \\
Female & 2002 & $343 / 7$ weeks & Prenatally & Vaginal & Type II & Unknown \\
Female & 2003 & $303 / 7$ weeks & Prenatally & Vaginal & Type II & Mature \\
Male & 2008 & $322 / 7$ weeks & Prenatally & Caesarean section & Type I & Immature
\end{tabular}




\begin{tabular}{|c|c|c|c|c|c|}
\hline $\begin{array}{l}\text { Surgical } \\
\text { approach }\end{array}$ & $\begin{array}{l}\text { Estimated } \\
\text { tumour } \\
\text { volume }\left(\mathrm{cm}^{3}\right)\end{array}$ & $\begin{array}{l}\text { Estimated } \\
\text { tumour } \\
\text { diameter (cm }\end{array}$ & $\begin{array}{l}\text { Estimated } \\
\text { tumour } \\
\text { weight (g) }\end{array}$ & $\begin{array}{l}\text { Cause } \\
\text { of death }\end{array}$ & $\begin{array}{l}\text { Age at } \\
\text { death (Days) }\end{array}$ \\
\hline Sacral & 1767 & 15 & 1275 & $\begin{array}{l}\text { Exsanguinating tumour haemorrhage; } \\
\text { death during operation }\end{array}$ & 7 \\
\hline Sacral & 762 & 13 & 785 & $\begin{array}{l}\text { Exsanguinating tumour haemorrhage; } \\
\text { death during operation }\end{array}$ & 1 \\
\hline Unknown & 4189 & 20 & Unknown & $\begin{array}{l}\text { Tumour haemorrhage; Treatment } \\
\text { stopped because of multiple } \\
\text { dysmorphic features }\end{array}$ & 0 \\
\hline $\begin{array}{l}\text { Abdominal- } \\
\text { sacral }\end{array}$ & 1750 & Unknown & 2000 & $\begin{array}{l}\text { Circulatory failure due to tumour } \\
\text { haemorrhage; death during operation }\end{array}$ & 9 \\
\hline $\begin{array}{l}\text { Abdominal- } \\
\text { sacral }\end{array}$ & 3050 & 18 & Unknown & $\begin{array}{l}\text { Exsanguinating tumour haemorrhage; } \\
\text { death during operation }\end{array}$ & 1 \\
\hline Sacral & 564 & 11 & 680 & $\begin{array}{l}\text { Tumour haemorrhage/ postoperative } \\
\text { bleeding and hypovolemic shock }\end{array}$ & 27 \\
\hline Unknown & Unknown & Unknown & 1370 & $\begin{array}{l}\text { Tumour haemorrhage with hydrops } \\
\text { foetalis; death during operation }\end{array}$ & 0 \\
\hline
\end{tabular}

\section{Patient- and disease-related characteristics associated with haemorrhagic mortality}

Table 2 shows the distribution of sex, prematurity, time of diagnosis, mode of delivery, decade of operation, necessity to perform an emergency resection, Altman type, tumour histology and tumour volume between those neonates who died as 


\section{Chapter 3}

consequence of haemorrhagic complications and those who did not. Patients in the haemorrhagic mortality group were significantly more often diagnosed prenatally, were more often premature and had more often a tumour volume greater than $1000 \mathrm{~cm}^{3}$. In addition, they underwent significantly more often an emergency procedure. We found no associations between haemorrhagic mortality and the different Altman types, tumour histology, sex, mode of delivery or decade of operation (Table 2).

Table 2. Patient- and disease related characteristics associated with haemorrhagic mortality

\begin{tabular}{|c|c|c|c|c|c|}
\hline Variable & Level & $\begin{array}{c}\text { Haemorrhagic } \\
\text { mortality } \\
\text { Yes }\end{array}$ & $\begin{array}{c}\text { Haemorrhagic } \\
\text { mortality } \\
\text { No }\end{array}$ & $\begin{array}{l}\text { Relative risk } \\
\qquad(95 \% \mathrm{Cl})\end{array}$ & $p$-value \\
\hline \multirow[t]{2}{*}{ Sex } & Male & 1 & 48 & & \\
\hline & Female & 6 & 180 & $0.63[0.07$ to 5.1$]$ & .670 \\
\hline \multirow[t]{2}{*}{ Prematurity } & Yes & 7 & 36 & & \\
\hline & No & 0 & 143 & $25.77[3.31$ to 200$]$ & $<.001^{*}$ \\
\hline Time of & Prenatal & 5 & 64 & & \\
\hline diagnosis & Postnatal & 2 & 163 & 5.98 [1.18 to 31.0$]$ & $.030^{*}$ \\
\hline Mode of & Vaginal & 2 & 116 & & \\
\hline delivery & Caesarean section & 5 & 48 & $0.18[0.04$ to 0.90$]$ & $.036^{*}$ \\
\hline Decade of & Before 1990 & 3 & 36 & & \\
\hline operation & After 1990 & 4 & 122 & $2.40[0.57$ to 10.36$]$ & .232 \\
\hline Emergency & Yes & 3 & 13 & & \\
\hline operation & No & 3 & 179 & 11.38 [2.50 to 51.82$]$ & $.001^{*}$ \\
\hline Altman & Type I or II & 5 & 131 & & \\
\hline type & Type III or IV & 2 & 90 & $1.70[0.34$ to 8.53$]$ & .524 \\
\hline Tumour & Malignant & 0 & & & \\
\hline histology & Benign & 354 & 189 & $1.54[0.13$ to 8.76$]$ & .961 \\
\hline Tumour & $>1000 \mathrm{~cm}^{3}$ & 5 & 9 & & \\
\hline volume & $<1000 \mathrm{~cm}^{3}$ & 2 & 104 & 18.93 [4.0 to 88.50$]$ & $.000^{*}$ \\
\hline
\end{tabular}




\section{DisCUSSION}

Mortality of infants with SCT can be divided in two groups of causes. Even an initially benign SCT tends to undergo malignant transformation in the first years of life if undetected and may return as a malignant tumour following incomplete resection. ${ }^{5,20-22}$ While malignant transformation and recurrent disease seem to be the main causes for mortality during infancy, neonatal mortality is often caused by tumour haemorrhage. ${ }^{9,18,19,23}$ Exsanguinating haemorrhage has been described in association with delivery or removal of large tumours and may lead to death. ${ }^{9,11,13}$ In contrast to the wide knowledge of risk factors predicting recurrence and malignant transformation of SCT, we have relatively little knowledge on the risk factors of haemorrhagic mortality in the neonatal period and most studies focused on risk factors predicting in utero surveillance of prenatally diagnosed SCT.

In the present study the incidence of haemorrhagic mortality was relatively high $(3.8 \%)$, accounting for more than one-third of the overall mortality. Deaths were caused by high output cardiac failure and perioperative hemodynamic complications, both direct consequences of tumour haemorrhage. Larger tumour volume, prematurity, the necessity to perform an emergency operation and prenatal diagnosis of SCT were associated with haemorrhagic mortality. There was no association between the decade of birth and mortality, although we had expected a decreased in mortality after 1990 owing to improvement and increased knowledge on neonatal intensive care.

In the present study prematurity and larger tumour volumes were analysed as independent risk factors for haemorrhagic mortality. However, these factors are known to be related to each other, as a greater tumour volume is known to predispose prematurity caused by preterm extension of the uterus. ${ }^{24}$ In addition, larger tumours are often well vascularized thereby increasing the risk of foetal hydrops and cardiac failure. ${ }^{25,26}$ We therefore estimate that these factors have an interrelated effect on haemorrhagic mortality.

In a national survey in Japan, Usui and colleagues recently reported a higher mortality rate in patients born at younger gestational age and found a trend toward higher mortality in those with larger tumour diameters; specific factors associated with haemorrhagic mortality were not analysed. ${ }^{8}$ Benachi and colleagues also 


\section{Chapter 3}

reported that a larger tumour diameter was predictive of worse outcome; yet the aim of their study was to identify risk factors predicting in-utero survival and not haemorrhagic mortality after birth. In addition, tumour size was not analysed as an independent risk factor but in combination with tumour vascularity and growth rate. ${ }^{7}$

The results of the present study emphasize that tumour haemorrhage represents a serious problem in neonates with SCT regardless of the time of diagnosis, prenatally or in a later stage. Haemorrhagic death includes both bleeding caused by delivery and bleeding during surgical resection and these causes cannot be clearly separated. Neonates with compression of a large tumour during delivery may bleed to death from internal tumour haemorrhage. These children are operated on instantly, and are prone to die during surgery because of their poor hemodynamic condition. Although our results are not able to provide evidence that caesarean section diminishes the risk of haemorrhagic mortality it should be taken into consideration to perform standard caesarean section for those neonates with greater tumour sizes or highly vascularized SCT to prevent tumour rupture during delivery. In addition, caesarean section might shorten the delivery time, which probably will translate in a better outcome for these neonates. Our results demonstrate that prematurity is one of the main risk factors of perinatal haemorrhage and early death. Foetuses with a large tumour have an increased risk of premature birth despite tocolysis. Foetal surgery and intrauterine tumour ablation have been performed in immature foetuses with SCT with relatively poor results and a high complication rate. $^{27}$ In premature foetuses with foetal hydrops intrauterine intervention may correct a low foetal haemoglobin concentration and so improve the condition of the foetus and postpone delivery. ${ }^{9,28}$ However, premature birth remains difficult to prevent.

Haemorrhagic control may particularly be necessary in the case of a large tumour size and also in premature neonates as they tolerate excessive blood loss less well. Several surgical approaches have been described to minimize bleeding during surgery. Laparoscopic ligation of the median sacral artery can reduce operative blood loss, but is not routinely applied. ${ }^{13}$ In addition to arterial control, ligation of veins draining to the presacral area has been shown to improve haemostatic control. ${ }^{29}$ In patients in whom the median sacral artery cannot be identified or in whom bleeding proceeds despite ligation, clamping of the abdominal aorta above the bifurcation can be successfully applied, although an open surgical 
approach is needed. ${ }^{25,30}$ If a highly vascularized tumour is too large for proximal surgical control, tumour embolization prior to surgical resection may serve as alternative pre-treatment. ${ }^{31,32}$

The association of prematurity and haemorrhagic mortality we found in the present cohort raises the question as to whether it would be advisable to delay surgical resection until a more stable hemodynamic and respiratory situation is achieved. However, preceding bleeding is one of the major causes for a worse hemodynamic situation leading to a vicious cycle. Smithers et al. described an alternative two phase approach to achieve stabilization in preterm children who tolerate surgical resection less well but need prompt stabilization of the hemodynamic situation: in a first step haemorrhagic control is achieved by ligation of feeding blood vessels and resection of a part of the tumour and in a second approach the remaining proportion of the tumour is resected at a later time. ${ }^{33}$

Some limitations inherent to the retrospective design of the present study deserve mention. First, tumour volume was not documented for all patients. Most of the neonates who died of haemorrhagic complications had not been weighed separately from their tumour as they died during or shortly after (emergency) surgery. Furthermore, there may be a discrepancy between the estimated tumour diameter and the actual tumour weight. This may be explained by the usual estimation of the largest tumour diameter and by an irregular shape of the tumour; however, it is probably the most influenced by blood loss from the highly vascularized tumour itself. In addition, the present data are based on surgical records. As a consequence we cannot report on those neonates who possibly bled to death in utero or supply details on prenatal development and complications. 


\section{Chapter 3}

\section{REFERENCES}

1 Pauniaho SL, Heikinheimo O, Vettenranta K, et al. High prevalence of sacrococcygealteratoma in Finland—a nationwide population based study. Acta Paediatr 2013;102(6):e251-256.

2 Derikx JP, De Backer A, van de Schoot L, et al. Long-term functional sequelae of sacrococcygeal teratoma: a national study in the Netherlands. J Pediatr Surg 2007;42(6):1122-1126.

3 Barson A. Congenital neoplasia: the society's experience. Arch Dis Child 1978;53:436.4 Swamy R, Embleton N, Hale J. Sacrococcygeal teratoma over two decades: birth prevalence, prenatal diagnosis and clinical outcomes. Prenat Diagn 2008;28(11):10481051.

5 Derikx JP, De Backer A, van de Schoot L, et al. Factors associated with recurrence and metastasis in sacrococcygeal teratoma. Br J Surg 2006;93(12):1543-1548.

6 De Corti F, Sarnacki S, Patte C, et al. Prognosis of malignant sacrococcygeal germ cell tumours according to their natural history and surgical management. Surg Oncol 2012;21(2):e31-37.

7 Benachi A, Durin L, VasseurMaurer S, et al. Prenatally diagnosed sacrococcygeal teratoma: a prognostic classification. J Pediatr Surg 2006;41(9):1517-1521.

8 Usui N, Kitano Y, Sago H, et al. Outcomes of prenatally diagnosed sacrococcygeal teratomas: the results of a Japanese nationwide survey. J Pediatr Surg 2012;47(3):441-447.

9 Murphy JJ, Blair GK, Fraser GC. Coagulopathy associated with large sacrococcygeal teratomas. J Pediatr Surg 1992;27(10):1308-1310.

10 Sy ED, Lee $\mathrm{H}$, Ball R, et al. Spontaneous rupture of fetal sacrococcygeal teratoma. Fetal Diagn Ther 2006;21(5):424-427.

11 Flake AW, Harrison MR, Adzick NS, et al. Fetal sacrococcygeal teratoma. J Pediatr Surg 1986;21(7):563-566.

12 Kaneyama K, Yamataka A, Kobayashi H, et al. Giant, highly vascular sacrococcygeal teratoma: report of its excision using the ligasure vessel sealing system. J Pediatr Surg 2004;39(12):1791-1793.

13 Bax NM, van der Zee DC. Laparoscopic clipping of the median sacral artery in huge sacrococcygeal teratomas. Surg Endosc 1998;12(6):882-883. 
14 Angel CA, Murillo C, Mayhew J. Experience with vascular control before excision of giant, highly vascular sacrococcygeal teratomas in neonates. J Pediatr Surg 1998;33(12):18401842 .

15 Akinkuotu AC, Coleman A, Shue E, et al. Predictors of poor prognosis in prenatally diagnosed sacrococcygeal teratoma: a multiinstitutional review. J Pediatr Surg 2015;50(5):771-774.

16 Coleman A, Shaaban A, Keswani S, et al. Sacrococcygeal teratoma growth rate predicts adverse outcomes. J Pediatr Surg 2014;49(6):985-989.

17 Westerburg B, Feldstein VA, Sandberg PL, et al. Sonographic prognostic factors in foetuses with sacrococcygeal teratoma. J Pediatr Surg 2000;35(2):322-325

18 Holterman AX, Filiatrault D, Lallier $M$, et al. The natural history of sacrococcygeal teratomas diagnosed through routine obstetric sonogram: a single institution experience. J Pediatr Surg 1998;33(6):899-903.

19 Altman RP, Randolph JG, Lilly JR. Sacrococcygeal teratoma: American Academy of Pediatrics Surgical Section Survey_1973. J Pediatr Surg 1974;9(3):389-398.

20 Engelskirchen R, Holschneider AM, Rhein R, et al. Sacral teratomas in childhood. An analysis of long-term results in 87 children. Z Kinderchir 1987;42(6):358-361.

21 Yoshida M, Matsuoka K, Nakazawa A, et al. Sacrococcygeal yolk sac tumor developing after teratoma: a clinicopathological study of pediatric sacrococcygeal germ cell tumors and a proposal of the pathogenesis of sacrococcygeal yolk sac tumors. J Pediatr Surg 2013;48(4):776-781.

22 Rescorla FJ, Sawin RS, Coran AG, et al. Long-term outcome for infants and children with sacrococcygeal teratoma: a report from the Childrens Cancer Group. J Pediatr Surg 1998;33(2):171-176.

23 Lund DP, Soriano SG, Fauza D, et al. Resection of a massive sacrococcygeal teratoma using hypothermic hypoperfusion: a novel use of extracorporeal membrane oxygenation. J Pediatr Surg 1995;30(11):1557-1559.

24 Adams Waldorf KM, Singh N, Mohan AR, et al. Uterine overdistention induces preterm labor mediated by inflammation: observations in pregnant women and nonhuman primates. Am J Obstet Gynecol 2015;213(6):830.e1-830.e19.

25 Teitelbaum D, Teich S, Cassidy S, et al. Highly vascularized sacrococcygeal teratoma: description of this atypical variant and its operative management. J Pediatr Surg 1994;29(1):98-101. 


\section{Chapter 3}

26 Bond SJ, Harrison MR, Schmidt KG, et al. Death due to high-output cardiac failure in fetal sacrococcygeal teratoma. J Pediatr Surg 1990;25(12):1287-1291.

27 van Heurn LW, Harrison MR. Fetal surgery: for selected patients. The experiences of the fetal treatment Center in San Francisco. Ned Tijdschr Geneeskd 2003;147(19):900-904.

28 Hedrick HL, Flake AW, Crombleholme TM, et al. Sacrococcygeal teratoma: prenatal assessment, fetal intervention, and outcome. J Pediatr Surg 2004;39(3):430-438.

29 Solari V, Jawaid W, Jesudason EC. Enhancing safety of laparoscopic vascular control for neonatal sacrococcygeal teratoma. J Pediatr Surg 2011;46(5):e5-7.

30 Lindahl H. Giant sacrococcygeal teratoma: a method of simple intraoperative control of hemorrhage. J Pediatr Surg 1988;23(11):1068-1069.

31 Cowles RA, Stolar CJ, Kandel JJ, et al. Preoperative angiography with embolization and radiofrequency ablation as novel adjuncts to safe surgical resection of a large,vascular sacrococcygeal teratoma. Pediatr Surg Int 2006;22(6):554-556.

32 Lahdes-Vasama TT, Korhonen PH, Seppanen JM, et al. Preoperative embolization of giant sacrococcygeal teratoma in a premature newborn. J Pediatr Surg 2011;46(1):e5-8.

33 Smithers CJ, Javid PJ, Turner CG, et al. Damage control operation for massive sacrococcygeal teratoma. J Pediatr Surg 2011;46(3):566-569 


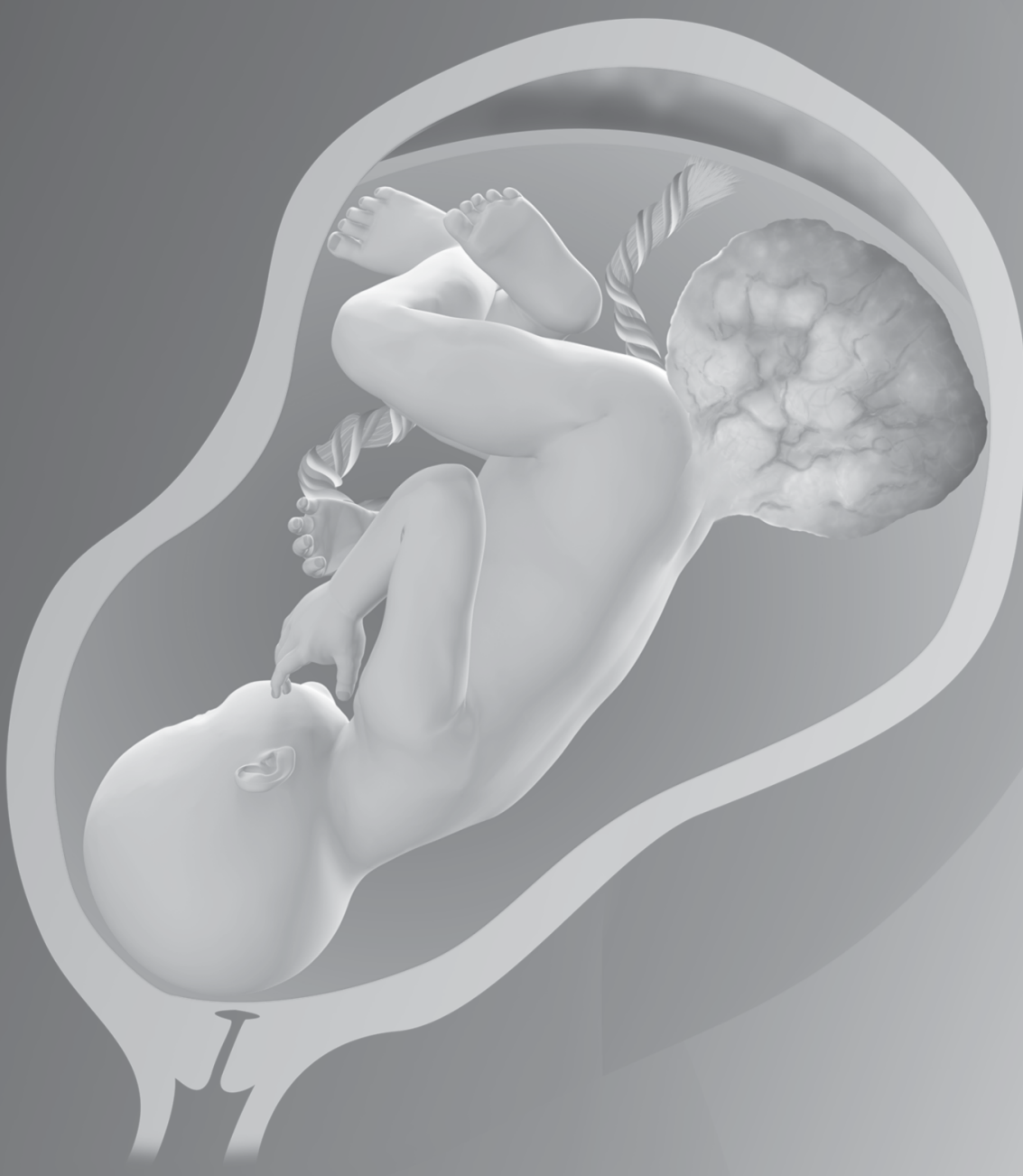




\section{Chapter 4}

\section{Patient reported defecation and}

micturition complaints in adults treated for sacrococcygeal teratoma during childhood the need for new surveillance strategies

Marijke E.B. Kremer, Joep P.M. Derikx, Robertine van Baren, Hugo A. Heij, Marc H.W.A. Wijnen, René M.H. Wijnen, David C. van der Zee and L.W. Ernest van Heurn

Adapted from: Pediatr Blood Cancer 2016;63:690-694 


\section{Chapter 4}

\section{ABSTRACT}

\section{Background}

To evaluate defecation and micturition complaints in adults treated for sacrococcygeal teratoma (SCT) during childhood and to identify risk factors for soiling, urinary incontinence, and constipation beyond childhood.

\section{Methods}

Records of patients aged 18 treated for SCT during infancy in the Netherlands were retrospectively reviewed. Frequency and severity of soiling, constipation, and urinary incontinence were evaluated using questionnaires designed in line with the Krickenbeck classification. Problems during childhood were compared to outcomes at adult age in part of the cohort. Associations between patient- and disease-related factors with complaints beyond childhood were analysed with the Chi-square test or Fisher's exact test, when appropriate.

\section{Results}

Of 47 included patients (mean age 26.2 years, $S D \pm 6.5$ ), $49 \%$ reported at least one defecation or micturition complaint. Urinary incontinence was present in $30 \%$ and had a greater negative impact than soiling $(24 \%)$. Ten patients $(21 \%)$ reported constipation; five found this severely bothering. Three patients reported social restrictions due to defecation or micturition complaints (6.4\%). While sex and tumour histology were not identified as risk factors, a tumour diameter of $>10 \mathrm{~cm}$ and Altman type I or type II SCT were associated with constipation during adulthood.

\section{Conclusion}

One-third of the patients treated for SCT during childhood reported urinary and defecation problems beyond childhood. In only a minority of cases, these led to social restrictions. A greater tumour diameter was associated with a higher risk of constipation during adulthood. Prolonged surveillance strategies are advised for all patients with SCT. 


\section{INTRODUCTION}

Dysfunctional bowel and urinary habits are frequent among patients treated for sacrococcygeal teratoma (SCT), which is the most common neoplasm in infancy, with an incidence of one in 15,000-40,000 live births. ${ }^{1,2}$ These sequelae have been attributed not only to damage of the autonomic innervation of bladder and bowel by tumour pressure but also to the extended surgical resection needed. ${ }^{3-7}$ Soiling is one of the most frequent long-term sequelae of SCT resection and affects $13-40 \%$ of the patients at the age of 6-10 years, whereas constipation and involuntary bowel movements are less common (8-16\% and $9-13 \%$, respectively). Urinary dysfunction after SCT resection includes incontinence and voiding difficulties. Urinary incontinence has been reported in 16-30\% of the patients at the age of 6-10 years. ${ }^{3,6}$ Functional sequelae of SCT resection have been studied mostly in paediatric cohorts. The frequency and severity of functional sequelae lasting beyond childhood remain relatively unknown. Two studies that evaluated anorectal function at adult age after SCT resection found improvement of soiling but an increasing incidence of constipation. ${ }^{7,8}$ Other studies confirmed these findings, however the majority of patients included in these studies were children. ${ }^{9,10}$

In this nationwide multicentre survey, we evaluated defecation and micturition patterns in young adults who underwent treatment for SCT during childhood and determined frequency and severity of problems. In addition, we set out to identify any patient- or disease-related characteristics associated with urinary incontinence, soiling, and constipation in adulthood.

\section{Methods}

\section{Patients}

After approval from the local medical ethical review board, retrospective chart review of patients treated for SCT after 1970 in either one of the six paediatric surgical centres of the Netherlands was carried out. Information on histopathological tumour classification, time of diagnosis, and details concerning the operation was obtained from the medical records. Tumours were classified according to the Altman classification that distinguishes four different types based on the location and extent 


\section{Chapter 4}

of the tumour. In type I, the tumour is located mainly externally with only a small intrapelvic component; in type II, the proportion of the intrapelvic component is larger; while in type III, the tumour is located mainly intrapelvically with only a small external mass. In type IV, the tumour is located completely intrapelvically without any visible external component. ${ }^{11}$ In addition, patients 18 years or older were invited by a letter sent to the last known address to fill out questionnaires. The letter provided information about the study and an informed consent form was enclosed. Those who did not respond were contacted two weeks later with a reminder letter and phone call.

Patients who returned the signed consent form received two questionnaires addressing their bowel and urinary function. One questionnaire concerned soiling, voluntary bowel movement and constipation in accordance to the Krickenbeck classification that was designed to assess the outcome of anorectal malformation repair, ${ }^{12}$ and in addition addressed various secondary gastrointestinal complaints (flatulence, abdominal pain, difficulty with evacuation, the feeling of incomplete evacuation, and abdominal bloating). The second questionnaire concerned urinary incontinence in terms of frequency, urge, and enuresis. Both questionnaires evaluated severity and frequency of complaints. Furthermore, information about the general medical history and medication use was obtained with additional structured questions. Patients whose bowel and micturition habits had already been evaluated during childhood were identified in our database, and for those patients any urinary and defecation complaints during childhood were compared with outcomes at adult age. ${ }^{3}$

\section{Statistical analysis}

Statistical analysis was performed using SPSS (Statistical Package for the Social Sciences) version 20.0 for Windows (IBM SPSS, Inc., Chicago, IL). Statistical analysis of the demographic baseline characteristics of participants and nonparticipants was performed using Chi-square test for categorical variables. Associations between patient- or disease-related factors (tumour histology, Altman type, sex, tumour diameter, surgical approach, age at surgery, and presence of symptoms in childhood for that subset) with urinary incontinence, soiling, or constipation beyond childhood were analysed with the Chi-square test or Fisher's exact test, when appropriate. All $p$-values were obtained with two-sided tests and statistical significance was defined as $p$-values of $\leq 0.05$. 


\section{Results}

Between 1970 and 1993, 112 infants were treated for SCT in the Netherlands, of whom 99 (78 females and 21 males) were known to have survived until the age of 18 years. As no contact information could be traced for 23 patients, the information letter was sent to the remaining 76 patients. Six patients responded by stating that they did not wish to participate, and 19 did not respond at all and could not be reached otherwise. Fifty-one patients returned the signed consent form and were sent the questionnaires. Altman type, tumour histology, and sex did not statistically significantly differ between patients included in the study and nonparticipants.

\section{Patient characteristics}

Eventually, 47 of the 51 patients who gave informed consent returned the completed questionnaires: 38 women and nine men with a mean age of 26.2 years $(\mathrm{SD} \pm 6.5$ years). The Altman classification was known for 45 patients: Altman type I or type II in 33 patients, type III in seven patients, and type IV in five patients. Based on the pathology reports available for 45 patients, 29 SCTs were classified as mature, five as immature, and eleven as malignant. All patients underwent surgical resection, with a sacral approach in $80 \%$ and combined abdominal-sacral approach in $20 \%$ of cases. Thirty- five patients were operated in the first six months of life, the other ten patients at a mean age of 1.6 years ( $\mathrm{SD} \pm 0.87$ years) and all within the first three years of age.

After the first operation, reconstructive urological surgery was required in four patients: two underwent ureteroplasty and the other two re-implantation of a ureter, with Mitrofanoff appendicovesicostomy at a later stage in one of them. Furthermore, one patient underwent a total colectomy with ileostomy due to Crohn's disease and another a rectopexy because of a rectal prolapse. Appendectomy was performed in two patients. Five patients had been diagnosed with irritable bowel syndrome or with slow-transit colon and one patient had an abnormal positioned anus due to the previous extension of the tumour (Altman type II, of immature histology, $15 \times 14 \times 8.5 \mathrm{~cm}$ tumour resected by a sacral approach whereby the involvement of the anal sphincter was not described). 


\section{Chapter 4}

\section{Soiling, bowel movements and constipation}

One participant was excluded from analysis of bowel complaints as she had undergone a colectomy with ileostomy. Thirty of 46 patients $(65.2 \%)$ reported no primary gastrointestinal complaints (involuntary bowel movements, soiling, or constipation). Eleven patients (23.4\%) suffered from soiling and in all but one, this occurred less than twice a week; in the one exceptional case, soiling occurred three to five times a week and only in the daytime. Two participants also reported soiling in the night. Two perceived the soiling as severely bothering whereas the majority of patients found it only slightly bothering (Table 1). Voluntary bowel movements were achieved by $96 \%$ of the patients during adulthood; only two patients treated for an Altman type II SCT with immature histology and Altman type I SCT with yolk sac tumour, respectively, were sometimes not able to control bowel movements and perceived this as severely bothering. Almost half of the participants (43\%) reported a feeling of incomplete bowel evacuation after defecation; in most cases, this occurred occasionally. Variable degrees of constipation were reported in ten patients $(21.7 \%)$, with four using laxatives and two applying dietary changes to facilitate defecation while no treatment was reported for the others. Five patients experienced constipation as severely bothering.

\section{Secondary gastrointestinal complaints}

Abdominal pain, abdominal bloating, and flatulence were considered as secondary gastrointestinal complaints. The incidence of each of these complaints was higher than involuntary bowel movements, soiling, and constipation. More than half of the patients suffered from one or more of these complaints, which in most cases occurred only occasionally. Secondary gastrointestinal complaints were reported as severely bothering by about one-third of the patients (Table 1). 
Table 1. Frequency and severity of primary and secondary gastrointestinal complaints

\begin{tabular}{|c|c|c|c|}
\hline & Patients affected & Frequency of complaints & Severity of complaints \\
\hline \multirow{3}{*}{ Soiling } & \multirow{3}{*}{$23.4 \%(n=11)$} & $90 \%$ once a week & $18 \%$ Not bothering \\
\hline & & \multirow[t]{2}{*}{$10 \% 3-5$ times a week } & $64 \%$ Slightly bothering \\
\hline & & & $18 \%$ Severely bothering \\
\hline \multirow{3}{*}{ Constipation } & \multirow{3}{*}{$21.7 \%(n=10)$} & $20 \% \leq$ once a week & $10 \%$ Not bothering \\
\hline & & $50 \%$ 2-3 times a week & $30 \%$ Slightly bothering \\
\hline & & $30 \%$ 5-6 times a week & $60 \%$ Severely bothering \\
\hline \multirow{3}{*}{ Flatulence } & \multirow{3}{*}{$67.4 \%(n=31)$} & 71\% Occasionally & $39 \%$ Not bothering \\
\hline & & $16 \%$ Sometimes & $36 \%$ Slightly bothering \\
\hline & & $13 \%$ Often & $25 \%$ Severely bothering \\
\hline \multirow{3}{*}{ Abdominal pain } & \multirow{3}{*}{$47.8 \%(n=22)$} & $68 \%$ Occasionally & $22 \%$ Not bothering \\
\hline & & $18 \%$ Sometimes & $45 \%$ Slightly bothering \\
\hline & & $14 \%$ Often & $33 \%$ Severely bothering \\
\hline \multirow{3}{*}{ Abdominal bloating } & \multirow{3}{*}{$54.3 \%(n=25)$} & $64 \%$ Occasionally & $28 \%$ Not bothering \\
\hline & & $20 \%$ Sometimes & $36 \%$ Slightly bothering \\
\hline & & $16 \%$ Often & $36 \%$ Severely bothering \\
\hline
\end{tabular}

\section{Urinary incontinence and voiding difficulties}

We excluded the patient with the Mitrofanoff stoma from analysis of urinary function, because presence of the stoma requires self-catheterization. Fourteen of 46 patients $(30.4 \%)$ reported urinary incontinence (Table 2 ). In one case this occurred daily; in eight, once per week or less; and in five, two to three times per week. Enuresis was reported by five patients and urinary loss without feeling urge by six patients. Almost all patients perceived urinary incontinence as moderate or severely bothering ( $n=13)$. Voiding difficulties reported by 15 patients $(32.6 \%)$ included having to wait before micturition begins, having to exert pressure to void, and involuntarily interrupted voiding. In most of them voiding difficulties occurred only occasionally (Table 2). Recurrent urinary tract infections requiring antibiotic prophylaxis were reported by two women, including the one who applied selfcatheterization. 


\section{Chapter 4}

Table 2. Frequency and severity of voiding complaints

\begin{tabular}{|c|c|c|c|}
\hline & Patients affected & Frequency of complaints & Severity of complaints \\
\hline $\begin{array}{l}\text { Having to wait } \\
\text { before micturition } \\
\text { begins }\end{array}$ & $10.9 \%(n=5)$ & $\begin{array}{l}60 \% \text { Occasionally } \\
27 \% \text { Sometimes } \\
13 \% \text { Often }\end{array}$ & $\begin{array}{l}80 \% \text { Not bothering } \\
20 \% \text { Slightly bothering }\end{array}$ \\
\hline $\begin{array}{l}\text { Having to exert } \\
\text { pressure to void }\end{array}$ & $28.3 \%(n=13)$ & $\begin{array}{l}62 \% \text { Occasionally } \\
15 \% \text { Sometimes } \\
23 \% \text { Often }\end{array}$ & $\begin{array}{l}62 \% \text { Not bothering } \\
23 \% \text { Slightly bothering } \\
15 \% \text { Severely bothering }\end{array}$ \\
\hline $\begin{array}{l}\text { Involuntary } \\
\text { interrupted voiding }\end{array}$ & $19.6 \%(n=9)$ & $\begin{array}{l}67 \% \text { Occasionally } \\
11 \% \text { Sometimes } \\
22 \% \text { Often }\end{array}$ & $\begin{array}{l}56 \% \text { Not bothering } \\
11 \% \text { Slightly bothering } \\
33 \% \text { Severely bothering }\end{array}$ \\
\hline
\end{tabular}

Table 3. Longitudinal course of defecation complaints and urinary incontinence beyond childhood

\begin{tabular}{lllll} 
Sex & Age & Age & VBM & \\
& $\left(1^{\text {st }}\right.$ evaluation $)$ & $\left(2^{\text {nd }}\right.$ evaluation $)$ & Childhood & Adulthood \\
\hline Male & 8.5 yrs. & 19.4 yrs. & No & Yes \\
Female & 11.5 yrs. & 18.5 yrs. & No & No \\
Male & 13.4 yrs. & 22.0 yrs. & Yes & Yes \\
Female & 13.3 yrs. & 22.4 yrs. & Yes & Yes \\
Males & 15.2 yrs. & 22.3 yrs. & Yes & Yes \\
Female & 11.1 yrs. & 18.8 yrs. & Yes & Yes \\
Female & 12.2 yrs. & 21.6 yrs. & Yes & Yes \\
Female & 11.0 yrs. & 19.7 yrs. & Yes & Yes \\
Male & 15.7 yrs. & 24.3 yrs. & Yes & Yes \\
Male & 9.7 yrs. & 18.3 yrs. & Yes & Yes \\
Female & 10.0 yrs. & 21.0 yrs. & Yes & Yes \\
Female & 16.1 yrs. & 24.8 yrs. & Yes & Yes \\
Female & 9.8 yrs. & 19.0 yrs. & Yes & Yes \\
Female & 12.8 yrs. & 19.8 yrs. & Yes & Yes \\
\hline
\end{tabular}

VBM = voluntary bowel movements; Soiling grade 1 = 0ccurring occasionally;

Soiling grade 2 = occurring daily without leading to social problems; Constipation grade 1 = managed by changes in diet; Constipation grade 2 = requiring laxatives. 
Social restrictions due to bowel- and urinary sequelae

Twenty-four of 47 (51\%) patients did not suffer from soiling, constipation, or urinary incontinence. Seven reported only urinary complaints, nine reported only defecation complaints, and seven suffered from both urinary and defecation problems. Two patients reported to be impaired in daily functioning because of bowel and urinary habits, with one of those in addition being impaired in social activities. Both perceived this as slightly bothering. One patient reported to be only restricted in social activities and found this severely bothering.

$\begin{array}{llllll}\text { Soiling } & \text { Constipation } & \text { Urinary incontinence } \\ \text { Childhood } & \text { Adulthood } & \text { Childhood } & \text { Adulthood } & \text { Childhood } & \text { Adulthood } \\ \text { Grade } 3 & \text { Grade } 1 & \text { No } & \text { No } & \text { Yes } & \text { No } \\ \text { Grade 1 } & \text { Grade 1 } & \text { Grade 2 } & \text { Grade 2 } & \text { Yes } & \text { Yes } \\ \text { No } & \text { Grade 1 } & \text { No } & \text { No } & \text { No } & \text { No } \\ \text { No } & \text { Grade 1 } & \text { No } & \text { No } & \text { No } & \text { No } \\ \text { No } & \text { Grade 1 } & \text { No } & \text { No } & \text { No } & \text { No } \\ \text { Grade 1 } & \text { Grade 1 } & \text { No } & \text { Grade 1 } & \text { No } & \text { No } \\ \text { Grade 1 } & \text { No } & \text { No } & \text { Grade1-2 } & \text { Yes } & \text { No } \\ \text { Grade 1 } & \text { No } & \text { Grade 2 } & \text { No } & \text { Yes } & \text { No } \\ \text { No } & \text { No } & \text { Grade 2 } & \text { No } & \text { No } & \text { No } \\ \text { No } & \text { No } & \text { No } & \text { No } & \text { Yes } & \text { Yes } \\ \text { Grade 1 } & \text { No } & \text { Grade 1 } & \text { No } & \text { Yes } & \text { Yes } \\ \text { No } & \text { No } & \text { Grade 1 } & \text { No } & \text { Yes } & \text { No } \\ \text { Grade 1 } & \text { No } & \text { Grade 1 } & \text { No } & \text { Yes } & \text { No } \\ \text { No } & \text { No } & \text { Grade 1 } & \text { No } & \text { No } & \text { Yes }\end{array}$




\section{Chapter 4}

\section{Course of complaints beyond childhood}

Fourteen patients were identified in our database whose bowel or micturition complaints had already been evaluated at childhood, at a mean age of $12.2, \mathrm{SD} \pm 2.4$ years. ${ }^{3}$ The results of this evaluation during childhood were compared to the present outcomes at mean age 20.9 years, SD \pm 2.1 years (mean age difference between first and second evaluations 8.7 years, $S D \pm 1.3$ years). All 14 patients had problems during childhood or developed complaints during adulthood (Table 3). Soiling receded in five patients, all but one of whom had suffered from mild soiling during childhood. In two patients, soiling had not improved and in three patients soiling had occurred for the first time during adulthood. Constipation had improved in six patients and two had developed a mild form of constipation during adulthood. Five patients suffering from urinary incontinence during childhood had achieved urinary continence, while one patient reported urinary incontinence for the first time during adulthood.

Table 4. Risk factors for urinary incontinence, soiling and constipation during adulthood

\begin{tabular}{|c|c|c|c|c|c|c|c|}
\hline & \multirow[b]{2}{*}{ Level } & \multicolumn{2}{|c|}{ Urinary incontinence } & \multicolumn{2}{|l|}{ Soiling } & \multicolumn{2}{|c|}{ Constipation } \\
\hline & & Rate & $p$-value & Rate & $p$-value & Rate & $p$-value \\
\hline \multirow[t]{2}{*}{ Histology } & Benign & 14 of 34 & & 7 of 33 & & 8 of 33 & \\
\hline & Malignant & 2 of 11 & 0.279 & 4 of 11 & 0.425 & 2 of 11 & 1.00 \\
\hline \multirow[t]{2}{*}{ Altman } & Type I or II & 13 of 33 & & 8 of 32 & & 9 of 32 & \\
\hline & Type III or IV & 3 of 12 & 0.491 & 3 of 12 & 1.00 & 0 of 12 & $0.047^{*}$ \\
\hline \multirow[t]{2}{*}{ Sex } & Female & 15 of 38 & & 8 of 37 & & 10 of 37 & \\
\hline & Male & 1 of 9 & 0.138 & 3 of 9 & 0.664 & 0 of 9 & 0.172 \\
\hline \multirow[t]{2}{*}{ Tumour diameter } & $<10 \mathrm{~cm}$ & 8 of 28 & & 5 of 28 & & 5 of 28 & \\
\hline & $>10 \mathrm{~cm}$ & 3 of 6 & 0.363 & 2 of 6 & 0.580 & 4 of 6 & $0.031^{*}$ \\
\hline \multirow[t]{2}{*}{ Surgical approach } & Sacral & 15 of 39 & & 10 of 38 & & 9 of 38 & \\
\hline & Abdominal-sacral & 1 of 7 & 0.394 & 0 of 7 & 0.320 & 1 of 7 & 1.00 \\
\hline \multirow[t]{2}{*}{ Age at surgery } & First six month & 9 of 23 & & 7 of 23 & & 6 of 22 & \\
\hline & One to three years & 3 of 13 & 0.468 & 3 of 13 & 0.716 & 2 of 13 & 0.680 \\
\hline Same complaints & Yes & 6 of 9 & & 2 of 3 & & 1 of 5 & \\
\hline during childhood & No & 8 of 32 & $0.042^{*}$ & 6 of 38 & 0.092 & 8 of 35 & 1.00 \\
\hline
\end{tabular}




\section{Risk factor analysis for urinary incontinence, soiling and constipation during adulthood}

Tumour histology, sex, surgical approach, and age at surgery were not risk factors for urinary incontinence, soiling, or constipation complaints in adulthood. A tumour diameter of $>10 \mathrm{~cm}$ was associated with constipation at adult age $(p=0.031)$. All patients who reported constipation at adult age had been treated for a type I or type II SCT. While the Altman type and tumour diameter were not predictive for urinary incontinence during adulthood, urinary incontinence during childhood was a risk factor for urinary incontinence at adult age ( $p=0.042$; Table 4).

\section{Discussion}

Studies of long-term sequelae after SCT resection in children found a high incidence of urinary and defecation complaints; however, the long-term course of bowel and urinary complaints beyond childhood has hardly been studied before. ${ }^{4,6}$. The present study reports a large cohort of adults treated for SCT during childhood. Approximately half of them reported defecation and micturition problems. In most cases, these problems occurred occasionally and were not considered a daily problem; these problems occurred frequently in one-third of the patients. Eventually, one-third of patients perceived their complaints to be a serious problem. Constipation was less prevalent than previously reported but had a relatively larger negative impact than other bowel complaints; nevertheless, some patients received no treatment for constipation. ${ }^{3,6}$ We found a higher incidence of urinary incontinence than previously reported for patients treated for SCT or anorectal malformations. ${ }^{7,8,13,14}$ In almost half of the patients in the present study, urinary incontinence occurred regularly, which possibly explains the more negative impact patients reported. Furthermore, 11-29\% of the patients reported abnormal voiding habits; none, however, needed selfcatheterization. A previous study found that patients treated for SCT rated their quality of life as good and the present study confirms that defecation and micturition problems need not lead to social restrictions, as only a small proportion of patients reported restrictions in social life and daily functioning due to these problems. ${ }^{15}$

Apart from inventorying defecation and micturition complaints at adult age, we had the opportunity to longitudinally evaluate the course of complaints in almost 


\section{Chapter 4}

$30 \%$ of the study population. We found favourable results in that in some cases soiling, constipation, and urinary incontinence problems had receded, although others had first experienced defecation and micturition problems beyond childhood.

Cozzi et al. suggested to consider secondary gastrointestinal symptoms in the evaluation of long-term outcomes after SCT resection, since they found a higher incidence of abdominal pain compared to controls. ${ }^{7}$ In the present study, the incidence of secondary gastrointestinal complaints was comparably high. We recommend monitoring of secondary gastrointestinal symptoms during surveillance, because as yet we do not know their cause, onset, and duration.

In the present study, we evaluated voiding complaints and urinary incontinence by means of a questionnaire without applying urodynamic investigations. It would seem worthwhile to further assess if there is a measurable cause for any urinary complaints, as urological imaging studies and rectomanometry in subjectively healthy patients with SCT showed relatively high incidences of abnormal results. 5,10,16 However, patients of the present cohort were recruited by retrospective record review. Regrettably these records do not provide information on any further investigations by urologists or gastroenterologists. Still, even taking into account that the complaints are self-reported, the findings point to an important problem, which is given little attention in current surveillance strategies for patients who underwent resection of an SCT during childhood. We recommend to include prospective investigations in these strategies and to inventory complaints during follow-up visits.

The present cohort of adults with prior SCT resection was relatively large, taking into account the low incidence of SCT. Nevertheless, we were not able to provide sufficient evidence for tumour-related risk factors that predict long-term urinary incontinence and soiling. Still it would seem prudent to state that patients with SCT who report urinary incontinence during childhood seem to be at risk for urinary incontinence during adulthood and should be closely followed, so as to enable early intervention if necessary.

None of the patients with a type III or type IV SCT reported constipation at adult age, in contrast to other studies in which higher Altman types proved a risk factor for late sequelae. ${ }^{10,17}$ Moreover, in the present cohort, a tumour diameter of more than $10 \mathrm{~cm}$ was associated with an increased risk of constipation at adult age. The combined findings suggest that the internal tumour extent does not necessarily 
predict functional complaints, but the more extended surgical resection required for large tumours possibly has a greater impact on defecation physiology than previously assumed.

None of the patient- or disease-related characteristics we analysed was able to predict functional sequelae during adulthood in general, but rather, some were associated with particular complaints. Consequently, predicting complaints later in life from these characteristics is not reliable. We therefore advise to closely monitor all patients treated for SCT, from surgery until adolescence, so that any gastrointestinal and urological sequelae are recognized early. Although bowel and urinary function may improve with time, it seems worthwhile to offer children with impaired bowel or urinary function supportive treatment modalities including continence training at an early stage. Therefore, surveillance should be longer than the three years recommended from an oncological point of view. ${ }^{18}$ Paediatric surgeons should perform an initial evaluation and, in close collaboration with paediatric gastroenterologists and urologists, initiate renal bladder ultrasound scan, urodynamic studies, and rectomanometry, if indicated. ${ }^{4}$ As we found that constipation and urinary incontinence may also present for the first time at older age, we recommend not to stop the surveillance program in those who do not report complaints at school age. 


\section{Chapter 4}

\section{REFERENCES}

1 Pauniaho SL, Heikinheimo O, Vettenranta K, et al. High prevalence of sacrococcygeal teratoma in Finland - A nationwide population-based study. Acta Paediatr 2013;102:e251e256.

2 Barksdale EM, Jr., Obokhare I. Teratomas in infants and children. Current Opin Pediatr 2009;21:344-349.

3 Derikx JP, De Backer A, van de Schoot L, et-al. Long-term functional sequelae of sacrococcygeal teratoma: A national study in The Netherlands. J Pediatr Surg 2007:42:1122-1126.

Berger $M$, Heinrich $M$, Lacher $M$, et al. Postoperative bladder and rectal function in children with sacrococcygeal teratoma. Pediatr Blood Cancer 2011;56:397-402.

Ozkan KU, Bauer SB, Khoshbin S, et al. Neurogenic bladder dysfunction after sacrococcygeal teratoma resection. J Urol 2006;175:292-296; discussion 296.

Havranek P, Rubenson A, Guth D, et al. Sacrococcygeal teratoma in Sweden: A 10-year national retrospective study. J Pediatr Surg 1992;27:1447-1450.

7 Cozzi F, Schiavetti A, Zani A, et al. The functional sequelae of sacrococcygeal teratoma: A longitudinal and cross-sectional follow-up study. J Pediatr Surg 2008;43:658-661.

Rintala R, Lahdenne P, Lindahl H, et al. Anorectal function in adults operated for a benign sacrococcygeal teratoma. J Pediatr Surg 1993;28:1165-1167.

9 Shalaby MS, Walker G, O'Toole S, et al. The long-term outcome of patients diagnosed with sacrococcygeal teratoma in childhood. A study of a national cohort. Arch Dis Child 2014;99:1009-1013.

10 Lahdenne P, Wikström S, Heikinheimo M, et al. Late urological sequelae after surgery for congenital sacrococcygeal teratoma. Pediatr Surg Int 1992;7:195-198.

11 Altman RP, Randolph JG, Lilly JR. Sacrococcygeal teratoma: American Academy of Pediatrics Surgical Section Survey-1973. J Pediatr Surg 1974;9:389-398.

12 Holschneider A, Hutson J, Pena A, et al. Preliminary report on the International Conference for the Development of Standards for the Treatment of Anorectal Malformations. J Pediatr Surg 2005;40:1521-1526.

13 Hassink EA, Rieu PN, Brugman AT, et al. Quality of life after operatively corrected high anorectal malformation: A long-term follow-up study of patients aged 18 years and older. J Pediatr Surg 1994;29:773-776. 
14 Rintala R, Mildh L, Lindahl H. Fecal continence and quality of life in adult patients with an operated low anorectal malformation. J Pediatr Surg 1992;27:902-905.

15 Kremer ME, Dirix M, Koeneman MM, et al. Quality of life in adulthood after resection of a sacrococcygeal teratoma in childhood: A Dutch multicentre study. Arch Dis Child Fetal Neonatal Ed 2015;100:F229-F232.

16 Engelskirchen R, Holschneider AM, Rhein R, et al. Sacral teratomas in childhood. An analysis of long-term results in 87 children. Z Kinderchir 1987;42:358-361.

17 Cost NG, Geller JI, Le LD, et al. Urologic comorbidities associated with sacrococcygeal teratoma and a rational plan for urologic surveillance. Pediatr Blood Cancer 2013;60:1626-1629.

18 Derikx JP, De Backer A, van de Schoot L, et al. Factors associated with recurrence and metastasis in sacrococcygeal teratoma. Br J Surg 2006;93:1543-1548. 


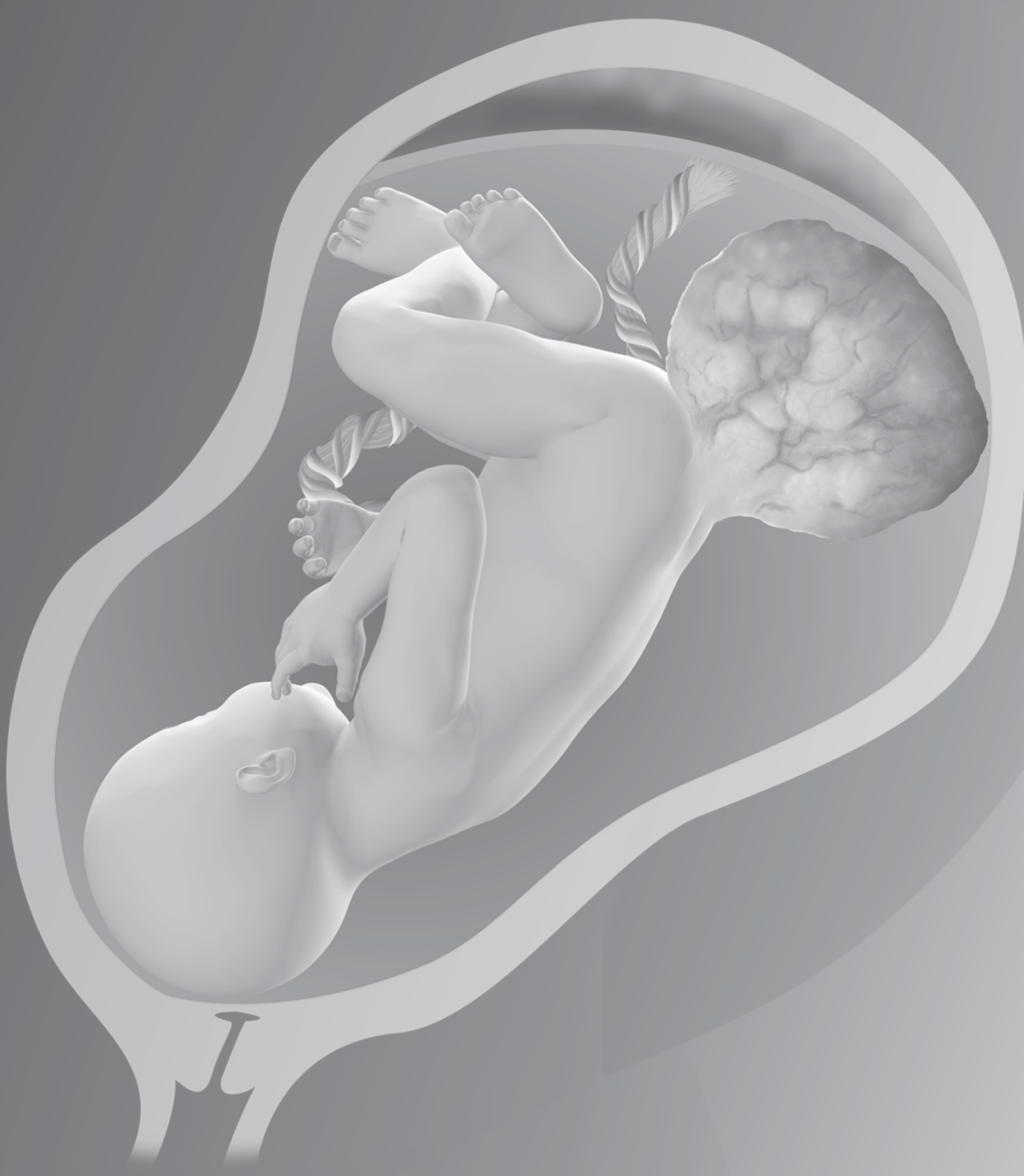




\section{CHAPTER 5}

\section{Sexual function after treatment for sacrococcygeal teratoma during childhood}

Marijke E.B. Kremer, Joep P.M. Derikx, Andrea Peeters, Moniek M. ter Kuile, Robertine van Baren, Hugo A. Heij, Marc H.W.A. Wijnen, René M.H. Wijnen, David C. van der Zee and L.W. Ernest van Heurn

Adapted from: J Pediatr Surg 2016 Apr;51(4): 534-540. 


\section{Chapter 5}

\section{AbStRACT}

\section{Background}

Children treated for sacrococcygeal teratoma (SCT) may suffer from sexual dysfunction later in life because of the extended pelvic surgery performed, however, structured evaluations have not been performed yet.

\section{Methods}

The Female Sexual Function Index (FSFI), the International Index of Erectile Function (IIEF) and the Body Image Questionnaire (BIQ) were sent to patients ( $\geq 18$ years) treated for SCT in the Dutch paediatric surgical centres after 1970.

\section{Results}

Forty-five of 76 patients returned the questionnaires; 28 women (median age 27.3 years, range 18.3-41.0) and seven men (median age 22.0 years, range 19.1-36.5) were eligible for analysis. The FSFI and IIEF results were compared to healthy controls. Female patients scored significantly lower on the desire $(p=0.014)$, arousal $(p=0.013)$ and lubrication domain $(p=0.019)$. FSFI total-scores of female patients were significantly lower compared to controls [median 30.5 (IQR 28.6-31.4) vs. median 32.4 (IQR 30.6-33.45) $p \leq 0.001$ ] but were above the threshold value for sexual dysfunction. Males reported normal erectile function and penetration ability with normal ejaculation. Females had significant lower BIQ results compared to males; BIQ-cosmesis scores were moderately correlated to the FSFI-desire score $(r=-0.37, p=0.028)$.

\section{Conclusion}

SCT resection in girls may result in diminished sexual function at adult age with worse self-perceived body image. The possibility of sexual complaints should be integrated in the surveillance strategies for these patients. 


\section{INTRODUCTION}

Sacrococcygeal teratoma (SCT) is the most common germ cell tumour in infancy arising early during embryonic development. Around the fourth to sixth gestational weeks these tumours develop because of failure of the normal migration of pluripotent primordial germ cells from the yolk sac along the mesentery to the gonadal ridge where the germ-line normally develops at a later time. ${ }^{1-3}$ The tumour continues to grow during pregnancy with possible intrapelvic and extrapelvic extension, defined by the Altman classification with higher Altman types describing a greater intrapelvic tumour extension. ${ }^{4}$ One in 15,000-40,000 live born neonates is affected, with females three to four times more often than males. ${ }^{5,6}$ Complete surgical resection is the standard treatment for these usually well-vascularized tumours and resection of the coccyx is essential to prevent recurrence. Usually SCTs are benign at birth and early resection is performed to avoid the risk of malignant transformation and haemorrhagic complications. ${ }^{3,7,8}$

Functional sequelae of surgical treatment of SCT, including micturition and defecation problems, have frequently been reported. ${ }^{9-12}$ The reasons are not fully clear, but both the mass effect of the tumour on anatomical structures and the consequences of extended pelvic surgery may contribute to their occurrence. ${ }^{10} \mathrm{Next}$ to functional sequelae dissatisfaction with the cosmetic result of the surgical treatment has been reported in $40 \%-50 \%$ of patients. ${ }^{13,14}$ The consequences of SCT and its treatment during childhood on sexual function later in life have sparsely been investigated, however, validated instruments have not been used. A few studies addressed sexual function in individual cases treated for SCT with varying results, but did not analyse the various subdomains of sexual function. ${ }^{13,15-18}$ Sexual dysfunction following SCT resection may be the consequence of iatrogenic damage to the neurovascular structures in close proximity to the intrapelvic components of the tumour, including the pudendal nerve and hypogastric plexus. Furthermore, integrity of the pelvic floor muscles in particular is compromised by the surgical resection. ${ }^{19,20}$ The varying degrees of buttock deformity and the postoperative scar may also contribute to sexual dysfunction through negative effects in body image and self-confidence. 


\section{Chapter 5}

The present multicentre study investigates sexual function of patients treated for SCT during childhood using validated and sex-specific questionnaires and compared the results to healthy controls. The patients' body self-image was evaluated to identify a possible correlation between body image and sexual function.

\section{Methods}

\section{Patients and study design}

Patients treated for SCT after 1970 in the six Dutch paediatric surgical centres who would have been $\geq 18$ years at the moment of data collection were identified from our database. ${ }^{14}$ After ethical approval by the medical ethical committee of the Maastricht University Medical Centre, records of these patients were reviewed to retrieve details on sex and age as well as Altman classification, histopathological tumour classification and surgical treatment. Patients in whom the teratoma was part of the Currarino triad were excluded, as they often show associated abnormalities including tethered cord or meningocele, with possible consequences for sexual function. ${ }^{21}$ Eligible patients for whom contact details were available were sent an information letter together with an informed consent form enclosed. Those returning the signed consent form were included in the study and received a set of questionnaires: a self-designed questionnaire on medical history and sociodemographic details such as educational attainment, relationship status and living situation, a sex-specific questionnaire evaluating sexual function and a questionnaire on body image.

\section{Questionnaires}

Sexual function of women was assessed using the "Female Sexual Function Index" (FSFI), which is a multidimensional self-reported measure that addresses sexual function during the past four weeks. ${ }^{22}$ It consists of 19 questions assessing six dimensions of female sexual function: sexual desire, arousal, lubrication, orgasm, satisfaction and coital pain. The values per domain score range from $0,0.8$ or 1.2 to 6. In addition, a total FSFI score can be calculated, ranging from 2 to 36 , where a total score of $\leq 26.55$ is assumed to indicate sexual dysfunction. ${ }^{22,23}$ Validity, reliability and applicability of the FSFI within the Dutch population have been confirmed earlier. ${ }^{24}$ 
Sexual function of men was assessed using the Dutch version of the International Index of Erectile Function (IIEF). ${ }^{25}$ This self-reported questionnaire evaluates male sexual function during the past four weeks. It consists of 15 questions grouped in five domains: erectile function (max. score 30), intercourse satisfaction (max. score 15) and orgasmic function, sexual desire and overall satisfaction (max. score 10). Domain scores are calculated by summating the scores on the individual questions. Higher scores indicate better sexual functioning, with erectile dysfunction defined as an erectile function score of $\leq 25.0 .{ }^{26,27}$ The IIEF has been proven a valid and reliable self-administered measure for the evaluation of erectile function; the linguistic validation of the Dutch version has been conducted previously. ${ }^{25-27}$

The Body Image Questionnaire (BIQ) evaluates surgically treated patients' body image and satisfaction with the cosmetic result. ${ }^{28}$ It comprises eight questions that are aggregated to two scales. Five questions address perception of body image and satisfaction with the bodily appearance. The scores of these items are summarized to a body image score ranging from 5 (lowest body image) to 20 (highest body image). The other three questions address satisfaction with the surgical scar cosmesis and the effect of the scar on the bodily appearance. These three items are summarized into a cosmesis score ranging from 3 (lowest satisfaction) to 24 (highest satisfaction). ${ }^{28}$

\section{Control populations}

FSFI-results of patients treated for SCT were compared to values of healthy female controls ( $n=169$ ) obtained from the Dutch validation study of the FSFI and a second study evaluating different treatments for vaginismus. ${ }^{24,29}$ All female controls were aged 18-60 years and were in a heterosexual relationship. They were recruited by responding to an advertisement in a local newspaper.

IIEF results were compared to values of a cohort of healthy Dutch males ( $n=$ 26, aged 18-33 years). Male passers-by were randomly contacted outside the Maastricht University Medical Centre and asked to complete the IIEF questionnaire anonymously. The completed questionnaires were sent back using a self-addressed stamped envelope. 


\section{Chapter 5}

\section{Statistical analysis}

Statistical analysis was performed using Graph Pad Prism 6 (GraphPad Software, Inc., La Jolla, CA, USA). Normal distribution of data was assessed with the D'Agostino-Pearson omnibus normality test. Statistical analysis of demographic baseline characteristics was performed using Fisher's exact test or Chi-square test for categorical variables. Between-group comparisons of IIEF, FSFI and BIQ results were performed using the Mann-Whitney $U$ test. Associations between the BIQ scores and the sexual function were tested with the Pearson or Spearman's correlation coefficient. All data are presented as median with range or interquartile range $(I Q R)$. All $p$-values were obtained with two-sided tests and statistical significance was defined as $p$-values of $\leq 0.05$.

\section{RESULTS}

As shown in Figure 1, 112 children have been treated for SCT in one of the six paediatric surgical centres in the Netherlands after 1970 and would have reached the age of 18 years at the time of data collection. Thirteen infants had died in the neonatal period or afterwards because of disease progression or treatment failure. Contact details were available for 76 patients and those were invited for participation. Six informed us that they would not participate and 19 did not respond at all and further attempts to contact them failed. Forty-five (59.2\%) returned the questionnaires. Altman type and tumour histology as well as the patients' sex did not statistically significant differ between those who participated in the study and those who did not.

\section{Female participants}

Thirty-six of 58 eligible women (62.1\%) with a median age of 25.8 years (range 18.3-41.0) returned the FSFI; one was excluded from analysis because more than $50 \%$ of values were missing. The FSFI control population included only women having a relationship as the FSFI also addresses vaginal penetration and relationship satisfaction.

To ensure good matching we excluded from the case group those who reported not to be in a relationship at that moment $(n=7)$. Thus, the FSFI results of 28 women 


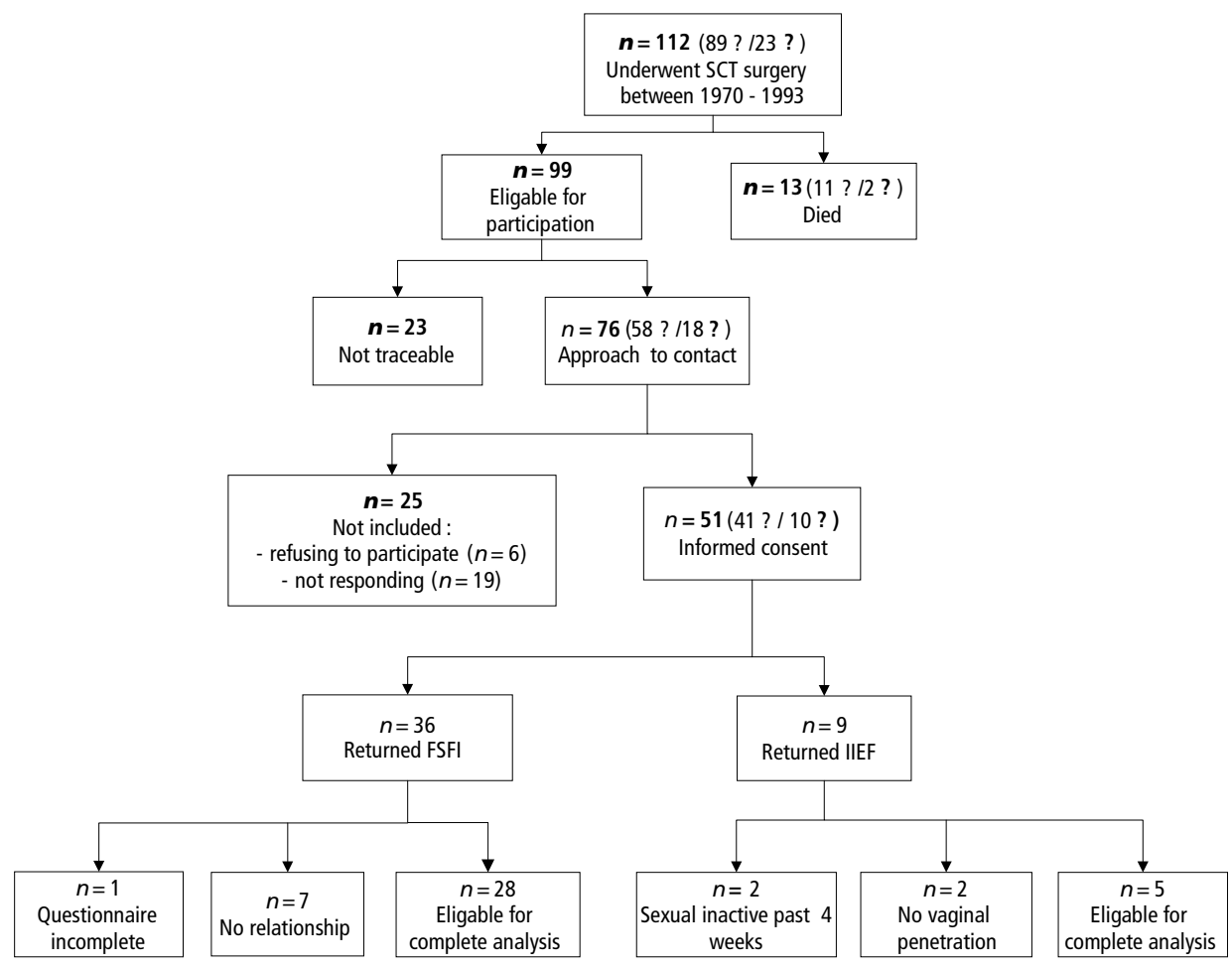

Figure 1. Patient recruitment and inclusion of patients for sexual function analysis.

FSFI = Female Sexual Function Index Questionnaire, IIEF = International Index of Erectile Function Questionnaire, SCT = sacrococcygeal teratoma.

with a median age of 27.3 years (range 18.3-41.0) were analysed (Figure 1).

Most SCTs had been classified as Altman type I $(n=13)$ or type II $(n=7)$; the minority as type III $(n=5)$ or type IV $(n=3)$. Most SCTs were histopathologically classified as benign $(n=19)$, the others as immature $(n=3)$ or as yolk sac tumour $(n=3)$ and in three the histopathological classification was unknown. None of these women reported recurrent disease. In the majority of patients a sacral approach was performed $(n=25)$, and in four of those in combination with an abdominal approach. In two patients the tumour was resected with a laparotomy and for one the operational approach was unknown. In 25 female patients the coccyx was removed, and for the others this information was missing. All women had a heterosexual 


\section{Chapter 5}

relationship with 18 living together with the partner. There were no statistically significant differences in age, relationship status, living situation and educational attainment between the case group and the controls (Table 1).

Two out of 35 women (5.7\%) underwent surgical correction of the scar, one because of cosmetic dissatisfaction and the other because of pain complaints.

\section{Male participants}

Nine of 18 eligible men (median age 22 years, range 18.3-36.5) returned the IIEF $(50.0 \%)$. The IIEF domain sexual desire was assessed for all responders $(n=9)$, as it is independent form sexual activity. Orgasmic function could be analysed for all sexually active males $(n=7)$, as it is independent from the relationship status and not included in calculations of other domain scores. Eventually, five participants were eligible for full analysis (Figure 1).

Four of the seven sexually active men (median age 22.0 years: range 19.136.5) had a mainly external SCT classified as Altman type I $(n=1)$ or II $(n=3)$, two had a SCT with mainly pelvic extension classified as Altman type III $(n=1)$ or IV $(n=1)$; the Altman type was unknown in one case. In all patients the tumour was resected with a sacral approach and in all the coccyx was resected. Most of the tumours were mature $(n=4)$ two were classified as either yolk sac tumour or embryonal carcinoma and one as immature. One patient treated for a yolk sac tumour had local tumour recurrence of the same histopathology and was treated with surgery alone. Another patient treated for a mature teratoma developed recurrence with yolk sac tumour histology and was treated with chemotherapy and surgical resection. One of the nine male responders $(11 \%)$ underwent surgical correction of the scar because of dissatisfaction with the cosmetic result. At the moment of data collection five men had a heterosexual relationship with two living together with the partner. Comparison of baseline characteristics between the case group and male controls showed no significant differences in age, relationship status, living status and educational level (Table 1). 
Table 1. Baseline characteristics of participants and the female and male control populations

\begin{tabular}{|c|c|c|c|}
\hline $\mathrm{FSFl}^{*}$ & $\begin{array}{l}\text { Female participants } \\
\text { treated for } \mathrm{SCT}^{\#} \\
(n=28)\end{array}$ & $\begin{array}{l}\text { Female control } \\
\text { population } \\
(n=169)\end{array}$ & $p$-value \\
\hline \multicolumn{4}{|l|}{ Age } \\
\hline Median in years (range) & $27.4(18.3-41.0)$ & $24.0(18.0-60.0)$ & 0.167 \\
\hline \multicolumn{4}{|l|}{ Relationship } \\
\hline Single & - & - & \\
\hline (Male) partner & $28(100 \%)$ & $169(100 \%)$ & \\
\hline \multicolumn{4}{|l|}{ Living status } \\
\hline Together with partner & $18(64.3 \%)$ & $76(45.0 \%)$ & \\
\hline Alone & $10(35.7 \%)$ & $93(55.0 \%)$ & 0.067 \\
\hline \multicolumn{4}{|l|}{ Education } \\
\hline Primary-lower secondary school & $3(10.7 \%)$ & $14(8.3 \%)$ & \\
\hline Middle-higher secondary school & $16(57.1 \%)$ & $114(67.5 \%)$ & \\
\hline \multirow[t]{2}{*}{ College or university } & $9(32.1 \%)$ & $41(24.2 \%)$ & 0.565 \\
\hline & $\begin{array}{l}\text { Male participants } \\
\text { treated for SCT } \\
(n=7)\end{array}$ & $\begin{array}{l}\text { Male control } \\
\text { population } \\
(n=26)\end{array}$ & $p$-value \\
\hline \multicolumn{4}{|l|}{ Age } \\
\hline Median in years (range) & $22.0(19.1-36.5)$ & $24.0(20.0-33.0)$ & 0.162 \\
\hline \multicolumn{4}{|l|}{ Relationship } \\
\hline Single & $2(28.6 \%)$ & $7(27.0 \%)$ & \\
\hline (Female) partner & $5(71.4 \%)$ & (16) $19(73.0 \%)$ & 1.000 \\
\hline \multicolumn{4}{|l|}{ Living status } \\
\hline Together with partner & $2(28.6 \%)$ & $10(38.5 \%)$ & \\
\hline Alone & $5(71.2 \%)$ & $16(61.5 \%)$ & 1.000 \\
\hline \multicolumn{4}{|l|}{ Education } \\
\hline Primary-lower secondary school & $2(28.5 \%)$ & $3(11.5 \%)$ & \\
\hline Middle-higher secondary school & $3(42.9 \%)$ & $7(26.9 \%)$ & \\
\hline College or university & $2(28.5 \%)$ & $16(60.8 \%)$ & 0.270 \\
\hline
\end{tabular}




\section{Chapter 5}

\section{Female sexual function: results of the FSFI}

The median FSFI total score for females treated for SCT was significantly lower than that for healthy controls [30.5 (IQR 28.6-31.4) vs. 32.4 (IQR 30.6-33.5), $p \leq 0.001$ ]. However, for all patients but one the total score exceeded the threshold value for sexual dysfunction. Females treated for SCT scored significantly lower than the controls on the FSFI domain desire [median 3.6 (IQR 3.0-4.2) vs. median 4.2 (IQR 3.6-4.8), $p=0.014$ ], arousal [median 5.4 (IQR 4.6-5.4) vs. median 5.4 (IQR 5.1-5.7), $p=0.013$ ] and lubrication [median 6.0 (IQR 5.4-6.0) vs. median 6.0 (IQR 6.0-6.0), $p=0.019]$. Scores on the FSFI domains pain, orgasm and satisfaction did not significantly differ between the groups. The results of FSFI are outlined in Figure 2.

The FSFI results on the domains desire and satisfaction with overall sex life of those not in a relationship $(n=7)$ are given in Table 2. Two patients did not answer the question about satisfaction with their sex life. There was no difference in desire score between participants in a relationship and those who were not (median 3.6, IQR 3.0-4.2). One patient had a low desire score in combination with a low BIQ and cosmesis score; for the others no clear association was observed between BIQ and cosmesis scores and sexual desire or satisfaction.

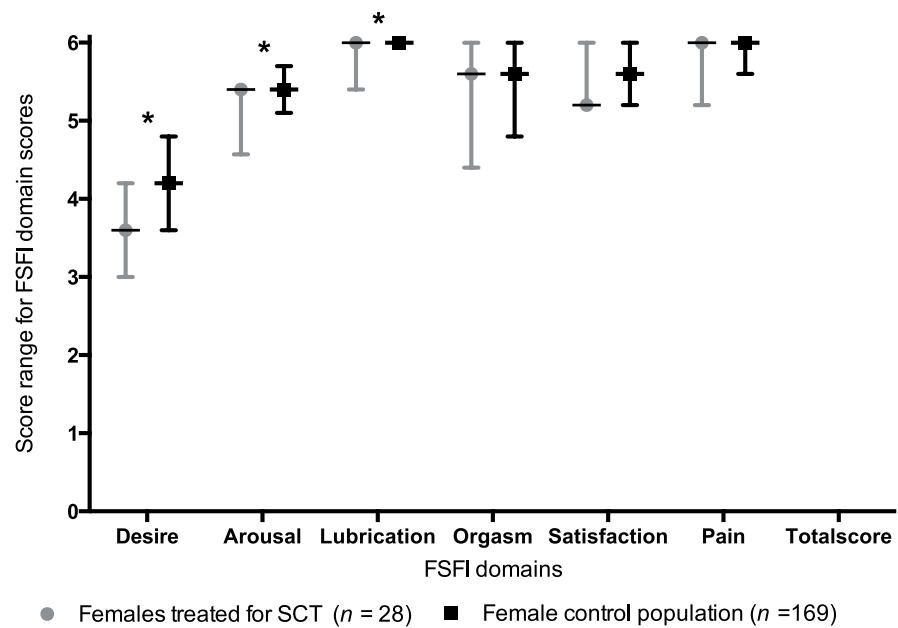

Figure 2. Results of the FSFI domain scores

SCT = sacrococcygeal teratoma, FSFI = Female Sexual Function Index, all values are median with IQR, * indicates statistical significant difference 
Table 2. Characteristics and results on FSFI domains desire and satisfaction of female participants excluded from the overall analysis $(n=7)$

\begin{tabular}{|c|c|c|c|c|c|c|c|}
\hline Relation-ship & $\begin{array}{l}\text { Sexually } \\
\text { active past } \\
4 \text { weeks }\end{array}$ & $\begin{array}{l}\text { Satisfaction } \\
\text { overall sex } \\
\text { life }^{\S}\end{array}$ & $\begin{array}{l}\text { Desire } \\
\text { score }^{+}\end{array}$ & $\begin{array}{l}\text { Surgical } \\
\text { approach }\end{array}$ & $\begin{array}{l}\text { Altman } \\
\text { type }\end{array}$ & $\begin{array}{l}\text { Cosmesis- } \\
\text { score }^{\#}\end{array}$ & $\begin{array}{l}\text { BIQ- } \\
\text { score* }\end{array}$ \\
\hline No & No & 2 & 3 & Sacral & I & 20 & 19 \\
\hline No & No & 3 & 4.2 & Sacral & $\|$ & 15 & 10 \\
\hline No & Yes & 3 & 4.8 & Abdominal-sacral & $\|$ & 14 & 8 \\
\hline No & No & Missing & 3.6 & Abdominal-sacral & $\|$ & 19 & 19 \\
\hline No & No & Missing & 1.2 & Sacral & $\|$ & 9 & 9 \\
\hline No & $\begin{array}{l}\text { Yes } \\
\text { (no vaginal } \\
\text { penetration) }\end{array}$ & 1 & 3.6 & Sacral & I & 11 & 17 \\
\hline No & Yes & 5 & 3.6 & Sacral & $\|$ & 14 & 17 \\
\hline
\end{tabular}

\section{Male sexual function: results of the IIEF}

IIEF scores of males treated for SCT did not significantly differ from those of the control population (Figure 3). Median scores on the subdomains for males treated for SCT versus controls were the following: erectile function [29.0 (IQR 29.0-30.0) vs. 30.0 (IQR 29.0-30.0), $p=0.544$ ], sexual desire [6.0 (IQR 5.0-9.0) vs. 7.5 (IQR 6.0-9.0), $p=0.117]$, orgasmic function [10.0 (IQR 10.0-10.0) vs. 10.0 (IQR 10.010.0), $p=0.888$ ], intercourse satisfaction [13.0 (IQR 10.0-14.0) vs. 13.5 (IQR 11.75-15.0), $p=0.445]$ and overall satisfaction [8.0 (IQR 8.0-10.0) vs. 9.5 (IQR 8.010.0), $p=0.601]$. Table 3 gives the results on the IIEF domains desire and satisfaction with sex life for all male participants, even for those who had not been sexually active during the past four weeks. One of the two participants who reported sexual inactivity had a low desire score, but was moderately satisfied with his sex life and scored high on the BIQ and cosmesis score. The other scored high on the desire score and was despite sexual inactivity equally satisfied and dissatisfied with his sex life. He had undergone a second operation because of disease recurrence and scored relatively low on the cosmesis score. 


\section{Chapter 5}

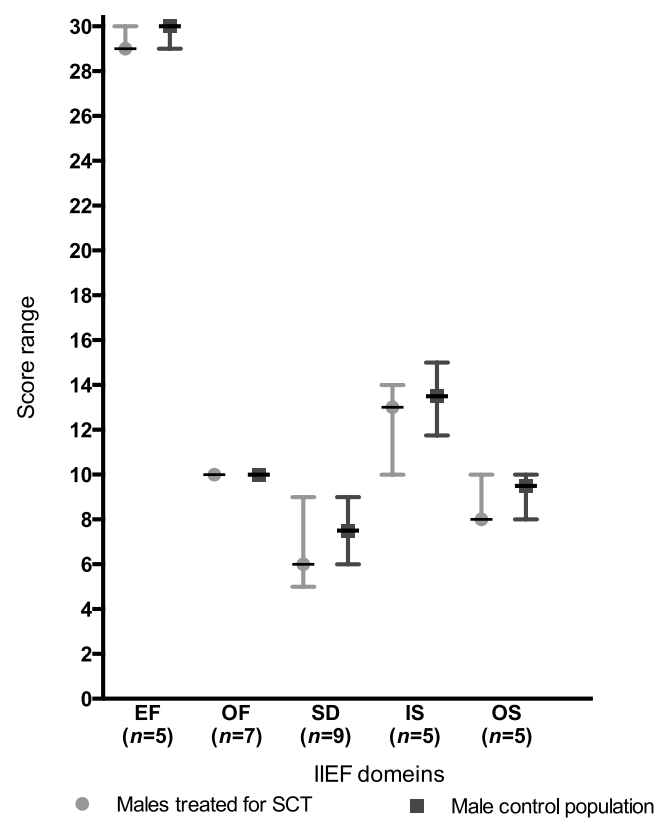

Figure 3. Results on the IIEF domain scores

$S C T=$ sacrococcygeal teratoma, IIEF = International Index of Erectile Function, EF =erectile function, $O F=$ orgasmic function, $S D=$ sexual desire, $I S=$ intercourse satisfaction, $O S=$ overall satisfaction, all values are median with IQR.

\section{Correlation of body image and sexual function}

Body image was assessed using the BIQ questionnaire and results of females were compared with results of males. One woman returned a blank questionnaire, and consequently the results of 27 women and nine men were analysed. Men appeared to have a significantly better perception of their body image [median 20 (IQR 18.020.0) vs. median 17.0 (IQR 13.0-18.0), $p=<0.001$ ] and a higher degree of satisfaction with the scar and the cosmetic result [cosmesis score: median 14.0 (IQR 12.5-17.5) vs. median 11.0 (IQR 8.0-13.0), $p=\leq 0.001$ ] (Figure. 4). 
Table 3. Characteristics of male participants and IIEF results of those excluded from the comparison to controls

\begin{tabular}{|c|c|c|c|c|c|c|c|c|}
\hline Relation-ship & $\begin{array}{l}\text { Sexually } \\
\text { active past } \\
4 \text { weeks }\end{array}$ & $\begin{array}{l}\text { Desire } \\
\text { score }^{+}\end{array}$ & $\begin{array}{l}\text { Satisfaction } \\
\text { overall sex } \\
\text { life }^{\S}\end{array}$ & $\begin{array}{l}\text { BIQ- } \\
\text { score* }\end{array}$ & $\begin{array}{l}\text { Cosmesis- } \\
\text { score }^{\#}\end{array}$ & $\begin{array}{l}\text { Surgical } \\
\text { approach }\end{array}$ & $\begin{array}{l}\text { Altman } \\
\text { type }\end{array}$ & $\begin{array}{l}\text { Recurrent } \\
\text { disease }\end{array}$ \\
\hline No & No & 2 & 4 & 20 & 18 & Sacral & $\|$ & No \\
\hline No & No & 5 & 3 & 15 & 6 & Sacral & 1 & $\begin{array}{l}\text { Yes } \\
\text { (CT + sacral } \\
\text { resection) }\end{array}$ \\
\hline No & $\begin{array}{l}\text { Yes } \\
\text { (no vaginal } \\
\text { penetration) }\end{array}$ & 5 & 4 & 18 & 13 & Sacral & III & $\begin{array}{l}\text { Yes } \\
\text { (RT + sacral } \\
\text { resection) }\end{array}$ \\
\hline No & $\begin{array}{l}\text { Yes } \\
\text { (no vaginal } \\
\text { penetration) }\end{array}$ & 9 & 5 & 20 & 12 & Sacral & I & No \\
\hline Yes & Yes & 7 & 4 & 20 & 18 & Sacral & $\|$ & No \\
\hline Yes & Yes & 6 & 5 & 18 & 14 & Sacral & $\|$ & No \\
\hline Yes & Yes & 9 & 5 & 20 & 13 & Sacral & $\|$ & No \\
\hline Yes & Yes & 7 & 4 & 20 & 15 & Sacral & Missing & No \\
\hline Yes & Yes & 5 & 4 & 19 & 17 & Sacral & IV & No \\
\hline
\end{tabular}

To identify a possible link between sexual function and body image correlation analysis of the FSFI and BIQ results for the women was performed. The male population was too small to perform reliable correlation analysis. The BIQ-cosmesis score proved, to be moderately associated with the FSFI desire score $(r=-0.37$, $p=0.028)$, the BIQ-body image score with both the FSFI lubrication score $(r=-$ $0.418, p=0.014)$ and orgasm score $(r=-0.356, p=0.034)$. There were no associations between the BIQ-cosmesis and body image scores and the other FSFI domains. 


\section{Chapter 5}

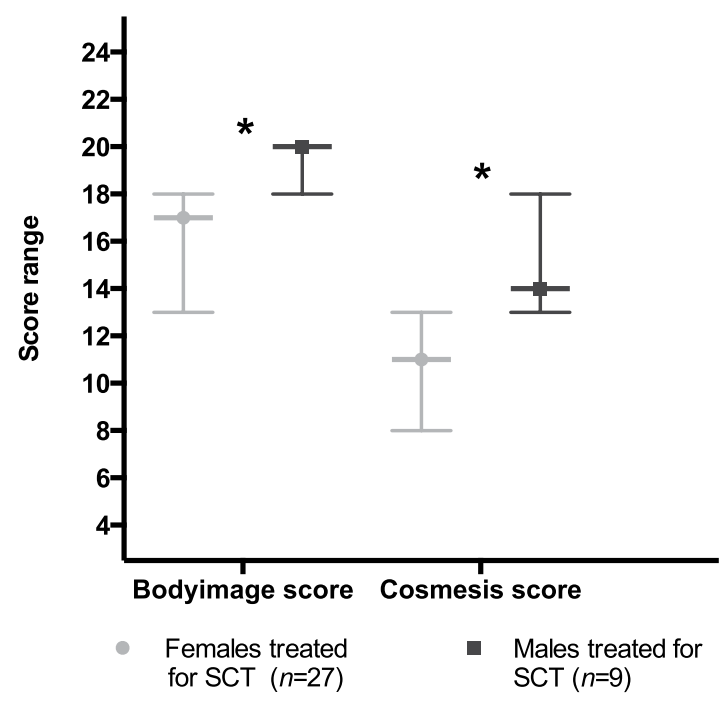

Figure 4. Results of the BIQ of males and females treated for SCT

$S C T=$ sacrococcygeal teratoma, all values are median with $I Q R$,

* indicates statistical significant difference

\section{Discussion}

Most studies evaluating functional outcome after SCT resection have been performed in the paediatric population; there are few data on outcomes beyond adolescence and it is unknown weather children treated for SCT experience problems with sexual function later in life.

The principal finding of our analysis is the decreased overall sexual function in females treated for SCT in comparison with healthy controls, although the sexual function score suggested sexual dysfunction for only one of the 28 women. This finding may largely be attributed to decreased sexual desire, as the median arousal and lubrication scores were equivalent for both groups. The decreased sexual desire may adversely have affected sexual arousal and lubrication, as these domains are closely related. ${ }^{19} \mathrm{~A}$ greater sample size would be needed to examine, whether sexual arousal and lubrication are actually decreased independently from the decreased sexual desire. 
In general females treated for SCT reported good orgasmic function and low pain scores during intercourse and none reported severe dyspareunia, suggesting adequate functioning of the pelvic floor during sexual activity, despite the fact that pelvic floor anatomy was compromised because of the tumour pressure or operative treatment in a large proportion of the patients.

The five male participants in this study reported normal erectile function and penetration ability with normal ejaculation, but a larger sample size would be needed to conclusively establish the findings.

Of all participants who returned the completed questionnaires 13.6\% reported sexual inactivity during the past four weeks. One explanation for sexual inactivity might be that all of them were not in a relationship. Sexual inactivity might also be related to dissatisfaction with the own body image. However, only two patients reporting sexual inactivity had low results on the BIQ and cosmesis score compared to the others and in addition, only two patients who were sexually inactive reported dissatisfaction with their sex life. Sexual inactivity might therefore be voluntary and could not be linked to a special tumour type, surgical approach or body image in general.

The present study investigated sexual function after SCT resection in a structured way with validated questionnaires addressing several domains of sexual function, whereas previous studies focused on self-reported general sexual function. Two previous studies reported normal adult sexual function after SCT resection during childhood in seven and five women, respectively, and in two men. ${ }^{13,17}$ Cozzi and colleagues reported urinary incontinence during intercourse in two and dyspareunia in one out of 13 young adults after SCT resection. ${ }^{16}$ Urinary- and faecal leakage during intercourse was also reported by Rintala et al. in two out of 26 patients, as well as one case of impotence. ${ }^{15}$ It is unknown if leakage during intercourse is a consequence of pelvic floor insufficiency or of urogenital anomalies that have been reported in females with SCT. ${ }^{30}$ Incontinence during sexual activity is not asked as part of the FSFI or IIEF; therefore we cannot provide this information for the present cohort.

Still the question remains whether it is the anatomical or the psychological factors that are the most responsible for the diminished overall sexual function found in women in the present study. Sexual desire may be sensitive to psychological and emotional factors including body image, self-confidence and self-acceptance. ${ }^{19} \mathrm{We}$ 


\section{Chapter 5}

found only moderate correlations of cosmesis scores with sexual desire and body image scores with lubrication and arousal scores in female participants. Therefore the diminished sexual functioning cannot solely be attributed to psychological and emotional factors. Paediatric surgeons should be aware that SCT treatment could affect sexual functioning at later age and are advised to pay special attention to the integrity of the pelvic floor, pudendal nerve and hypogastric plexus during the surgical resection.

Some limitations of the present study need to be addressed. First, duration and onset of sexual problems remained unclear and could not be included in the analysis. Second, as SCT predominantly occurs in women, the group of male participants was small. Results for male participants must therefore be interpreted with caution to the effect that there is no strong evidence but rather only a trend of normal sexual function. Third, the retrospective design may have led to selection bias, even though the disease-related baseline characteristics did not differ between those included and nonresponders. It cannot be excluded, however, that those suffering from more severe sexual problems would have been less willing to report these problems and conversely those not suffering from sexual complaints were less willing to participate as they consider themselves as healthy. Lastly, participants did not undergo physical examination and therefore we could not relate results of physical examination and hormone levels to sexual complaints.

Based on the findings of this study on sexual function and body image in patients treated for SCT in childhood, we recommend multidisciplinary consultations at ages 14 and 18 in the follow-up of these patients at academic centres. Issues relating to body image and sexual function should be discussed in a sensitive manner to identify those individuals who may be in need of further medical input in these areas. Patients with significant scarring of buttock deformity should be offered referral to a plastic surgeon. Problems with sexual function should be addressed by the appropriate. 


\section{RefERENCES}

1 Barksdale Jr EM, Obokhare I. Teratomas in infants and children. Curr Opin Pediatr 2009;21:344-349.

2 Lakhoo K. Neonatal teratomas. Early Hum Dev 2010;86:643-7.

3 Frazier AL, Weldon C, Amatruda J. Fetal and neonatal germ cell tumors. Semin Fetal Neonatal Med 2012;17:222-230.

4 Altman RP, Randolph JG, Lilly JR. Sacrococcygeal teratoma: American Academy of Pediatrics Surgical Section Survey-1973. J Pediatr Surg 1974;9:389-398.

5 Pauniaho SL, Heikinheimo O, Vettenranta K, et al. High prevalence of sacrococcygeal teratoma in Finland - a nationwide population-based study. Acta Paediatr 2013; 02:e251256.

6 Yoshida M, Matsuoka K, Nakazawa A, et al. Sacrococcygeal yolk sac tumor developing after teratoma: a clinicopathological study of pediatric sacrococcygeal germ celltumors and a proposal of the pathogenesis of sacrococcygeal yolk sac tumors. J Pediatr Surg 2013;48:776-781.

7 Derikx JP, De Backer A, van de Schoot L, et al. Factors associated with recurrence and metastasis in sacrococcygeal teratoma. Br J Surg 2006;93:1543-1548.

8 Rescorla FJ, Sawin RS, Coran AG, et al. Long-term outcome for infants and children with sacrococcygeal teratoma: a report from the Childrens Cancer Group. J Pediatr Surg 1998;33:171-176.

9 Berger $M$, Heinrich $M$, Lacher $M$, et al. Postoperative bladder and rectal function in children with sacrococcygeal teratoma. Pediatr Blood Cancer 2011;56:397-402.

10 Boemers TM, van Gool JD, de Jong TP, et al. Lower urinary tract dysfunction in children with benign sacrococcygeal teratoma. J Urol 1994;151:174-176.

11 Malone PS, Spitz L, Kiely EM, et al. The functional sequelae of sacrococcygeal teratoma. J Pediatr Surg 1990;25:679-680.

12 Schmidt B, Haberlik A, Uray E, et al. Sacrococcygeal teratoma: clinical course and prognosis with a special view to long-term functional results. Pediatr Surg Int 1999;15:573-576.

13 Bittmann S, Bittmann V. Surgical experience and cosmetic outcomes in children with sacrococcygeal teratoma. Curr Surg 2006;63:51-54. 


\section{Chapter 5}

14 Derikx JP, De Backer A, van de Schoot L, et al. Long-term functional sequelae of sacrococcygeal teratoma: a national study in the Netherlands. J Pediatr Surg 2007; 42:1122-1126.

15 Rintala $\mathrm{R}$, Lahdenne $\mathrm{P}$, Lindahl $\mathrm{H}$, et al. Anorectal function in adults operated for a benign sacrococcygeal teratoma. J Pediatr Surg 1993;28:1165-1167.

16 Cozzi F, Schiavetti A, Zani A, et al. The functional sequelae of sacrococcygeal terato- ma: a longitudinal and cross-sectional follow-up study. J Pediatr Surg 2008;43: 658-661.

17 Draper $\mathrm{H}$, Chitayat $\mathrm{D}$, Ein $\mathrm{SH}$, et al. Long-term functional results following resection of neonatal sacrococcygeal teratoma. Pediatr Surg Int 2009;25:243-246.

18 Shalaby MS, Dorris L, Carachi R. The long-term psychosocial outcomes following excision of sacrococcygeal teratoma: a national study. Arch Dis Child Fetal Neonatal Ed 2014;99:F149-152.

19 Berman JR, Adhikari SP, Goldstein I. Anatomy and physiology of female sexual function and dysfunction: classification, evaluation and treatment options. Eur Urol 2000;38:20-29.

20 Keating JP. Sexual function after rectal excision. ANZ J Surg 2004;74:248-259.

21 Emans PJ, Kootstra G, Marcelis CL, et al. The Currarino triad: the variable expression. J Pediatr Surg 2005;40:1238-1242.

22 Rosen R, Brown C, Heiman J, et al. The Female Sexual Function Index (FSFI): a multidimensional self-report instrument for the assessment of female sexual function. J Sex Marital Ther 2000;26:191-208.

23 Wiegel $M$, Meston $C$, Rosen $R$. The female sexual function index (FSFI): cross-validation and development of clinical cutoff scores. J Sex Marital Ther 2005;31:1-20.

24 ter Kuile MM, Brauer M, Laan E. The Female Sexual Function Index (FSFI) and the Female Sexual Distress Scale (FSDS): psychometric properties within a Dutch population. J Sex Marital Ther 2006;32:289-304.

Rosen RC, Riley A, Wagner G, et al. The international index of erectile function (IIEF): a multidimensional scale for assessment of erectile dysfunction. Urology 1997;49:822830.

26 Rosen RC, Cappelleri JC, Gendrano III N. The International Index of Erectile Function (IIEF): a state-of-the-science review. Int J Impot Res 2002;14:226-244.

27 Cappelleri JC, Rosen RC, Smith MD, et al. Diagnostic evaluation of the erectile function domain of the International Index of Erectile Function. Urology 1999;54: 346-351. 
28 Dunker MS, Stiggelbout AM, van Hogezand RA, et al. Cosmesis and body image after laparoscopic-assisted and open ileocolic resection for Crohn's disease. Surg Endosc 1998;12:1334-1340.

29 van Lankveld JJ, ter Kuile MM, de Groot HE, et al. Cognitive-behavioral therapy for women with lifelong vaginismus: a randomized waiting-list controlled trial of efficacy. J Consult Clin Psychol 2006;74:168-178.

30 Shalaby MS, O'Toole S, Driver C, et al. Urogenital anomalies in girls with sacrococcygeal teratoma: a commonly missed association. J Pediatr Surg 2012;47:371-374 


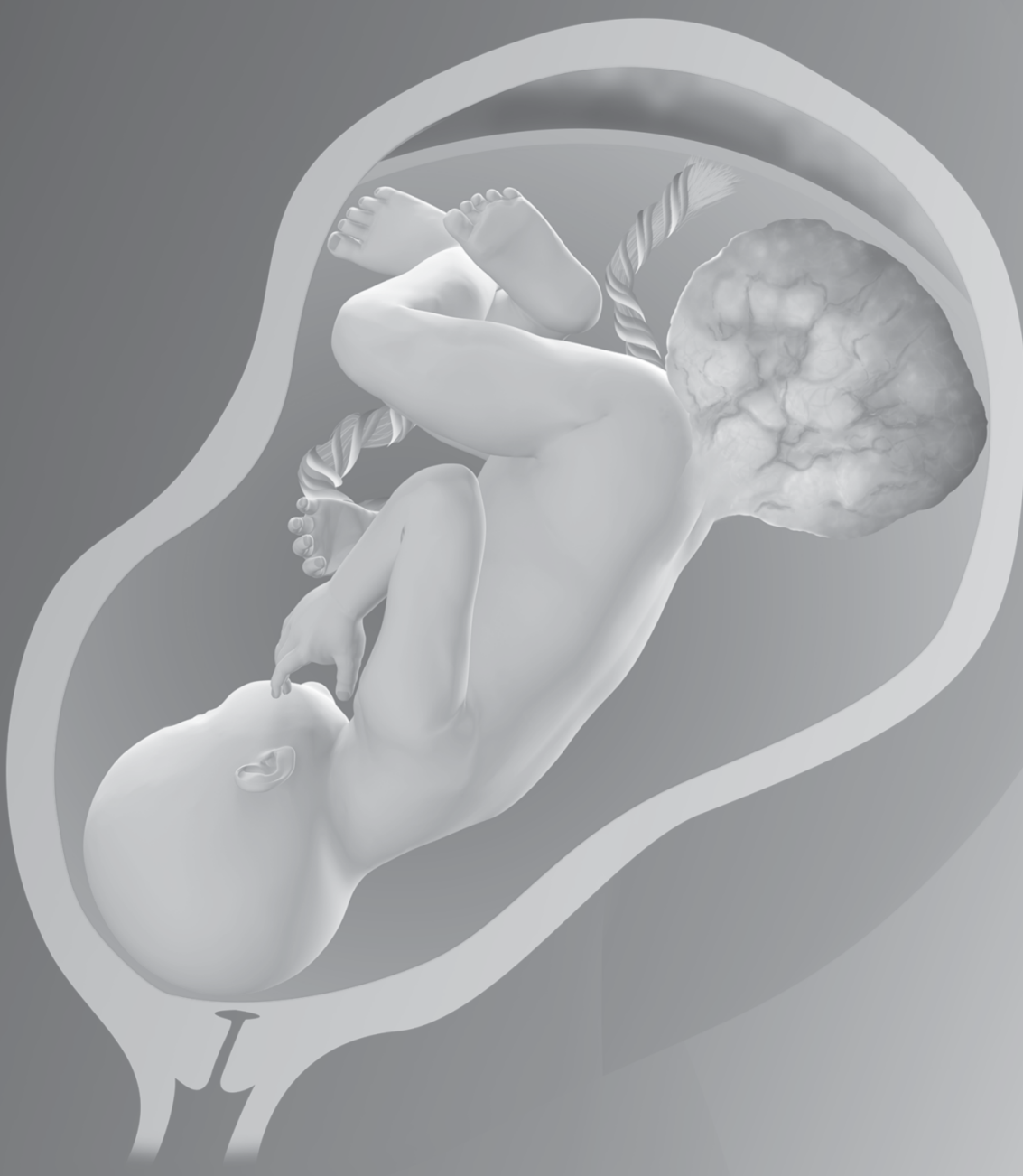




\section{ChAPTER 6}

\section{Evaluation of pregnancy and delivery in 13 women who underwent resection of a}

sacrococcygeal teratoma during early childhood

Marijke E.B. Kremer, Margot M. Koeneman, Joep P.M. Derikx, Audrey Coumans, Robertine van Baren, Hugo A. Heij, Marc H.W.A. Wijnen, René M.H. Wijnen, David C. van der Zee and L.W. Ernest van Heurn 


\section{Chapter 6}

\section{AbStRACT}

\section{Background}

Sacrococcygeal teratoma resection often brings changes in pelvic anatomy and physiology with possible consequences for defecation, micturition and sexual function. It is unknown, whether these changes have any gynaecological and obstetric sequelae. Until now four pregnancies after sacrococcygeal teratoma resection have been described and caesarean section has been suggested to be the method of choice for delivery. We evaluated the pregnancy course and mode of delivery in women previously treated for a sacrococcygeal teratoma.

\section{Methods}

The records of all patients who underwent sacrococcygeal teratoma resection after 1970 in one of the six paediatric surgical centres in the Netherlands were reviewed retrospectively. Women aged 18 years and older were eligible for participation. Patient characteristics, details about the performed operation and tumour histology were retrieved from the records. Consenting participants completed a questionnaire addressing fertility, pregnancy and delivery details.

\section{Results}

Eighty-nine women were eligible for participation; 20 could not be traced. Informed consent was received from 41 , of whom 38 returned the completed questionnaire $(92.7 \%)$. Thirteen of these 38 women conceived, all but one spontaneously. In total 20 infants were born, 17 by vaginal delivery and three by caesarean section, in one necessitated by previous intra-abdominal surgery as a consequence of sacrococcygeal teratoma resection. Conversion to a caesarean section was never necessary. None of the 25 women without offspring reported involuntary childlessness.

\section{Conclusion}

There are no indications that resection of a sacrococcygeal teratoma in female patients is associated with reduced fertility: spontaneous pregnancy is possible and vaginal delivery is safe for mother and child, irrespective of the sacrococcygeal teratoma classification or tumour histology. 


\section{INTRODUCTION}

Sacrococcygeal teratoma (SCT) is the most common tumour in infancy with a reported incidence between one in 15,000 to 40,000 live births and a female to male ratio of $4: 1 .^{1-5}$ Four types are distinguished according to the Altman classification, which describes the intra- and extra-pelvic extension of the tumour mass.6] Early resection with the coccyx en bloc is the standard treatment to prevent malignant transformation of these usually benign tumours. ${ }^{7-9}$ Both the pressure of tumour mass and extended pelvic surgery in childhood may be associated with gynaecological and obstetric sequelae. SCT resection during childhood has been associated with various anatomical changes of the pelvis and pelvic cavity, such as a hypo-plastic sacral bone and spondylolysis of the fifth lumbar vertebra. ${ }^{10}$ In addition, there is iatrogenic damage of the pelvic anatomy as in almost all cases the tumour is completely resected together with the coccyx and several perineal and pelvic muscles are fully or partly resected. ${ }^{8}$ In women this may lead to pelvic functional changes such as organ prolapse. ${ }^{11}$

It is unknown if the changes of the female pelvic anatomy and function, which may result in alteration of the birth channel, influence fertility, pregnancy and delivery. Until now, four cases of pregnancy after SCT resection have been described. ${ }^{12-14}$ Caesarean section has been suggested to be the method of choice for delivery due to no progression of descend during childbirth. ${ }^{12,13}$ Others reported an uncomplicated spontaneous vaginal delivery of a healthy term baby. ${ }^{14}$

The aim of this retrospective multicentre study was to evaluate pregnancy and delivery outcomes in women treated for SCT during childhood.

\section{MethodS}

\section{Patients}

After ethical approval by the medical ethical committee of the Maastricht University Medical Centre, the records of all patients treated for SCT after 1970 in one of the six Dutch paediatric surgical centres (Emma Children's Hospital University Medical Centre and VU Medical

Centre Amsterdam, University Medical Centre Groningen, Maastricht University 


\section{Chapter 6}

Medical Centre, St. Radboud University Medical Centre Nijmegen, Sophia Children's Hospital Rotterdam and Wilhelmina Children's Hospital Utrecht) were retrospectively reviewed and women aged 18 years and older at the time of data collection were eligible for participation.

Patient characteristics including age, sex, tumour histology, Altmanclassification ${ }^{6}$ and operation details were retrieved from the records. A self-designed questionnaire addressed the following issues: medical history, number of pregnancy attempts, completed pregnancies, involuntary childlessness, mode of delivery, obstetric intervention during delivery and details about possible perineal rupture. Furthermore the newborn's characteristics gestational age, birth weight and neonatal condition post-delivery (good -moderate - bad) were assessed.

All patients were initially contacted with an information letter sent to the most recent address explaining the background of the study together with an informed consent form. Those who not responded were contacted two weeks later by telephone and by post. The questionnaire was sent after the signed informed consent had been returned.

\section{Statistical analysis}

To test for baseline differences between women with intention to become pregnant and those with no intention to become pregnant, Fisher's exact test was applied for categorical variables (Altman classification, tumour histology and coccyx resection). Mann-Whitney $U$ test was applied to test for differences in age distribution between both groups. $P$-values of $\leq 0.05$ were considered to be statistically significant. Statistical analysis was performed using Graph Pad Prism 6 (GraphPad Software, Inc., La Jolla, CA, USA).

\section{Results}

Between 1970 and 1993, SCT resection has been performed in 112 children of whom 89 were female. Eleven of those 89 had died in the neonatal period or afterwards because of malignant transformation of the tumour; 20 patients could not be traced. Thus, 58 women were invited to participate. Five declined participation and twelve did not respond, maybe due to inability to deliver the information letter 
or because they were not willing to participate. Eventually, 41 women returned the signed consent form and received the questionnaire, of whom 38 returned the completed questionnaire. A flow chart illustrating the participant recruitment is given in Figure 1.

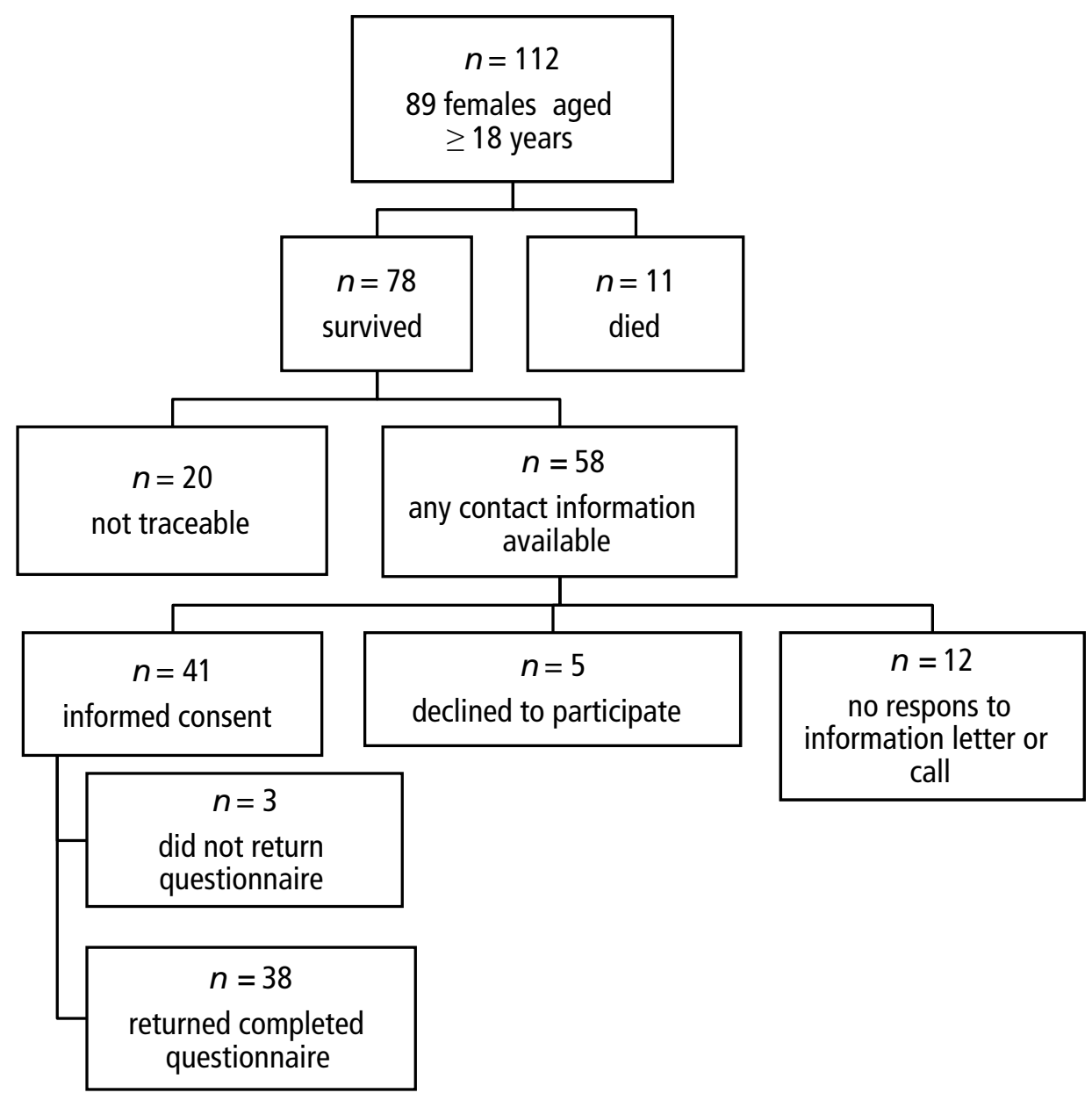

Figure 1. Flowchart illustrating participant recruitment 


\section{Chapter 6}

\section{Patient characteristics}

Data of 38 women were analysed. Details about SCT surgery and tumour characteristics are listed in Table 1. Additional intra-abdominal operations were performed in five women: two underwent appendectomy, two underwent ureteral surgery during childhood with later an appendicovesicostomy in one and one woman was treated for urethral stricture. One woman had received adjuvant chemotherapy during childhood due to a malignant SCT. A total of thirteen women with a median age of 31.2 years (range 25.6 - 36.5 years) had become pregnant.

Table 1. Altman classification, tumor histology and operation details of women with or without offspring

\begin{tabular}{|c|c|c|c|}
\hline & $\begin{array}{l}\text { Women treated } \\
\text { for SCT* } \\
\text { with offspring } \\
(n=13)\end{array}$ & $\begin{array}{l}\text { Women treated } \\
\text { for SCT* } \\
\text { without offspring } \\
(n=25)\end{array}$ & $p$-value \\
\hline \multicolumn{4}{|l|}{ Age } \\
\hline Median in years (range in years) & $31.2(25.6-36.5)$ & $24.1(18.5-41.2)$ & $<.001$ \\
\hline \multicolumn{4}{|l|}{ Altman classification [6] } \\
\hline Altman type I or II & $n=8(61.5 \%)$ & $n=18(72.0 \%)$ & \\
\hline Altman type III or IV & $n=5(38.5 \%)$ & $n=6(24.0 \%)$ & 0.46 \\
\hline Unknown & & $n=1(4.0 \%)$ & \\
\hline \multicolumn{4}{|l|}{ Tumour histology } \\
\hline Benign & $n=10(76.9 \%)$ & $n=20(80.0 \%)$ & \\
\hline Malignant EST ${ }^{\#}$ & $n=1(7.7 \%)$ & $n=4(16.0 \%)$ & 0.53 \\
\hline Unknown & $n=2(15.4 \%)$ & $n=1(4.0 \%)$ & \\
\hline \multicolumn{4}{|l|}{ Coccyx resection } \\
\hline Yes & $n=11(84.6 \%)$ & $n=22(88.0 \%)$ & \\
\hline No & $n=1(7.7 \%)$ & & 0.30 \\
\hline Unknown & $n=1(7.7 \%)$ & $n=3(12.0 \%)$ & \\
\hline
\end{tabular}




\section{Fertility and pregnancy}

Twelve women became pregnant spontaneously; one became pregnant after in-vitro fertilization. The 25 women without offspring were significantly younger (median age 23.4 years, range: $18.4-41.1$ years) than those with offspring and all reported that the childlessness was not involuntary.

Eight women were pregnant more than once with spontaneous abortion in two. The reason for the abortion was unknown. One woman had three abortions after a completed pregnancy. Her Altman type II SCT with mature histology had been completely removed with coccygeal resection with a sacral approach. The other woman with a spontaneous abortion was treated for Altman type I mature SCT that was also completely removed with the coccyx by a sacral approach. She had a successful pregnancy after a previous spontaneous abortion. No other complications during the pregnancies were reported.

\section{Delivery}

Details of the course of all 26 pregnancies are shown in Figure 2. Of the 13 women who had become pregnant, a gynaecologist performed pregnancy surveillance in six and a midwife in seven. Two of the women followed up by a gynaecologist had been referred due to their previous history of SCT surgery. Twelve women with

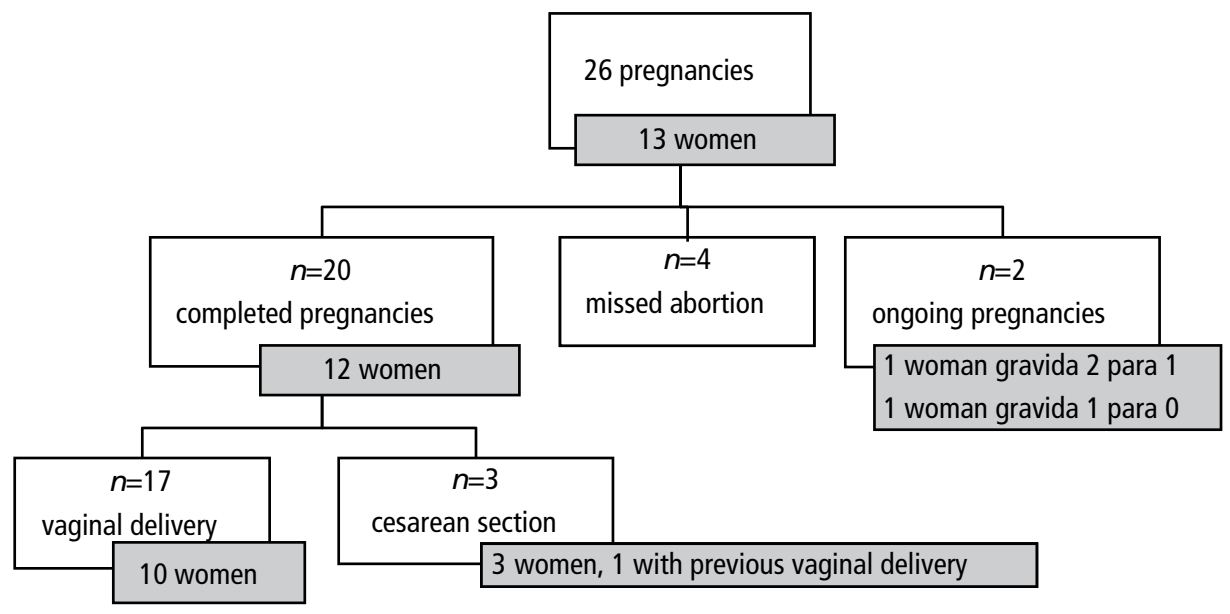

Figure 2. Overview of the course of all pregnancies 


\section{Chapter 6}

completed pregnancies gave birth to 20 infants of whom 17 were delivered vaginally, one by vacuum extraction. One of these women reported a complete anal sphincter rupture; the others only minimal perineal tears, or the perineum remained intact.

Conversion to a caesarean section was never necessary. Three women underwent a caesarean section, of whom one previously had a vaginal delivery. In two this had been an emergency procedure due to deterioration of the child's condition and not as a consequence of the prior SCT resection. In one the caesarean section had been planned because of previous intra-abdominal operations.

\section{Infants}

The median gestational age of the infants was 39 weeks (range 30 weeks -41 weeks); the median birth weight $3387 \mathrm{~g}$ (range $1156 \mathrm{~g}-4620 \mathrm{~g}$ ). Three infants were born prematurely. While the minority of the infants had a difficult $(n=2)$ or a moderate difficult $(n=1)$ start after the delivery, the majority had a good start $(n=17)$.

\section{Discussion}

Sacrococcygeal teratoma is a neonatal tumour resected at young age. ${ }^{15}$ The longterm outcome is relatively unknown and particularly pregnancy and delivery of women with prior SCT resection has been hardly addressed..$^{16}$ Our series of 20 deliveries is much larger than other series, however 20 deliveries remains a relatively small number.

Kohlberger and colleagues reported the case of a 23-year-old woman who had undergone resection during childhood of an Altman type II teratoma and had given birth to an infant by caesarean section. The caesarean section was needed due to insufficient descend of the infant during vaginal delivery. Post-delivery MRI imaging of the patient showed a dorsal bending of the sacrum with an area of scar tissue in front of it. The authors considered this anatomical transformation as an obstacle for vaginal delivery, even though the MRI scan showed a conjugate vera of $13.4 \mathrm{~cm} .{ }^{12}$ Others described conversion from vaginal delivery to a caesarean section in a 28year-old woman, previously treated for $\mathrm{SCT}$, as she had a rigid coccyx leading to a narrow pelvic outlet. ${ }^{13}$ Nowadays, SCT surgery almost always included resection of the coccyx to achieve complete tumour resection. ${ }^{4}$ We suppose that pelvic outlet 
obstruction during vaginal delivery is less relevant anymore. Recently, Shalaby and colleagues reported the obstetric outcome of two women previously treated for SCT who completed pregnancy. One gave birth to a healthy term baby by an uncomplicated vaginal delivery and in the other an emergency caesarean section was necessary due to the child's condition. ${ }^{14}$

The present study evaluates pregnancy and delivery in a cohort of 13 women who underwent SCT surgery during childhood. Our data suggests that these women can become pregnant spontaneously and that vaginal delivery is safe for mother and child, irrespective of SCT classification or tumour histology. In a relatively large proportion delivery was done by a midwife. However, it may be questionable of specialist delivery would not be preferable in a patient with previous pelvic surgery.

It has to be noted, that a presacral teratoma may be part of Currarino triad, which strictly seen is a different disorder but may have a similar clinical presentation. A Currarino triad consists of a presacral mass, sacral bone abnormalities and functional or anatomical rectal abnormalities. Moreover, myeloma abnormalities including tethered cord or meningocele are frequently seen, which may affect delivery. ${ }^{15,17,18}$ Therefore, we have not included these patients in our analysis.

None of the women who did not become pregnant reported involuntary childlessness. However the proportion of women without children appears to be relatively large compared to the proportion of women who gave birth to one or more children. The women without children were on average much younger than the women with children. Actually, in the Netherlands the age at which women become pregnant is relative high (mean 29.4 years) and this may be the most logical explanation for this high proportion of women without children in our group as there are no differences in any of the other characteristics (Table 1). ${ }^{19}$

One of the limitations of the study is the way the data were collected. Data were self- retrieved from patient records and self-reported by participants. This may have led to selection bias, as patients with problems or worse outcome may be less willing to report their problems and to complete the questionnaire. Still, the response rate was $92.7 \%$, which suggests that any potential underestimation of problems, if present, is probably relative small. On the other hand, patients were not called back to the hospital and physical examination and imaging was not performed and thus we were not able to quantify the incidence of abnormal pelvic anatomy or functional 


\section{Chapter 6}

changes. The questionnaire we used was 'self-designed'. It included objective and measurable items giving exact information about pregnancy, delivery and birth. However, we deliberately did not ask for an exact Apgar score because we supposed that most participants would not be able to answer this question. We used a rather subjective scoring method (good - moderate - bad) to assess the neonatal condition after birth instead.

Based on our results, we do not recommend routine caesarean section for women previously treated for SCT, as vaginal delivery seems to be safe in most cases for both mother and child. Caesarean section may be indicated for women with a medical history of multiple intra-abdominal operations as a consequence of the previous SCT surgery.

Health professionals involved in the care of these patients during pregnancy should be informed of the patient's medical history in order to recognize problems at an early stage and to plan the optimal route of delivery individually. 


\section{REFERENCES}

1 Lakhoo K, Sowerbutts H: Neonatal tumours. Pediatr Surg Int 2010;26(12):1159-1168.

2 Barson A. Congenital Neoplasia: The Society's experience. Arch Dis Child 1978;53:436.

3 Pauniaho SL, Heikinheimo O, Vettenranta K, et al. High prevalence of sacrococcygeal teratoma in Finland - a nationwide population-based study. Acta Paediatr 2013; 102(6):e251-256.

4 Barksdale EM, Jr., Obokhare I. Teratomas in infants and children. Curr Opin Pediatr 2009;21(3):344-349.

5 Peterson CM, Buckley C, Holley S, et al. Teratomas: a multimodality review. Curr Probl Diagn Radiol 2012;41(6):210-219.

6 Altman RP, Randolph JG, Lilly JR. Sacrococcygeal teratoma: American Academy of Pediatrics Surgical Section Survey-1973. J Pediatr Surg 1974;9(3):389-398.

7 Derikx JP, De Backer A, van de Schoot L, et al. Factors associated with recurrence and metastasis in sacrococcygeal teratoma. Br J Surg 2006;93(12):1543-1548.

8 Azizkhan RG: Perineal Tumors. In: The Surgery of Childhood Tumors. 2nd corrected and enlarged edition. Edited by Carachi R, Grosfeld JL, Azmy AF: Springer-Verlag Berlin Heidelberg; 2008;145-169.

9 Lakhoo K: Neonatal teratomas. Early Hum Dev 2010;86(10):643-647.

10 Lahdenne P, Heikinheimo M, Jaaskelainen J, et al. Vertebral abnormalities associated with congenital sacrococcygeal teratomas. J Pediatr Orthop 1991;11(5):603-607.

11 Park SY, Lee JE, Lee SR. Unusual late sequela of excision surgery for sacrococcygeal teratoma: advanced pelvic organ prolapse in a woman in her early twenties. Eur J Obstet Gynecol Reprod Biol 2013;168(2):238-239.

12 Kohlberger P, Helbich T, Schaller A: Delivery following surgically treated sacrococcygeal teratoma in the mother. Z Geburtshilfe Neonatol 1997;201(4):148-151.

13 Bittmann S, Bittmann V. Surgical experience and cosmetic outcomes in children with sacrococcygeal teratoma. Curr Surg 2006;63(1):51-54.

14 Shalaby MS, Walker G, O'Toole S, et al. The long-term outcome of patients diagnosed with sacrococcygeal teratoma in childhood. A study of a national cohort. Arch Dis Child 2014.

15 Dirix M, van Becelaere T, Berkenbosch L, et al. Malignant transformation in sacrococcygeal teratoma and in presacral teratoma assosicated with Currarino syndrome: A comperative study. J Pediatr Surg 2015;Mar;50(3):462-4. 


\section{Chapter 6}

16 Derikx JP, De Backer A, van de Schoot L, et al. Long-term functional sequelae of sacrococcygeal teratoma: a national study in The Netherlands. J Pediatr Surg 2007; 42(6):1122-1126.

17 Currarino G, Coln D, Votteler T. Triad of anorectal, sacral, and presacral anomalies. AJR Am J Roentgenol 1981;137(2):395-398.

18 Emans PJ, Kootstra G, Marcelis CL, et al. The Currarino triad: the variable expression. J Pediatr Surg 2005;40(8):1238-1242.

19 CBS Statistics

Netherlandshttp://statline.cbs.nl/StatWeb/publication/?DM=SLEN\&PA=37422eng\&D1=018,20,22-34,43-46,48\&D2=0,10,20,30,40,50,(I-1)-I\&LA=EN\&VW=T] 
Pregnancy and delivery after SCT treatment during childhood 


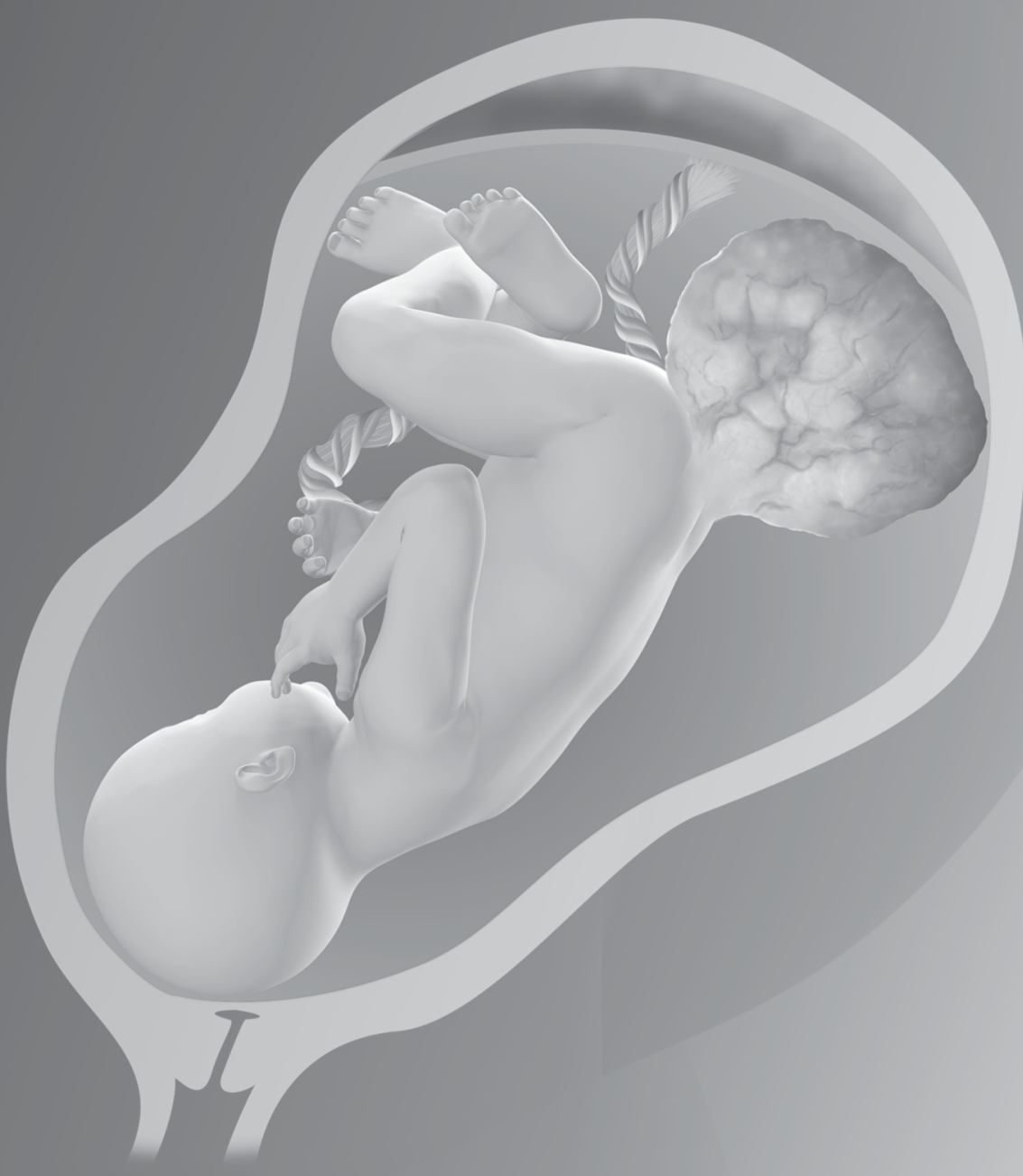




\section{CHAPTER 7}

\section{Quality of life in adulthood after resection of a sacrococcygeal teratoma in childhood - a Dutch multicentre study}

Marijke E.B. Kremer, Marc Dirix, Margot M. Koeneman, Robertine van Baren, Hugo A. Heij, Marc H.W.A. Wijnen, René M.H. Wijnen, David C. van der Zee and L.W. Ernest van Heurn

Adapted from: Arch Dis Child Fetal Neonatal Ed 2015;100: F229-F232 


\section{AbSTRACT}

\section{Background}

Children treated for sacrococcygeal teratoma (SCT) may experience functional sequelae later in life. It is not known whether SCT and associated problems affect the patient's general quality of life (QoL). In a national survey, we evaluated general QoL in adults treated for SCT during childhood and compared the results to reference values for the Dutch population.

\section{Methods}

The records of patients aged $\geq 18$ years treated for an SCT in one of the six paediatric surgical centres in the Netherlands from 1970 to 1993 were retrospectively reviewed; patient characteristics were retrieved from medical records. General QoL was evaluated using the

Short Form 36 Health Survey (SF-36). The means of the eight SF-36 domain scores of patients treated for SCT were compared to reference values for the Dutch population ( $n=757$, aged $18-43$ years). Linear regression analysis was used to adjust for differences in baseline characteristics between both groups.

\section{Results}

Forty-six of 51 patients treated for SCT during childhood (90.2\%), with a mean age of 26.3 years (range 18.3-41.1), returned completed SF-36 questionnaires. Their scores on all SF-36 subcategories were equivalent to those of the Dutch reference population. No significant differences in the scores of the SF-36 subcategories were found after linear regression analysis adjusting for differences in age, sex and living status between both groups.

\section{Conclusion}

The long-term QoL of patients treated for SCT during childhood does not differ from that of the general population. Moreover, patients do not show impairment in social, physical or emotional functioning in adulthood. 


\section{INTRODUCTION}

Sacrococcygeal teratoma (SCT) is the most common tumour in the newborn, with a reported incidence of 1 in 15000 - 40000 live births. ${ }^{1-2}$ Long-term outcome studies after SCT resection show that children may experience functional sequelae, including urinary and defecation problems..$^{3-7}$ The pressure of the tumour on pelvic structures and surgical injury during radical resection causes changes in pelvic anatomy and physiology with possible consequences for micturition and defecation. ${ }^{3,8,9}$

Although functional sequelae after SCT resection are relatively common, little is known about the quality of life (QoL) of adolescents and adults who have undergone resection during childhood as QoL studies after SCT resection using validated questionnaires and control populations have not been performed. Nevertheless, it has been suggested that QoL is reduced due to defecation problems and urinary incontinence. ${ }^{3,7}$

Therefore, we assessed general QoL in adolescents and adults treated for SCT during childhood in a national survey using a validated questionnaire and compared the results with reference values for an age-matched Dutch population.

\section{MethodS}

\section{Patients}

All patients aged 18 years and older who underwent resection of an SCT in one of the six paediatric surgical centres in the Netherlands (Emma Children's Hospital University Medical Centre and VU Medical Centre Amsterdam, University Medical Centre Groningen, Maastricht University Medical Centre, St. Radboud University Medical Centre Nijmegen, Sophia Children's Hospital Rotterdam and Wilhelmina Children's Hospital Utrecht) between 1970 and 1993 were eligible for participation and their records were analysed retrospectively. Patients were excluded if the SCT was part of the Currarino triad or if they were unable to complete the questionnaires due to intellectual disability. Patient characteristics such as sex, age and tumour-related characteristics including Altman classification ${ }^{10}$ and histopathological classification were retrieved from the records. Sociodemographic data on living situation, educational attainment and current occupation were collected with structured questions. 


\section{Questionnaire}

General QoL was assessed using the validated Dutch version of the Short Form 36 Health Survey (SF-36). ${ }^{11}$ SF-36 outcomes were compared to the values of a Dutch reference population of 757 healthy subjects aged 18-43 years. The reference values were extracted from a validation study of the Dutch version of the SF-36. ${ }^{11}$

The SF- $36^{12}$ is a multidimensional measure composed of 36 questions, categorized into eight domains: physical functioning, role limitations due to physical problems, social functioning, bodily pain, general mental health, role limitations due to emotional problems, vitality and general health perception. The SF-36 questions are constructed so that the Likert method of summated ratings can be used. ${ }^{13}$ The scores given by the patient per item are linearly converted into a scale of 0 to 100, with higher scores indicating a higher level of functioning. ${ }^{12,14}$ The eight subcategory-scores are used to calculate a Physical Component Summary scale (PCS) and a Mental Component Summary scale (MCS). These scores are calculated by aggregating highly correlating domain scores to give an overall physical and mental health profile (mean 50, SD 10). ${ }^{13}$ The validity and reliability of the SF-36 have previously been assessed in the Dutch population. ${ }^{11}$

\section{Data collection and statistical analysis}

An information letter explaining the goals of the study and introducing the questionnaire was sent to the last known address of each patient. Those who did not respond were contacted by phone and with a reminder letter two weeks later. The patients received the questionnaire after they had provided written informed consent to participate. The study was approved by the medical ethics committee of the Maastricht University Medical Centre.

The Chi-square test was applied for nominal variables (sex, living status and educational attainment) and the independent samples t-test for continuous variables (age) to test for sociodemographic differences between participants and the reference population.

The means of the SF-36 domain scores and the PCS and MCS of the participants were compared to reference values from an aged-matched Dutch population $(n=757 \text {, aged } 18-43 \text { years })^{11}$ using unadjusted and adjusted linear regression analysis, correcting for possible confounders including age, sex, living status and educational attainment; $p$-values $\leq 0.05$ were considered to be statistically 
significant. Statistical analysis was performed using SPSS (Statistical Package for the Social Sciences) V.20.0 for Windows (IBM SPSS, Chicago, Illinois, USA).

\section{ResULTS}

The records of 112 patients who had undergone SCT resection between 1970 and 1993 were identified. As 13 patients had died, 99 were eligible to participate in the study. However, 23 of these were untraceable, so 76 patients were contacted and invited to participate. As 25 could not be included, this left 51 who returned the signed consent form and received the questionnaire. Of these, 46, consisting of 37 women and nine men with a mean age of 26.3 years (range 18.3-41.1), returned the completed SF-36 questionnaire (Figure 1). Altman type, tumour histology and sex did not significantly differ statistically between patients included in the study and non-responders.

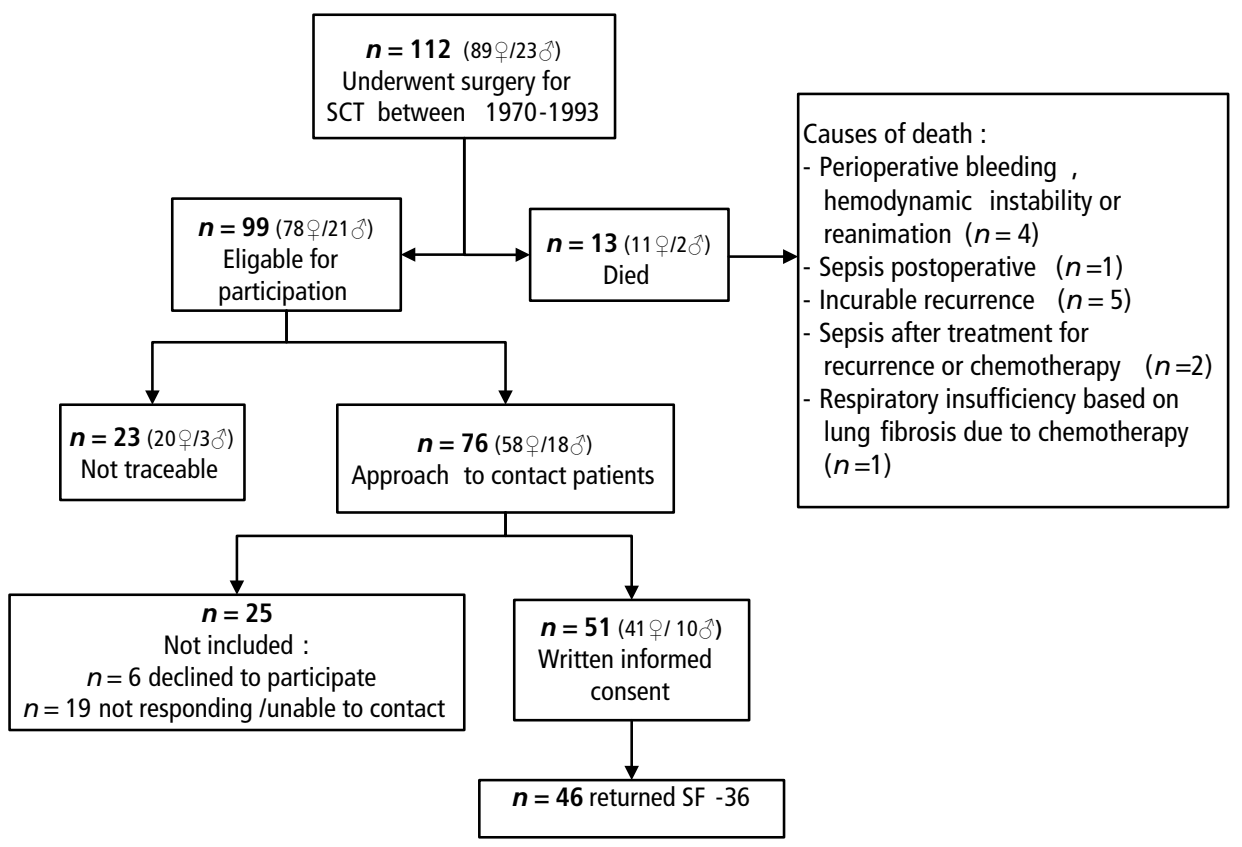

Figure 1. Recruitment of the patient cohort 
Table 1. Characteristics of participants and the reference group

\begin{tabular}{|c|c|c|c|}
\hline & $\begin{array}{l}\text { Patients with } \\
\text { prior SCT } \\
\text {-resection } \\
(\mathrm{n}=46)\end{array}$ & $\begin{array}{l}\text { SF-36 reference } \\
\text { group of Dutch } \\
\text { controls } \\
\text { (n=757) }\end{array}$ & $p$-values \\
\hline \multicolumn{4}{|l|}{ Sex } \\
\hline Male & $9(19.6 \%)$ & $376(49.7 \%)$ & $<.001 *$ \\
\hline Female & 37 (80.4\%) & $381(50.3 \%)$ & \\
\hline \multicolumn{4}{|l|}{ Age } \\
\hline $\begin{array}{l}\text { Mean in years } \\
\text { (range) }\end{array}$ & $\begin{array}{l}26.3 \\
(18.3-41.1)\end{array}$ & $\begin{array}{l}31.7 \\
(18.0-43.0)\end{array}$ & $<.001^{*}$ \\
\hline \multicolumn{4}{|l|}{ Living status } \\
\hline Living with partner & $20(43.5 \%)$ & $501(66.2 \%)$ & $<.001^{*}$ \\
\hline Living alone & $5(10.9 \%)$ & $171(22.6 \%)$ & \\
\hline Living with parents & $21(45.7 \%)$ & $81(10.7 \%)$ & \\
\hline Unknown & & $4(0.5 \%)$ & \\
\hline \multicolumn{4}{|l|}{ Education } \\
\hline High school & $16(34.8 \%)$ & $213(28.2 \%)$ & 0.637 \\
\hline Further education & $27(58.7 \%)$ & $490(64.7 \%)$ & \\
\hline University & $3(6.5 \%)$ & $54(7.1 \%)$ & \\
\hline \multicolumn{4}{|l|}{ Occupation } \\
\hline Full-time & $16(34.8 \%)$ & & \\
\hline Part-time & $11(23.9 \%)$ & & \\
\hline Unemployed & $13(28.3 \%)$ & Data not available & - \\
\hline Incapacitated & $4(8.7 \%)$ & & \\
\hline Homemaker & $2(4.3 \%)$ & & \\
\hline
\end{tabular}

The SCT of the participants had been classified as Altman type I ( $n=18)$ or type II ( $n=15)$; a minority had an Altman type III $(n=7)$ or type IV ( $n=4)$ SCT. The Altman classification was unknown for two patients. In the majority of patients $(n=33)$, 
surgical resection was performed in the neonatal period (median age 3 days, range 0-30 days). Eleven patients were operated on afterwards (median age 1.4 years, range $0.5-2.8$ years); the age at surgical resection was unknown for two patients.

The resection margins were tumour free in 36 patients, incomplete in six and unknown in four. Histopathological data from the medical records showed that 29 SCT had been classified as mature, five as immature and ten as malignant, while histopathology was unknown for two cases. However, as one patient developed a malignant recurrence after a primary benign teratoma, a total of eleven patients were treated for a malignant SCT.

The baseline characteristics of the study population and the reference group of Dutch healthy controls are given in Table 1 . There were significantly more males in the reference group than in the study population. Other significant differences were found regarding age and living status.

\section{SF-36 RESULTS}

The SF-36 results of participants and the Dutch reference population are outlined in Table 2. Patients treated for SCT had similar scores on all SF-36 subcategories as the Dutch reference population. In addition, the PCS and MCS showed no significant differences between patients treated for SCT and the Dutch controls. We applied linear regression analysis to adjust for differences in baseline characteristics (living status, age and sex) between patients and the control group; however, no statistically significant differences in the results of the SF-36 subcategories were found between the groups. 
Table 2. Comparison of SF-36 subcategory scores of participants with the Dutch reference group

\section{Means of the SF-36 scores}

\begin{tabular}{lll} 
& $\begin{array}{l}\text { SCT-population } \\
(\mathrm{n}=46)\end{array}$ & $\begin{array}{l}\text { Reference group } \\
(\mathrm{n}=757)\end{array}$ \\
SF-36 subcategories & Mean (SD) & $92.6(12.4)$ \\
\hline Physical functioning & $91.3(16.1)$ & $85.3(28.2)$ \\
Physical role functioning & $85.9(32.2)$ & $80.3(19.8)$ \\
Bodily pain & $79.7(23.2)$ & $77.7(17.8)$ \\
General health & $72.7(23.8)$ & $70.5(16.9)$ \\
Vitality & $67.3(18.6)$ & $87.3(19.9)$ \\
Social functioning & $89.1(17.6)$ & $85.4(29.8)$ \\
Emotional role functioning & $89.1(29.9)$ & $78.6(15.7)$ \\
Mental health & $79.0(14.2)$ & \\
\hline SF-36 component summaries & & $52.7(7.0)$ \\
\multicolumn{1}{c}{ Physical component summary } & $51.5(10.1)$ & $51.9(9.3)$ \\
\hline \multicolumn{1}{c}{ Mental component summery } & $52.5(9.6)$ &
\end{tabular}

Results were adjusted for differences in age, sex and living status in linear regression analysis.

SCT, sacrococcygeal teratoma; SF-36, Short Form 36 Health Survey.

\section{DisCUSSION}

Previous evaluations of long-term functional outcome after SCT resection showed that patients may experience urinary and defecation problems. ${ }^{3,4,6,7}$ Therefore, it has been suggested that their QoL may be decreased, but this was not confirmed with validated questionnaires in a large cohort. The present study adds to our knowledge from previous reports, as it is the first study investigating long-term QoL after SCT resection with a validated QoL measure, the Dutch version of the SF-36. ${ }^{11}$

The main finding of the present study is that the QoL of patients treated for SCT does not differ from that of the general population. Scores on all SF-36 subcategories were equivalent to those of healthy Dutch controls. Furthermore, patients treated 


\begin{tabular}{llllll}
\multicolumn{2}{c}{ Unadjusted comparison } & \multicolumn{5}{c}{$\begin{array}{c}\text { Comparison adjusted for possible } \\
\text { confounders (age, sex \& living status) }\end{array}$} \\
Mean difference & $95 \% \mathrm{Cl}$ & $p$-value & Mean difference & $95 \%$ Cl & $p$-value \\
& & & & & \\
& & & & & \\
-1.304 & $-5.07-2.46$ & .497 & -1.304 & $-5.21-2.53$ & .497 \\
.611 & $-7.90-9.12$ & .888 & -0.191 & $-9.01-8.64$ & .966 \\
-0.586 & $-6.57-5.40$ & .848 & -0.903 & $-7.01-5.29$ & .775 \\
-5.238 & $-10.44-0.37$ & .680 & -5.238 & $-10.86-0.39$ & .680 \\
-3.275 & $-8.36-1.81$ & .206 & -2.105 & $-7.30-3.09$ & .427 \\
1.747 & $-4.13-7.62$ & .560 & 1.948 & $-4.11-8.00$ & .528 \\
3.739 & $-5.16-12.64$ & .410 & 6.153 & $-3.06-15.4$ & .190 \\
.333 & $-4.32-4.99$ & .888 & 1.417 & $-3.32-6.15$ & .557 \\
-1.189 & $-3.34-0.96$ & .278 & -1.605 & $-3.84-0.62$ & .158 \\
.594 & $-2.17-3.36$ & .422 & 1.407 & $-1.42-4.24$ & .330 \\
\hline
\end{tabular}

for SCT during childhood do not show impairment in social, physical or emotional functioning in later life.

In a previous evaluation of anorectal function in 26 adults who underwent resection of a benign SCT in infancy, reported social restrictions due to impaired anal function $(n=7)$ or urinary incontinence $(n=3),{ }^{7,10}$ These social restrictions were self-reported and did not directly address QoL. The authors concluded that QoL was reduced due to anorectal and urogenital dysfunction. Others found a reduced QoL in 76 patients (median age 9.0 years, range 3.2-22.6) who had undergone SCT resection: $30 \%$ reported urinary incontinence and $13 \%$ soiling, both leading to 
social restrictions and to a lower QoL. ${ }^{3}$ QoL was not evaluated with a validated measure in either study. In addition, participants in the latter study were much younger than in our study and completed the questionnaire with parental support. This may be one explanation for the better results in our group as the incidence of functional sequelae and their impact on QoL may vary between different age groups. In the present study, patients treated for SCT differed from the Dutch reference group regarding their group distribution of age, living status and sex. The difference in sex distribution between the participant group and the Dutch control population can be best explained by the known female to male preponderance of SCT, with a female to male ratio of $4: 1 .^{15}$ By applying linear regression analysis, we adjusted for these possible confounders.

The present study has some limitations. Even though the sample size was large for a rare anomaly like SCT, selection bias between responders and non-responders cannot be excluded. Patients with more serious sequelae of the disorder may have been reluctant to report problems, which would result in an overestimation of QoL in the SCT group. However, patient characteristics including Altman classification, tumour histology and sex did not differ between responders and non-responders.

The SF-36 is a measure of general QoL that evaluates disease-specific functioning in more general physical and emotional terms than just urinary and defecation complaints. As a result we could not analyse the particular impact of defecation and urinary complaints on the SF-36 scores. As a general QoL measure it may be less sensitive to the implications of specific sequelae compared to diseasespecific questionnaires. Further studies are needed to clarify whether particular complaints may have a greater impact on general QoL after SCT resection.

The functional sequelae of SCT have been suggested to improve over time. ${ }^{4}$ This might explain the good QoL in our study population, as only adults were included. Furthermore, it has been reported that children affected by a chronic disease such as diabetes type I or survivors of childhood cancer do not have impaired QoL in later life compared to their healthy peers. ${ }^{16,17}$ This may be explained by readjustment of subjective QoL standards and values over time. Patients with chronic disease seem to adapt to several disease-dependent restrictions and develop personal coping strategies. ${ }^{18}$ This might also hold true for the participants in the present study, and may explain the good QoL in later life. 


\section{RefERENCES}

1 Lakhoo K, Sowerbutts H. Neonatal tumours. Pediatr Surg Int 2010;26(12):1159-1168.

2 Pauniaho SL, Heikinheimo O, Vettenranta K, et al. High prevalence of sacrococcygeal teratoma in Finland - a nationwide population-based study. Acta Paediatr 2013;102(6):e251-256.

3 Derikx JP, De Backer A, van de Schoot L, et al. Long-term functional sequelae of sacrococcygeal teratoma: a national study in The Netherlands. J Pediatr Surg 2007;42(6):1122-1126.

4 Cozzi F, Schiavetti A, Zani A, et al. The functional sequelae of sacrococcygeal teratoma: a longitudinal and cross-sectional follow-up study. J Pediatr Surg 2008;43(4):658-661.

5 Tailor J, Roy PG, Hitchcock R, et al. Long-term functional outcome of sacrococcygeal teratoma in a UK regional center (1993 to 2006). J Pediatr Hematol Oncol 2009;31(3):183186.

6 Malone PS, Spitz L, Kiely EM, et al. The functional sequelae of sacrococcygeal teratoma. J Pediatr Surg 1990;25(6):679-680.

7 Rintala $\mathrm{R}$, Lahdenne $\mathrm{P}$, Lindahl $\mathrm{H}$, et al. Anorectal function in adults operated for a benignsacrococcygeal teratoma. J Pediatr Surg 1993;28(9):1165-1167.

8 Ozkan KU, Bauer SB, Khoshbin S, et al. Neurogenic bladder dysfunction after sacrococcygeal teratoma resection. J Urol 2006;175(1):292-296

9 Boemers TM, van Gool JD, de Jong TP, et al. Lower urinary tract dysfunction in children with benign sacrococcygeal teratoma. J Urol 1994;151(1):174-176.

10 Altman RP, Randolph JG, Lilly JR. Sacrococcygeal teratoma: American Academy of Pediatrics Surgical Section Survey-1973. J Pediatr Surg 1974;9(3):389-398.

11 Aaronson NK, Muller M, Cohen PD, et al. Translation, validation, and norming of the Dutch language version of the SF-36 Health Survey in community and chronic disease populations. J Clin Epidemiol 1998;51(11):1055-1068.

12 Ware JE, Jr., Sherbourne CD. The MOS 36-item short-form health survey (SF-36). I. Conceptual framework and item selection. Medical care 1992;30(6):473-483.

13 Likert R. A technique for the measurement of attitudes. Arch Psychol 1932;140:1-55.

14 Ware JE KM, Keller SD. SF-36 Physical and Mental Summery Scales: A User's Manual 4th printing, revised ed. Boston: MA: Health Institute, 1994. 


\section{Chapter 7}

15 Peterson CM, Buckley C, Holley S, et al. Teratomas: a multimodality review. Curr Probl Diagn Radiol 2012;41(6):210-219.

16 Stahl A, Strassburger K, Lange K, et al. Health-related quality of life among German youths with early-onset and long-duration type 1 diabetes. Diabetes Care 2012;35(8):1736-1742.

17 Langeveld NE, Stam H, Grootenhuis MA, et al. Quality of life in young adult survivors of childhood cancer. Support Care Cancer 2002;10(8):579-600.

18 Jaser SS, White LE. Coping and resilience in adolescents with type 1 diabetes. Child Care Health Dev 2011;37(3):335-342. 


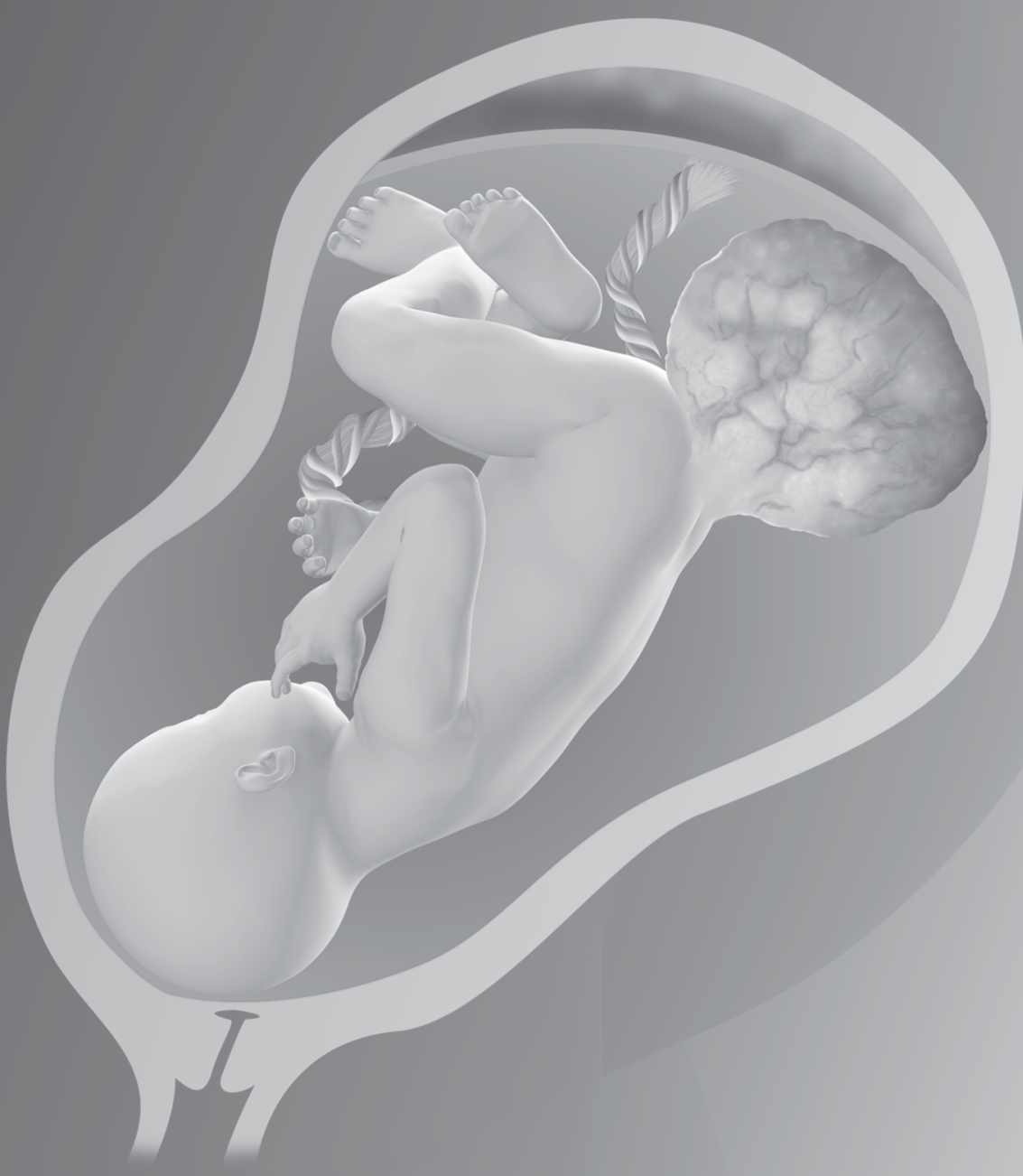




\section{CHAPTER 8}

\section{Evaluation of chemotherapeutic sequelae and quality of life in survivors of malignant sacrococcygeal teratoma}

Marijke E.B. Kremer, Joep P.M. Derikx, Leontien C.M. Kremer, Robertine van Baren' Hugo A. Heij, Marc H.W.A. Wijnen, René M.H. Wijnen, David C. van der Zee and L.W. Ernest van Heurn

Adapted from: Pediatr Surg Int 2016 Mar 14;32(3):261-268. 


\section{Chapter 8}

\section{AbStRACT}

\section{Background}

The impact of chemotherapeutic sequelae on long-term quality of life (QoL) for survivors of malignant sacrococcygeal teratoma (SCT) is unknown. The incidence of chemotherapeutic toxicity in patients treated for malignant SCT and possible effects on the QoL were analysed.

\section{Methods}

Retrospective chart review of patients $\geq 18$ years treated for SCT in the Netherlands was performed. Present QoL was evaluated using the SF-36 questionnaire. The results of survivors of malignant SCT were compared to those of patients treated for benign SCT.

\section{Results}

Fifty-one of 76 traceable patients consented to participate. The results of $47(92.2 \%)$, nine men and 38 women (median age 25.4 years, range 18.3-41.2), were analysed. Eleven had been treated for malignancy; $63.6 \%$ suffered from at least one chemotherapeutic sequel with hearing loss as the most common one. Results for both groups were similar on all but one SF-36 subcategory; those treated for malignant tumour scored significantly lower on the subcategory physical functioning $(p=0.02)$.

\section{Conclusion}

Despite the high incidence of chemotherapeutic sequelae among survivors of malignant SCT, their QoL does not differ from that of those treated for benign SCT. Even though their physical functioning is restricted, daily activities and psychosocial functioning of survivors of malignant SCT are not restricted. 


\section{INTRODUCTION}

Sacrococcygeal teratoma (SCT) is an extra-gonadal germ cell tumour, which occurs in between one in 15,000-40,000live births, affecting predominantly female neonates. ${ }^{1-4}$ Even though SCT is the most common neoplasm in this age group malignant disease at the time of initial diagnosis is rare and relates to $7-17 \%$ of all cases. ${ }^{4-7}$ These usually benign tumours tend to undergo malignant degeneration in a short time, as a result of which the malignancy rate increases to up to $40-70 \%$ in the first month to years. ${ }^{4,5}$ With a relapse rate of 9-20\%, SCTs are more likely to recur than other germ cell tumours and $15-50 \%$ of the recurrent tumours are malignant with yolk sac tumour (YST) as the most common histological classification. ${ }^{7-10}$ Generally recognized risk factors for recurrence are incomplete resection and malignant tumour histology at initial diagnosis. Complete tumour resection is therefore considered the standard treatment for SCT with in addition platinum-based chemotherapy for malignant SCT. Overall survival rates of $80-90 \%$ have been achieved with this approach. ${ }^{5,10-13}$ Adjustments of chemotherapeutic regimens have been evaluated to minimize the chemotherapeutic toxicity; however, acute and chronic chemotherapeutic side effects still occur with possibly irreversible damage to organ systems such as the renal, audiological and cardiovascular system. $^{14-16}$

Surveillance by paediatric surgeons and paediatricians focuses mainly on the recognition of recurrent tumour and on functional outcome. Less attention has been paid to patients' long-term quality of life (QoL). While chemotherapeutic sequelae and the risk of relapse and metastatic spread may have impact on patients' QoL and personal and educational development, it remains unclear if the contemporary follow-up strategies pay enough attention to the psychosocial outcomes. The purpose of this multicentre analysis was to evaluate the incidence of chemotherapy-related sequelae in patients treated for malignant SCT and to compare their long-term QoL with that of patients treated for benign SCT. 


\section{Chapter 8}

\section{Methods}

\section{Patients}

The present study is an extension of a long-term follow-up study of patients treated for SCT after 1970 in the six paediatric surgical centres in the Netherlands. ${ }^{17}$ Following ethical approval by the Medical Ethical Committee of the Maastricht University Medical Centre, the records of all patients were retrospectively reviewed for data on age and sex as well as time of diagnosis, histopathological tumour classification, Altman type, treatment history and details about recurrence and chemotherapeutic sequelae. Sociodemographic characteristics (living and relationship status, educational attainment and occupation) were collected using a self-designed questionnaire. Patients were eligible for participation if they were 18 years or older at the time of data collection. Those patients in whom the tumour was part of the Currarino triad were excluded, as strictly seen this is a disorder with a different malignant transformation behaviour than SCT. ${ }^{18,19}$

Eligible patients were first sent an information letter to the last-known address explaining the background of the study and with an informed consent form enclosed. Non-responders were contacted two weeks later with an information letter and by telephone. Those who returned the signed consent form received the questionnaires.

\section{Questionnaire}

QoL was investigated using the Dutch version of the Short Form 36 (SF-36) Health survey. ${ }^{20}$ This measure is composed of 36 questions, evaluating eight categories of QoL: physical functioning, role limitations due to physical problems, social functioning, bodily pain, general mental health, role limitations due to emotional problems, vitality and general health perception. Questions about physical functioning included questions concerning daily activities such as running, lifting heavy objects, climbing several flights of stairs, walking a certain distance or carry groceries. Patients scored these activities by choosing from three possible answers "Yes, limited a lot", "Yes, limited a little" or "No, not limited at all". Subcategory scores are summarized and converted in a scale reaching from 0 to 100 , with higher scores indicating a better functioning. In addition, a Physical Component Summary scale (PCS) and a Mental Component Summary scale (MCS) can be calculated by 
summarizing highly correlating domain scores. These scores are used to give overall physical and mental health profiles (mean 50, SD 10). ${ }^{21}$ Validity and reliability of the SF-36 have been assessed for the Dutch population. ${ }^{20}$ The SF-36 results of patients who underwent treatment for a malignant SCT were compared to results of patients treated for a benign SCT.

\section{Statistical analysis}

Statistical analysis was performed using Graph Pad Prism 6 (GraphPad Software, Inc., La Jolla, CA, USA). Differences in categorical baseline characteristics between patients treated for malignant SCT and those treated for a benign SCT were tested with the Chi-Square test or Fisher's exact test. Differences in continuous variables and in the median scores of the SF-36 subcategories between both groups were tested with the Mann-Whitney $U$ test. All values are given as median with interquartile range unless otherwise indicated with two-sided $p$-values. Statistical significance was defined by $p$-values of 0.05 or smaller.

\section{ResULTS}

One hundred twelve infants were treated for SCT in the Netherlands between 1970 and 1993; 13 died of perioperative or postoperative hemodynamic complications $(n=5)$, incurable recurrence $(n=5)$, consequences of chemotherapy-related sepsis $(n=2)$ or chemotherapeutic sequelae $(n=1)$. Thus, 99 patients met the eligibility criteria for inclusion into the study. As 23 of those were not traceable, 76 patients were invited to participate. Six patients declined to participate without giving reasons, 19 did not respond and attempts to contact them otherwise failed. Fiftyone patients, 10 men and 41 women, returned the informed consent form and received the questionnaires. Those patients were included in the QoL analysis (Figure 1). 


\section{Chapter 8}

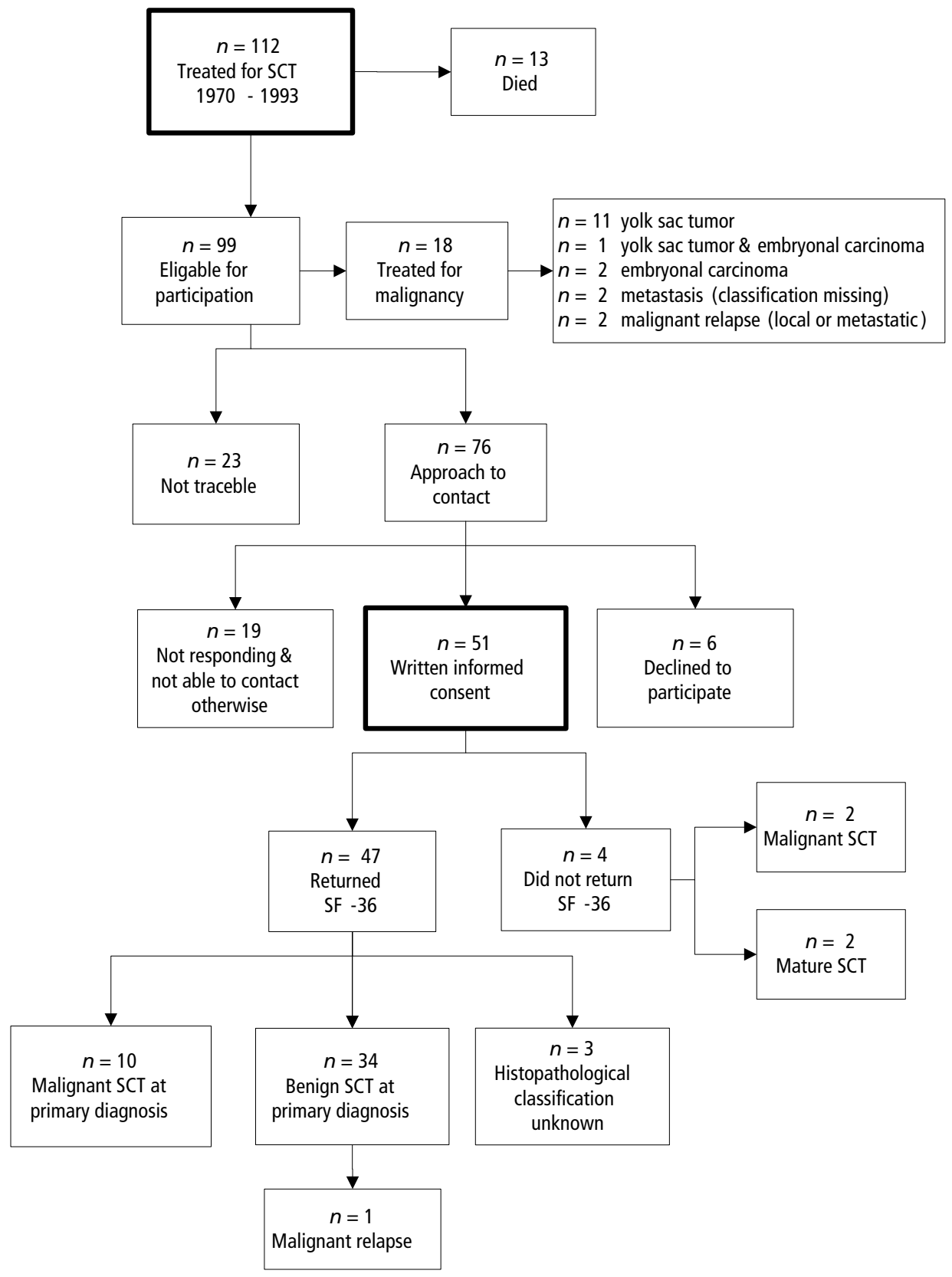

Figure 1. Participant recruitment and patient selection for QoL analysis 
Table 1. Patient- and disease related characteristics of participants of the QoL analysis

\begin{tabular}{|c|c|c|c|}
\hline & $\begin{array}{l}\text { Patients treated for } \\
\text { malignant SCT }(n=11)\end{array}$ & $\begin{array}{l}\text { Patients treated for } \\
\text { benign SCT }(n=36)\end{array}$ & $p$-value \\
\hline \multicolumn{4}{|l|}{ Sex } \\
\hline Female & $8(73 \%)$ & $30(83 \%)$ & 0.4 \\
\hline Male & $3(27 \%)$ & $6(17 \%)$ & \\
\hline \multicolumn{4}{|l|}{ Age } \\
\hline Median in years (range) & $22.4(19.4-34.9)$ & $25.9(18.3-41.2)$ & .30 \\
\hline \multicolumn{4}{|l|}{ Time of diagnosis } \\
\hline Prenatal or at birth & $2(18 \%)$ & $29(81 \%)$ & $.000^{*}$ \\
\hline After birth & $9(82 \%)$ & $6(17 \%)$ & \\
\hline Missing & - & 1 & \\
\hline \multicolumn{4}{|l|}{ Age at initial operation } \\
\hline Median age (range) & 1.6 years ( 1 day- 2.8 years) & 3 days ( 0 days -0.5 years) & $.000^{*}$ \\
\hline \multicolumn{4}{|l|}{ Altman classification[3] } \\
\hline Type I and II & $3(27 \%)$ & $29(81 \%)$ & $.002^{*}$ \\
\hline Type III and IV & $7(64 \%)$ & $6(17 \%)$ & \\
\hline Unknown & $1(9 \%)$ & $1(1 \%)$ & \\
\hline \multicolumn{4}{|l|}{ Living situation } \\
\hline Together with partner & $4(36 \%)$ & $15(44 \%)$ & .09 \\
\hline Alone & $1(9 \%)$ & $3(2 \%)$ & \\
\hline Together with parents & $6(55 \%)$ & $18(50 \%)$ & \\
\hline \multicolumn{4}{|l|}{ Relationship status } \\
\hline Having a relationship & $8(73 \%)$ & $27(75 \%)$ & 1.0 \\
\hline Single & $3(27 \%)$ & $9(25 \%)$ & \\
\hline \multicolumn{4}{|l|}{ Educational attainment } \\
\hline Primary and lower education & $3(27.3 \%)$ & $9(25 \%)$ & .61 \\
\hline Intermediate education & $6(54.5 \%)$ & $15(41.7 \%)$ & \\
\hline Middle and higher education & $2(18.2 \%)$ & $12(33.3 \%)$ & \\
\hline \multicolumn{4}{|l|}{ Current occupation } \\
\hline Employed & $6(55 \%)$ & $21(58.3 \%)$ & 1.0 \\
\hline Unemployed (student) & $5(1)(45 \%)$ & $15(1)(41.7 \%)$ & \\
\hline
\end{tabular}




\section{Chapter 8}

QoL of 47 patients (92.2\%) was analysed, i.e. nine men and 38 women with a median age of 25.4 years (range 18.3-41.2). Thirty-six had been treated for benign SCT and eleven either for malignant SCT $(n=10)$ or malignant recurrence $(n=1)$. Patient- and disease-related characteristics for both groups are given in Table 1. Patients treated for malignant SCT were significant older at time of diagnosis, had more often Altman type III or IV SCT and had more often been diagnosed after birth. Only two patients treated for malignant SCT underwent surgery in the first week after birth. In the others, SCT was diagnosed at a later stage due to an internal position of the tumour.

There were no statistically significant differences in the baseline characteristics sex, Altman classification and tumour histology between patients included in the QoL analysis and those who were eligible for participation but were not included into the study (Table 2).

Table 2. Comparison of baseline characteristic between participants and nonresponders

\begin{tabular}{|c|c|c|c|}
\hline & $\begin{array}{l}\text { Patients included in } \\
\text { QoL analysis ( } n=47)\end{array}$ & $\begin{array}{l}\text { Patients not included in } \\
\text { QoL analysis ( } n=52 \text { ) }\end{array}$ & $p$-value \\
\hline \multicolumn{4}{|l|}{ Sex } \\
\hline Female & $38(80.9 \%)$ & $43(82.7 \%)$ & 1.0 \\
\hline Male & $9(19.1 \%)$ & $9(17.3 \%)$ & \\
\hline \multicolumn{4}{|c|}{ Altman classification ${ }^{3}$} \\
\hline Type I & $18(38.3 \%)$ & $24(46.2 \%)$ & .762 \\
\hline Type II & $15(31.9 \%)$ & $14(26.9 \%)$ & \\
\hline Type III & $7(14.9 \%)$ & $6(11.5 \%)$ & \\
\hline Type IV & $5(10.6 \%)$ & $8(15.4 \%)$ & \\
\hline Missing & $2(4.3 \%)$ & - & \\
\hline \multicolumn{4}{|c|}{ Histological classification } \\
\hline Mature & $30(63.8 \%)$ & $35(67.3 \%)$ & .687 \\
\hline Immature & $6(12.8 \%)$ & $9(17.3 \%)$ & \\
\hline Malignant & $7(14.9 \%)$ & $6(11.5 \%)$ & \\
\hline Missing & $4(8.5 \%)$ & $2(3.8 \%)$ & \\
\hline
\end{tabular}




\section{Details of chemotherapeutic sequelae}

All patients but one of the malignant SCT group had been treated with a combination of surgery and chemotherapy: in five, chemotherapy was started preoperatively and in four postoperatively. Patients were usually treated according the MAKEI protocols or the POG9049 protocol. ${ }^{12,16,22}$ These treatment regimens have been described in detail elsewhere. Not for all patients the chemotherapeutic doses have been explicitly registered. However, if these data were available, all patients reporting hearing loss were treated with cisplatin-based regimens. One patient with YST was solely treated with surgical resection without later recurrence. The patient with malignant recurrence received chemotherapy before re-excision of the tumour. In both primary and recurrent diseases, YST was the most common diagnosis. Two patients developed recurrence of YST: one had previously been treated for YST and one for a mature teratoma. Both recurrences were treated with surgical resection with additional chemotherapy in one and radiotherapy in the other. Seven of the eleven patients in this group (63.6 \%) suffered from at least one chemotherapeutic sequel. Hearing loss was validated with audiometric testing during the follow-up period and was reported as the most common sequelae $(n=6)$. In all patients with available details about chemotherapeutical regimens who reported hearing loss, the regimen included cisplatin. One patient had pulmonary fibrosis following bleomycin treatment, one had a complete left branch bloc with left ventricle dilatation, two had decreased renal function and one patient, treated with radiotherapy, was diagnosed with epiphysiolysis of the left proximal femur (Table 3). 


\section{Chapter 8}

Table 3. Treatment modalities and chemotherapeutic sequelae of participants treated for malignant SCT

\begin{tabular}{|c|c|c|c|c|}
\hline $\begin{array}{l}\text { Patients } \\
\text { (sex) }\end{array}$ & $\begin{array}{l}\text { Tumour } \\
\text { histology }\end{array}$ & $\begin{array}{l}\text { Tumour } \\
\text { volume }\end{array}$ & Metastasis & $\begin{array}{l}\text { Start \& type of } \\
\text { chemotherapy }\end{array}$ \\
\hline $1(\mathrm{~m})$ & YST and EC & $8 \times 5 \times 4 c m$ & No & $\begin{array}{c}\text { Postoperative } \\
\text { P0G9049 protocol: } \\
\text { 4xBEP cycles }\end{array}$ \\
\hline 2 (f) & YST & Missing & No & Postoperative \\
\hline $3(f)$ & YST & $8 \times 6 \times 5 \mathrm{~cm}$ & Missing & Preoperative \\
\hline $4(f)$ & $\mathrm{EC}$ & $5 \times 4 \times 4 \mathrm{~cm}$ & $\begin{array}{l}\text { Lung- and } \\
\text { vertebral } \\
\text { metastases }\end{array}$ & $\begin{array}{l}\text { Preoperative } \\
\text { MAKEI } 89 \text { protocol: } \\
\text { 3xBEP, 3xVIP }\end{array}$ \\
\hline $5(f)$ & Unknown & Missing & Liver metastases & Preoperative \\
\hline $6(f)$ & Immature & $5 \mathrm{~cm}$ circumference & $\begin{array}{l}\text { Lymph node } \\
\text { metastases }\end{array}$ & $\begin{array}{c}\text { Preoperative } \\
\text { MAKEI } 83 \text { protocol: } \\
\text { 4xPVB, 4xPEI }\end{array}$ \\
\hline $7(\mathrm{~m})$ & YST & $5 \times 4 \times 2 \mathrm{~cm}$ & No & $\begin{array}{c}\text { Preoperative } \\
\text { MAKEI } 83 \text { protocol: } \\
\text { 4xPVB, 4xPEI }\end{array}$ \\
\hline 8 (f) & YST & Missing & Missing & Only surgical resection \\
\hline $9(\mathrm{~m})$ & Mature & $16 \times 13 \times 6.5 \mathrm{~cm}$ & No & $\begin{array}{l}\text { Initially solely } \\
\text { surgical resection }\end{array}$ \\
\hline $10(f)$ & YST & $7 \times 5 \times 4.5 \mathrm{~cm}$ & No & $\begin{array}{c}\text { Postoperative } \\
\text { MAKEI } 83 \text { protocol: } \\
\text { 4xPVB, 4xPEI }\end{array}$ \\
\hline $11(f)$ & YST & $9 \times 9 \times 7 \mathrm{~cm}$ & No & $\begin{array}{c}\text { Postoperative } \\
\text { Cisplatin/Bleomycin/ } \\
\text { Teniposide \& VAC }\end{array}$ \\
\hline \multicolumn{5}{|c|}{$\begin{array}{l}\text { m=male, f=female, SCT = sacrococcygeal teratoma, YST = yolk sac tumor, EC = embryional carcinoma, } \\
\text { POG9049 = Pediatric Oncology Group } 9049 \text { chemotherapeutic protocol22], BEP = cisplatin - etopside - bleomycin, } \\
\text { PEI = cisplatin - etopside - iphosphamid, AFP = alpha-fetoprotein, RT = radiotherapy }\end{array}$} \\
\hline
\end{tabular}




\begin{tabular}{|c|c|c|c|c|}
\hline $\begin{array}{l}\text { Year of treatment } \\
\text { (age) }\end{array}$ & $\begin{array}{c}\text { AFP-value } \\
\text { preoperatively }\end{array}$ & Relapse & $\begin{array}{l}\text { Treatment for } \\
\text { relapse }\end{array}$ & $\begin{array}{c}\text { Treatment } \\
\text { related sequelae }\end{array}$ \\
\hline $\begin{array}{c}1990 \\
(2.4 \text { yrs.) }\end{array}$ & $20,800 \mu \mathrm{g} / \mathrm{l}$ & No & - & Not reported \\
\hline $\begin{array}{c}1993 \\
(2.6 \mathrm{yrs} .)\end{array}$ & $173.6 \mu g / l$ & No & - & Not reported \\
\hline $\begin{array}{c}1995 \\
(2.0 \text { yrs.) }\end{array}$ & Missing & No & - & $\begin{array}{l}\text { Asthmatic due to bleomycin } \\
\text { related long fibrosis }\end{array}$ \\
\hline $\begin{array}{c}1991 \\
(1.3 \mathrm{yrs} .)\end{array}$ & $20,000 \mu \mathrm{g} / \mathrm{l}$ & No & - & $\begin{array}{l}\text { Hearing loss, complete left branch } \\
\text { bloc \& left ventricle dilatation, } \\
\text { scoliosis, incomplete paraplegia }\end{array}$ \\
\hline $\begin{array}{c}1994 \\
(2.8 \mathrm{yrs} .)\end{array}$ & Missing & No & - & Hearing loss \\
\hline $\begin{array}{c}1988 \\
(1.6 \mathrm{yrs} .)\end{array}$ & $41,000 \mu \mathrm{g} / \mathrm{l}$ & No & - & Not reported \\
\hline $\begin{array}{c}1991 \\
(2.0 \mathrm{yrs} .)\end{array}$ & $78,000 \mu \mathrm{g} / \mathrm{l}$ & YST & Surgery \& RT (45 Gy) & $\begin{array}{l}\text { High frequency hearing loss } \\
\text { (using a hearing aid), diminished } \\
\text { renal function, epiphysiolysis of } \\
\text { the left proximal femur }\end{array}$ \\
\hline $\begin{array}{l}1976 \\
\text { (1 day) }\end{array}$ & Missing & No & - & Not reported \\
\hline $\begin{array}{c}1987 \\
\text { (1 day) }\end{array}$ & $56.000 \mu \mathrm{g} / \mathrm{l}$ & $\begin{array}{l}\text { YST and } \\
\text { metastases }\end{array}$ & $\begin{array}{c}\text { In 1988: } \\
\text { 4x PVB followed } \\
\text { by surgery } \\
\text { (Cumulative bleomycin } \\
\text { dose: } 90 \mathrm{mg} / \mathrm{m} 2 \text { ) }\end{array}$ & $\begin{array}{c}\text { Hearing loss } \\
4000 \mathrm{~Hz} \text { : right } 65 \mathrm{~dB} \text {, left } 40 \mathrm{~dB} \\
3000 \mathrm{~Hz} \text { : right } 45 \mathrm{~dB} \text {, left } 30 \mathrm{~dB} \\
\text { Moderate obstructive lung disease }\end{array}$ \\
\hline $\begin{array}{c}1986 \\
(1.1 \mathrm{yrs} .)\end{array}$ & $63,500 \mu \mathrm{g} / \mathrm{l}$ & No & - & $\begin{array}{l}\text { High frequency hearing loss, } \\
\text { left kidney non -functional }\end{array}$ \\
\hline $\begin{array}{c}1983 \\
(2.7 \mathrm{yrs} .)\end{array}$ & $29,000 \mu \mathrm{g} / \mathrm{l}$ & No & - & $\begin{array}{l}\text { Hearing loss } \\
(70 \mathrm{~dB})\end{array}$ \\
\hline
\end{tabular}




\section{Chapter 8}

\section{Comparison of the SF-36 results}

Patients treated for a malignant SCT scored similar to patients treated for benign SCT on the SF-36 subcategories social functioning $(p=0.85)$ and emotional role functioning $(p=0.60)$. There was a trend towards lower scores for patients treated for malignant SCT on the subcategories general health $(p=0.34)$, vitality $(p=0.23)$, mental health $(p=0.16)$, physical role functioning $(p=0.06)$ as well as on the MCS score $(p=0.23)$, and PCS score $(p=0.07)$; however, differences did not reach statistical significance. Patients treated for malignant SCT scored significant lower on the subcategory physical functioning than patients treated for benign SCT [median 85 (range 60-100) vs. median 100 (range 40-100): $p=0.02$ ]. The results of the SF-36 are outlined in Figure 2.

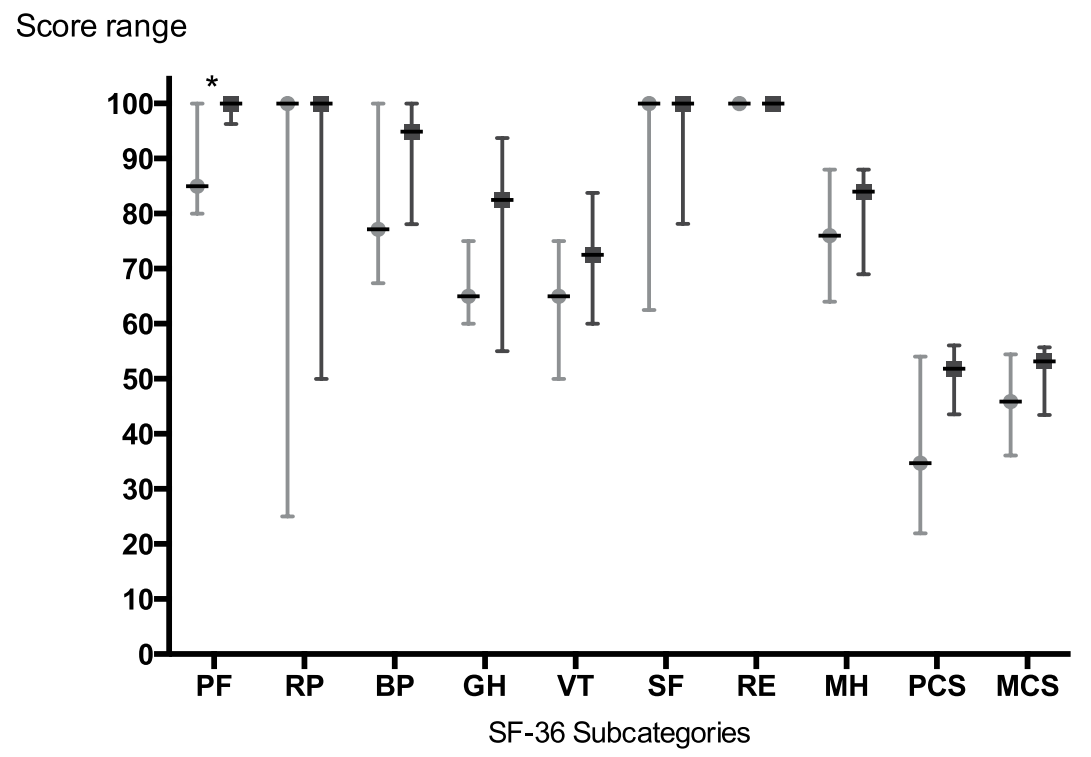

- Patients treated for benign SCT - Patients treated for malignant SCT

Figure 2. Results of the SF-36: malignant SCT groups vs. benign SCT group

$P F=$ Physical Functioning, $R P=$ Role-Physical, $B P=$ Bodily Pain, GH = General Health, $V T=$ Vitality, SF = Social Functioning, RE = Role-Emotional, MH = Mental Health, PCS = Physical Summary Scale, MCS = Mental Summery Scale, all values are median with interquartile range,

* indicates statistical significance 


\section{DisCUSSION}

The prognosis for patients with malignant SCT has substantially improved since the introduction of platinum-based chemotherapy regimens. As a downside, many survivors of childhood cancer show chemotherapeutic toxicity. ${ }^{13-15}$ Acute toxicity can cause reversible infections and blood count changes. Chronic toxicity, on the other hand, leads to irreversible damage ranging from mild impairment to deafness, pulmonary failure or subfertility and thereby can have serious consequences for the patients' personal development and QoL. ${ }^{14,16}$ However, platinum-based chemotherapy remains the standard treatment for malignant SCT, thereby putting patients at risk for chemotherapeutic sequelae. ${ }^{12,23}$

The present study focused on the effect of chemotherapeutic sequelae on QoL in a cohort of patients treated for malignant SCT. The results were compared to QoL of patients treated for benign SCT. As the initial situation is similar for both patient groups and patients in both groups underwent surgical treatment during childhood, this design enabled to evaluate the true effect of malignancy on survivors' QoL.

A substantial proportion (63.6\%) of patients who underwent chemotherapeutic treatment appeared to suffer from chronic toxicity with hearing loss as the most reported morbidity. Analysis of these patients' QoL shows an unexpected favourable outcome: the reported restrictions in physical performance do not seem to influence emotional and psychosocial functioning. Even though we found a trend towards lower scores on physical role functioning and the PCS, daily life activities seem not to be restricted.

Likewise we also did not find impairments in educational achievements and interpersonal relations of patients treated for malignant SCT as the distribution among relationship status, educational attainment and occupation status did not differ from those treated for a benign SCT.

Reports concerning chemotherapeutic toxicity after treatment for malignant SCT are scanty and evaluations of the effect on QoL have not been published yet. Hale and colleagues reported a comparable incidence of hearing loss $(58 \%)$ in a cohort of patients treated with cisplatin-based therapy ( $n=73$, median age of 11.3 years) that also included eleven patients treated for a malignant SCT. ${ }^{15}$ Mann et al. reported more favourable long-term chemotherapeutic sequelae in their cohort of 


\section{Chapter 8}

patients treated for malignant extracranial non-gonadal tumours with the majority of patients treated for a malignant sacrococcygeal teratoma (59 out of 89). Among the survivors treated with cisplatin-based regimens $(n=30) 20 \%$ suffered from renal impairment and $36.7 \%$ from varying degrees of deafness. ${ }^{14}$

The retrospective design of the present study is associated with certain limitations. Some of the patients invited to participate did not respond to the information letter and four who gave informed consent did not return the questionnaire. Although patient characteristics did not differ between responders and non-responders, we cannot exclude selection bias. Second, details of chemotherapeutic sequelae were retrieved from medical reports in which the degree of impairment was not classified following recent classification systems for hearing loss, renal impairment and pulmonary capacity. Thus we could not objectively define the severity of sequelae, as recent information during adulthood was not available. Yet, it has been reported that symptoms of platinum induced hearing loss may occur with delay and possibly get worse even if treatment has been discontinued. In addition, chemotherapy-induced hearing loss seems to be underreported as highfrequency hearing loss is affected first and therefore may occur without being noticed by the patients. ${ }^{24}$ Therefore it should not be assumed that chemotherapy-induced hearing loss invariably improves over time. Chemotherapeutic sequelae reported in this study are possibly underestimated; therefore the QoL results possibly overestimate the true situation. Due to the small sample size, the variety of chemotherapeutic protocols used and the incompleteness of chemotherapeutic details we were not able to determine risk factors for poor physical functioning score or serious sequelae of chemotherapy.

In the Netherlands, an outpatient program known as "Stichting KInderOncologie Nederland-Lange TERmijn- effecten (SKION LATER)" has been established in all paediatric oncological centres. It provides a standardized follow-up schedule for survivors of childhood cancer who are at least five years after the diagnosis. ${ }^{25}$ Our results emphasize that such programs are needed to support affected patients at an early stage and thereby minimize possibly adverse effects on QoL and personal development. 


\section{RefERENCES}

1 Pauniaho SL, Heikinheimo O, Vettenranta K, et al. High prevalence of sacrococcygeal teratoma in Finland - a nationwide population-based study. Acta Paediatr 2013;102(6):e251-256.

2 Schropp KP, Lobe TE, Rao B, et al. Sacrococcygeal teratoma: the experience of four decades. J Pediatr Surg 1992;27(8):1075-1078

3 Altman RP, Randolph JG, Lilly JR. Sacrococcygeal teratoma: American Academy of Pediatrics Surgical Section Survey-1973. J Pediatr Surg 1974;9(3):389-398.

4 Yoshida M, Matsuoka K, Nakazawa A, et al. Sacrococcygeal yolk sac tumor developing after teratoma: a clinicopathological study of pediatric sacrococcygeal germ cell tumors and a proposal of the pathogenesis of sacrococcygeal yolk sac tumors. J Pediatr Surg 2013;48(4):776-781.

5 Derikx JP, De Backer A, van de Schoot L, et al. Factors associated with recurrence and metastasis in sacrococcygeal teratoma. Br J Surg 2006;93(12):1543-1548.

6 Rescorla FJ. Pediatric germ cell tumors. Semin Pediatr Surg 2012;21(1):51-60.

7 Rescorla FJ, Sawin RS, Coran AG, et al. Long-term outcome for infants and children with sacrococcygeal teratoma: a report from the Childrens Cancer Group. J Pediatr Surg 1998;33(2):171-176

8 Engelskirchen R, Holschneider AM, Rhein R, et al. Sacral teratomas in childhood. An analysis of long-term results in 87 children. Z Kinderchir 1987;42(6):358-361.

9 Gobel U, Calaminus G, Blohm M, et al. Extracranial non-testicular teratoma in childhood and adolescence: introduction of a risk score for stratification of therapy. Klin Padiatr 1997;209(4):228-234.

10 Calaminus G, Schneider DT, Bokkerink JP, et al. Prognostic value of tumor size, metastases, extension into bone, and increased tumor marker in children with malignant sacrococcygeal germ cell tumors: a prospective evaluation of 71 patients treated in the German cooperative protocols Maligne Keimzelltumoren (MAKEI) 83/86 and MAKEI 89. J Clin Oncol 2003;21(5):781-786.

11 Gobel U, Schneider DT, Calaminus G, et al. Multimodal treatment of malignant sacrococcygeal germ cell tumors: a prospective analysis of 66 patients of the German cooperative protocols MAKEI 83/86 and 89. J Cin Oncol 2001;19(7):1943-1950. 


\section{Chapter 8}

12 De Corti F, Sarnacki S, Patte C, et al. Prognosis of malignant sacrococcygeal germ cell tumours according to their natural history and surgical management. Surgical oncology 2012;21(2):e31-37.

13 Mann JR, Raafat F, Robinson K, et al. UKCCSG's germ cell tumour (GCT) studies: improving outcome for children with malignant extracranial non-gonadal tumours-carboplatin, etoposide, and bleomycin are effective and less toxic than previous regimens. United Kingdom Children's Cancer Study Group. Med Pediatr Oncol 1998;30(4):217-227.

14 Hale GA, Marina NM, Jones-Wallace D, et al. Late effects of treatment for germ cell tumors during childhood and adolescence. J Pediatr Hematol Oncol 1999;21(2):115-122.

Gobel U, Calaminus G, Teske C, et al. BEP/VIP in children and adolescents with malignant non-testicular germ cell tumors. A comparison of the results of treatment of therapy studies MAKEI 83/86 and 89P/89. Klin Padiatr 1993;205(4):231-240.

16 Derikx JP, De Backer A, van de Schoot L, et al. Long-term functional sequelae of sacrococcygeal teratoma: a national study in The Netherlands. J Pediatr Surg 2007;42(6):1122-1126.

17 Dirix $M$, van Becelaere $T B L$, van Baren $R$, et al. Malignant transformation in sacrococcygeal teratoma and in presacral teratoma assosicated with Currarino syndrome: A comperative study. J Pediatr Surg 2015;Mar;50(3):462-4.

18 Currarino G, Coln D, Votteler T. Triad of anorectal, sacral, and presacral anomalies. AJR Am J Roentgenol 1981;137(2):395-398.

19 Aaronson NK, Muller M, Cohen PD, et al. Translation, validation, and norming of the Dutch language version of the SF-36 Health Survey in community and chronic disease populations. J Clinical Epidemiol 1998;51(11):1055-1068.

20 Ware JE, Kosinski M. Interpreting SF-36 summary health measures: a response. Qual Life Res 2001;10(5):405-413

21 Gobel U, Haas RJ, Harms D, et al. Treatment strategy in non-testicular malignant germ cell tumors in children and adolescents-concept of the MAKEI 83 cooperative therapeutic study of the Society for Pediatric Oncology. Klin Padiatr 1983;195(3):201-206.

22 Rescorla F, Billmire D, Stolar C, et al. The effect of cisplatin dose and surgical resection in children with malignant germ cell tumors at the sacrococcygeal region: a pediatric intergroup trial (POG 9049/CCG 8882). J Pediatr Surg 2001;36(1):12-17.

23 Gobel U, Calaminus G, Engert J, et al. Teratomas in infancy and childhood. Med Pediatr Oncol 1998;31(1):8-15. 
24 Gobel U, Schneider DT, Calaminus G, et al. Germ-cell tumors in childhood and adolescence. GPOH MAKEI and the MAHO study groups. Ann Oncol 2000;11(3):263-271.

25 Schacht J, Talaska AE, Rybak LP. Cisplatin and aminoglycoside antibiotics: hearing loss and its prevention. Anat Rec 2012;295(11):1837-1850.

26 SKION LATER Work group. Richtlijn follow-up na kinderkanker meer dan 5 jaar na diagnose. Den Haag/Amsterdam 2010. 54 p. 


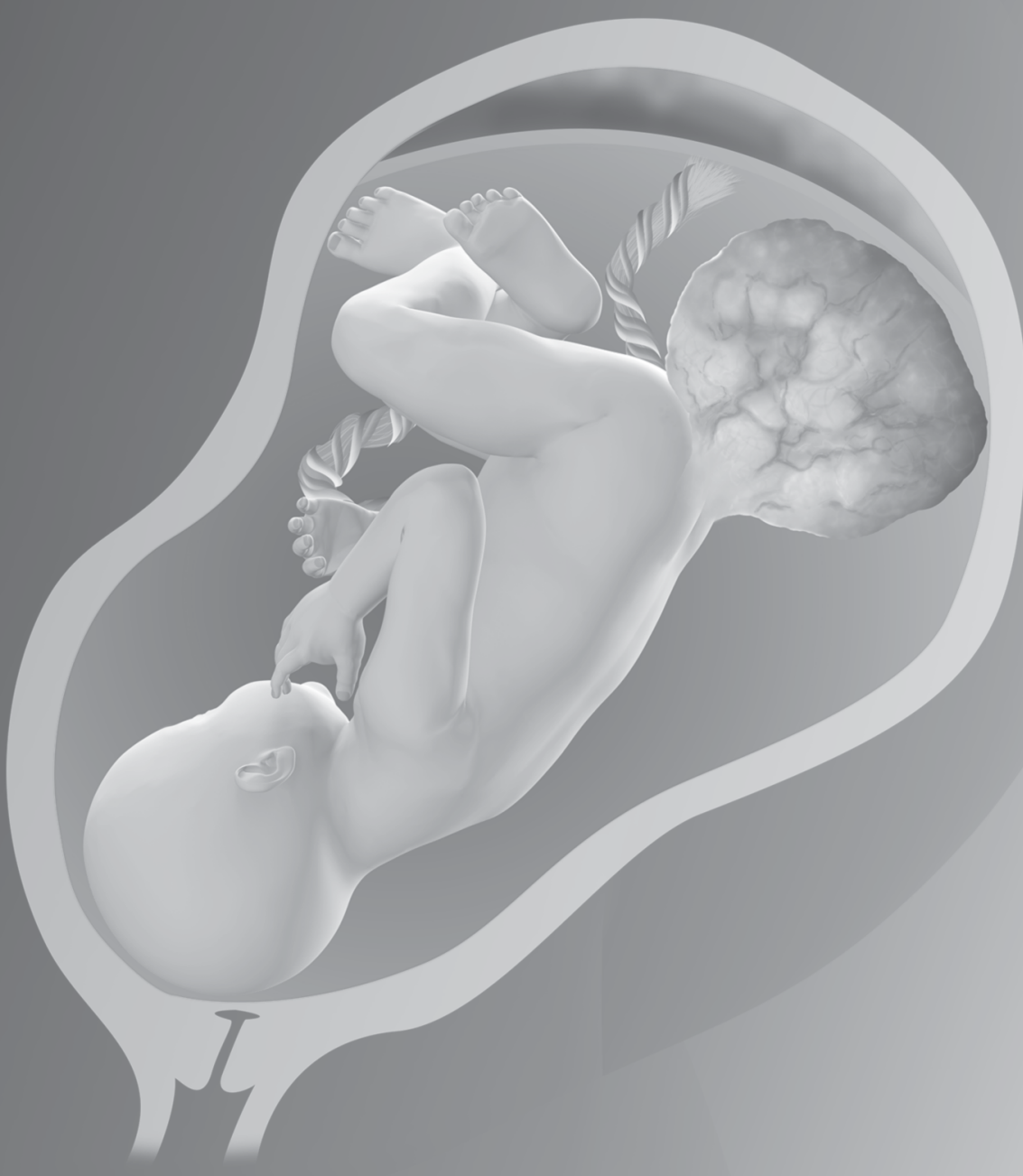




\section{CHAPTER 9}

\section{General discussion and summary}


Chapter 9 
Surgical treatment for SCT was first described in 1841 by Dr Blizard, but it was not until 1951 that Dr Robert E. Gross first described removing the coccygeal bone together with the tumour to achieve complete resection and prevent recurrence. ${ }^{1,2}$ Unfortunately, his further knowledge on this rare disease was never published in his book "The Surgery of Infancy and Childhood" as the manuscript contributing to SCT had fallen from the radiator in his office and was found too late between the radiator and the wall.

Since those early days the treatment of SCT has been improved leading to an overall good survival in the majority of infants. ${ }^{3,4}$ Surgical resection is mandatory in all children, with additional platinum-based chemotherapeutic therapy in those with metastatic disease. ${ }^{5}$ Most of the patients survive with this approach, but may have to deal with the implications of the treatment and the disease itself. Although we have gained more knowledge on SCT and its biological behaviour, the various aspects of short and long-term complications have been relatively rarely investigated and there is no uniform follow-up care program for these patients.

With the work of the present thesis we aimed to gain more insight in the perioperative mortality and the occurrence of associated anomalies in patients treated for SCT, and in addition to investigate the long-term functional sequelae beyond childhood. The ultimate goal was to design an evidence-based follow-up scheme that takes into account all of these aspects and that can be implemented as a guideline for the holistic follow-up of children diagnosed with SCT.

\section{Perioperative considerations in the treatment of sacrococcygeal teratoma}

Sacrococcygeal teratoma is prenatally diagnosed through routine ultrasound screenings in the majority of cases. ${ }^{6}$ Despite intense research on the aetiology of this rare tumour, no gross genetic cause explaining its occurrence or the female predominance has been discovered yet. ${ }^{7}$ Nevertheless, associated congenital anomalies have often been described in patients with SCT. The spectrum of these anomalies includes neurological and cardiopulmonary defects as well as musculoskeletal deformations. ${ }^{6,8}$ Despite the knowledge of these anomalies, little attention has been given to routine screening and evaluation of these anomalies, probably because only case reports or small sample data were available in literature. In chapter two, the incidence and extent of anomalies associated with SCT were 


\section{Chapter 9}

evaluated in a cohort of 235 neonates born with SCT between 1970 and 2010 in the Netherlands. In addition, patient- and disease related risk factors predictive for the occurrence of these anomalies were investigated in this study. We found that about one-third of the neonates were affected by anomalies. However, in general these anomalies are mild and normally not life-threatening itself. It appeared that some of the most common anomalies, such as hydronephrosis, are related to the location and extent of the tumour while other anomalies are more related to prematurity (i.e. cardiopulmonary anomalies) or occur spontaneously (i.e. chromosomal aberration, oesophageal atresia). While the cardiopulmonary system is usually screened for anomalies during pregnancy, neonates who are born with SCT are not routinely screened for tumour-related anomalies such as hydronephrosis. In addition, we showed that hip dysplasia often occurs concomitantly with hydronephrosis but is also not screened for in daily practice. Our results provide evidence that it is worthwhile to implement standard screening ultrasound of hips and kidneys in the follow-up of patients with SCT. Although we did not perform cost-effectiveness analysis of these extra screening programs we think that the financial burden for the community is predictable and reasonable. Annually only a few children are affected by SCT and will be screened using this inexpensive and patient-friendly screening modality. Moreover, the knowledge of the high incidence of anomalies not related to the tumour itself deserves to be included in the counselling of parents of affected children.

Foetal hydrops as a consequence of cardiac failure or intrauterine haemorrhage from the well-vascularized tumour is related to poor foetal outcome. ${ }^{9-11}$ Mortality of those born alive can be either shortly after birth caused by haemorrhagic complications or during infancy due to malignant transformation. While the risk factors for intrauterine fatal outcome are well investigated, the risk factors and reasons for early mortality in those born alive are less known. Therefore, in chapter three we focused on neonatal mortality and possible patient- and disease-related risk factors associated with haemorrhagic mortality shortly after birth. Early mortality after birth was evaluated retrospectively in the above-mentioned cohort. We found that tumour haemorrhage is the most common cause of neonatal mortality and that approximately $4 \%$ of the neonates born with SCT die due to haemorrhagic complications independently of the timing of diagnosis. Our results showed that a 
larger tumour size is predictive for neonatal outcome as it is an independent risk factor for haemorrhagic mortality. Surgical interventions to prevent haemorrhagic complications such as laparoscopic clipping of the median sacral artery are not routinely performed in patients with a high risk of major haemorrhage. Our findings emphasize the need of consistent surgical strategies in the treatment for SCT, with haemorrhagic control in selected cases prior to surgical resection, including those with large, well vascularised tumours or preoperative hemodynamic instability. The question remains if standard caesarean section should be performed when larger tumours are diagnosed in utero. Our studies do not supply sufficient evidence to support this theory, although a caesarean section may decrease the risk of pressurerelated bleeding into the tumour and the risk of tumour rupture, and may shorten the duration of delivery, which may translate into a decrease of haemorrhagic mortality.

\section{Functional outcomes after surgical treatment for sacrococcygeal teratoma}

Tumour pressure on vital structures and the extended surgical resection early during infancy are held responsible for impairment of and damage to vital structures located in the lower pelvis, thereby leading to functional complaints. ${ }^{12,13}$ Several studies performed in paediatric cohorts provide evidence of defecation and micturition complaints after treatment for SCT. ${ }^{12-15}$ The few available studies performed in adult cohorts hypothesize improvement of existing soiling complaints but a higher percentage of constipation. ${ }^{16,17}$ In chapter four we assessed long-term micturition and defecation complaints in adults treated for SCT during childhood with questionnaires that also addressed frequency and severity of complaints. The survey results suggest that patients treated for SCT during infancy may suffer from micturition and defecation complaints beyond childhood, although less frequent and severe than suspected: although almost half of the patients reported defecation or micturition complaints, in most cases occurring occasionally. However, urinary incontinence was reported by approximately one-third of the patients. Contrary to our expectations, these complaints in general resulted in limitations of daily life in only $6.5 \%$ of respondents.

Our evaluation on the long-term course of micturition and defecation complaints from childhood to adolescence did not show a clear trend towards 


\section{Chapter 9}

improvement or deterioration of complaints later in life. In addition, contrary to others we could not confirm that patient- or disease-related factors are able to predict the occurrence of long-term functional complaints in general. ${ }^{18,19}$ Thus the question what anatomical and/or physiological changes are responsible for incontinence and constipation in patients treated for SCT remains unanswered. Urodynamic investigations and anorectal manometry by others showed contradictory results, with some reporting a good correlation of urodynamic studies and clinical symptoms while others found abnormal results in asymptomatic patients. ${ }^{13,18}$ We therefore conclude that in the clinical follow-up the focus should be put on early evaluation of micturition and defecation complaints during school age with further investigations in the case of complaints.

Functional complaints and the patients' perception of these complaints may be influenced by age: while a school-aged child will probably care less about the body image and the postoperative scar, an adolescent will give much more attention to body image and is probably also concerned about the influence of the previous treatment on sexuality. As only a few case reports on this topic are available in the literature the scope of chapter five was to evaluate various domains of sexual function and personal body image during adulthood after treatment for SCT in a prospective structured way, using validated measures. Data showed that women perceived a lower sexual function compared to the general population, although there was no evidence for sexual dysfunction. Interestingly, women's lower overall sexual function scores seemed to be mainly influenced by their significantly lower sexual desire. There was no evidence for dyspareunia or orgasmic dysfunction. The men in the present cohort did not report any sexual dysfunction and reported normal erectile function. However the male cohort is too small to prove that SCT treatment in males does not affect their sexual function, as others previously reported incontinence during intercourse and impotence. ${ }^{16,17}$

We considered that the worse body image and lower satisfaction with the cosmetic postoperative result of the women compared to the men contribute to the lower sexual desire in the women. We were not able to support this theory in the present sample, however, as only moderate correlations of body image and sexual desire were found. The study design did not provide for physical examination including hormonal evaluations. Such assessment may give further insight in the 
aetiology of the diminished desire in female patients. The results presented in chapter five imply that evaluation of sexual complaints should be implemented in future surveillance strategies to gain more insight in onset and duration of complaints.

Data in chapters four and five support the necessity to extend the current surveillance program for patients treated for SCT longer than three years, which period was chosen from an oncological point of view to detect recurrent disease. Dissatisfaction with body image and sexual complaints might become obvious for the first time beyond childhood. Moreover, these results draw attention to the currently discussed problem of transition from paediatric to adult care: young adult patients initially treated for a congenital anomaly by paediatric surgeons require care by doctors in the adult setting who are also experienced in the primary congenital anomaly. ${ }^{20}$

There is on-going discussion if patients treated for SCT during childhood need to be under close supervision by gynaecologists during pregnancy. Moreover, it has been suggested that caesarean section is the delivery mode of choice for these patients as scar tissue after previous operations and deformity of the sacral bone might lead to insufficient progression during labour. ${ }^{21,22}$ As the current literature only provides descriptions of a few cases of pregnancy outcomes after SCT resection our aim was to gain more insight in pregnancy and delivery in females previously treated for SCT. Chapter six provides data on the course and outcomes of 26 pregnancies of 13 women. The results show that vaginal delivery was performed in the majority of cases without adverse effects for mother or child despite the previous surgical treatment. Conversion to caesarean section was never necessary, emphasising that SCT resection not necessarily leads to a narrow pelvic outlet as previously described. ${ }^{22}$ Consequently, opposite to previous suggestions there is no necessity to routinely perform caesarean section in women with previous SCT resection. Furthermore, our results suggest that regular monitoring by gynaecologists during pregnancy is not indicated, provided that health care givers are familiar with the previous history and are able to anticipate on unsuspected problems during pregnancy or delivery. 


\section{Chapter 9}

\section{Quality of life in patients treated for sacrococcygeal teratoma}

In the third part of this thesis the long-term influences of SCT and its surgical and medical treatment on the patient's quality of life (QoL) were evaluated with the SF36 questionnaire. Chapter seven shows the outcome on the SF-36 questionnaire of adults previously treated for SCT compared to values of the general Dutch population. There was no difference in the QoL between former SCT patients and the general population. In addition, there was no evidence of impairment in social, physical or emotional functioning of these patients later in life. After correction for differences in age, sex and living status between participants and the control population, the conclusions remained the same.

The SF-36 is a validated measure to evaluate general QoL and does not specifically address certain disease related complaints. ${ }^{23}$ Nonetheless we assume that the findings of the present QoL analysis are representative, as we previously showed a low impact of functional sequelae on daily life in the vast majority of patients (chapter four). The results from the studies described in chapters four and seven contradict the widespread assumption that functional sequelae after SCT resection necessarily lead to diminished QoL.

Patients who receive chemotherapeutic treatment for malignant SCT remain a minority, as malignancy affects no more than $7-17 \% .{ }^{8,24-26}$ These patients form a special subgroup, as they are at risk of chemotherapeutic toxicity next to tumourand treatment related sequelae. To explore if the current follow-up strategies meet the demands of this group, a sub-analysis of the QoL of these patients was performed in chapter eight. For this purpose chemotherapeutic toxicity in terms of renal impairment, audiological functioning, cardiovascular and pulmonary functioning and musculoskeletal impairment was analysed retrospectively. Furthermore results on the SF-36 of patients treated for a benign SCT were compared to results of patients previously treated for malignant SCT. Both patient groups underwent surgical treatment thereby creating a comparable initial situation enabling us to evaluate the effect of chemotherapeutic sequelae on QoL. While more than half of the patients previously treated for malignant SCT reported chemotherapeutic toxicity, only physical functioning was restricted without negatively affecting daily activities, psychosocial functioning or the overall QoL. The high incidence of oncological treatment related sequelae however emphasises the need for a structured long-term 
oncological follow-up. In the Netherlands this is already achieved by the SKION LATER (Stichting KInderOncologie Nederland -LAngeTERmijneffecten) program. Still, follow-up of these patients requires a close collaboration between paediatric oncologists and paediatric surgeons with referral to centres performing these longterm surveillance programs.

\section{Concluding remarks}

From the data in this thesis we may conclude that the current screening and followup of SCT patients can be improved. Screening for hip dysplasia and renal impairment should be part of routine screening and arterial ligation of the tumour's blood supply should be considered in large, well vascularised tumours to minimize the risk of haemorrhagic complications.

The long-term follow-up of patients who underwent treatment for SCT should be extended to include evaluation of functional sequelae at different ages. Notably micturition and defecation complaints should be monitored, particularly at the age children normally become continent for urine and faeces. Evaluation of body image and sexuality should take place during puberty and adolescence. 


\section{Chapter 9}

\section{REFERENCES}

1 Gross RW, Clatworthy HW, Jr., Meeker IA, Jr. Sacrococcygeal teratomas in infants and children; a report of 40 cases. Surg Gyneco Obstetr. 1951;92(3):341-354.

2 Stanley E. On congenital tumours of the pelvis. Med Chir Trans. 1841;24:231-252.

3 Gobel U, Calaminus G, Blohm M, Booss D, Felberbauer F, Hofmann U, et al. Extracranial non-testicular teratoma in childhood and adolescence: introduction of a risk score for stratification of therapy. Klin Padiatr. 1997;209(4):228-234.

4 De Corti F, Sarnacki S, Patte C, et al. Prognosis of malignant sacrococcygeal germ cell tumours according to their natural history and surgical management. Surg Oncol. 2012;21(2):e31-37.

5 Gobel U, Calaminus G, Schneider DT, et al. Management of germ cell tumors in children: approaches to cure. Onkologie. 2002;25(1):14-22.

6 Pauniaho SL, Heikinheimo O, Vettenranta K, et al. Prevalence of sacrococcygeal teratoma in Finland - a nationwide population-based study. Acta Paediatr. 2013;102(6):e251-256.

7 Barksdale EM, Jr., Obokhare I. Teratomas in infants and children. Curr Opin Pediatr. 2009;21(3):344-349.

8 Altman RP, Randolph JG, Lilly JR. Sacrococcygeal teratoma: American Academy of Pediatrics Surgical Section Survey-1973. J Pediatr Surg. 1974;9(3):389-398.

9 Westerburg B, Feldstein VA, Sandberg PL, et al. Sonographic prognostic factors in fetuses with sacrococcygeal teratoma. J Pediatr Surg. 2000;35(2):322-325

10 Akinkuotu AC, Coleman A, Shue E, et al. Predictors of poor prognosis in prenatally diagnosed sacrococcygeal teratoma: A multiinstitutional review. J Pediatr Surg. 2015;50(5):771-774.

11 Benachi A, Durin L, Vasseur Maurer S, et al. Prenatally diagnosed sacrococcygeal teratoma: a prognostic classification. J Pediatr Surg. 2006;41(9):1517-1521.

12 Ozkan KU, Bauer SB, Khoshbin S, et al. Neurogenic bladder dysfunction after sacrococcygeal teratoma resection. J Urol. 2006;175(1):292-296

13 Berger $M$, Heinrich $M$, Lacher $M$, et al. Postoperative bladder and rectal function in children with sacrococcygeal teratoma. Pediatr Blood Cancer. 2011;56(3):397-402.

14 Boemers TM, van Gool JD, de Jong TP, et al. Lower urinary tract dysfunction in children with benign sacrococcygeal teratoma. J Urol. 1994;151(1):174-176. 
15 Shalaby MS, Walker G, O'Toole S, et al. The long-term outcome of patients diagnosed with sacrococcygeal teratoma in childhood. A study of a national cohort. Arch Dis Child. 2014;99(11):1009-1013.

16 Rintala R, Lahdenne P, Lindahl $\mathrm{H}$, et al. Anorectal function in adults operated for a benign sacrococcygeal teratoma. J Pediatr Surg. 1993;28(9):1165-1167.

17 Cozzi F, Schiavetti A, Zani A, et al. The functional sequelae of sacrococcygeal teratoma: a longitudinal and cross-sectional follow-up study. J Pediatr Surg. 2008;43(4):658-661.

18 Lahdenne P, Wikström S, Heikinheimo M, et al. Late urological sequelae after surgery for congenital sacrococcygeal teratoma. Pediatr Surg Int. 1992;7(3):195-198.

19 Cost NG, Geller JI, Le LD, et al. Urologic co-morbidities associated with sacrococcygeal teratoma and a rational plan for urologic surveillance. Pediatr Blood Cancer.

2013;60(10):1626-1629.

20 Naiditch JA, Rothstein DH. Transitional care from pediatric to adult surgery. JAMA Surg. 2014;149(11):1099-1100.

21 Kohlberger P, Helbich T, Schaller A. Delivery following surgically treated sacrococcygeal teratoma in the mother. Z Geburtshilfe Neonatol. 1997;201(4):148-151.

22 Bittmann S, Bittmann V. Surgical experience and cosmetic outcomes in children with sacrococcygeal teratoma. Curr Surg. 2006;63(1):51-54.

23 Aaronson NK, Muller M, Cohen PD, et al. Translation, validation, and norming of the Dutch language version of the SF-36 Health Survey in community and chronic disease populations. J Clinical Epidemiol. 1998;51(11):1055-1068.

24 Yoshida M, Matsuoka K, Nakazawa A, et al. Sacrococcygeal yolk sac tumor developing after teratoma: a clinicopathological study of pediatric sacrococcygeal germ cell tumors and a proposal of the pathogenesis of sacrococcygeal yolk sac tumors. J Pediatr Surg. 2013;48(4):776-781.

25 Rescorla FJ. Pediatric germ cell tumors. Semin Pediatr Surg. 2012;21(1):51-60.

26 Derikx JP, De Backer A, van de Schoot L, et al. Factors associated with recurrence and metastasis in sacrococcygeal teratoma. Br J Surg. 2006;93(12):1543-1548. 


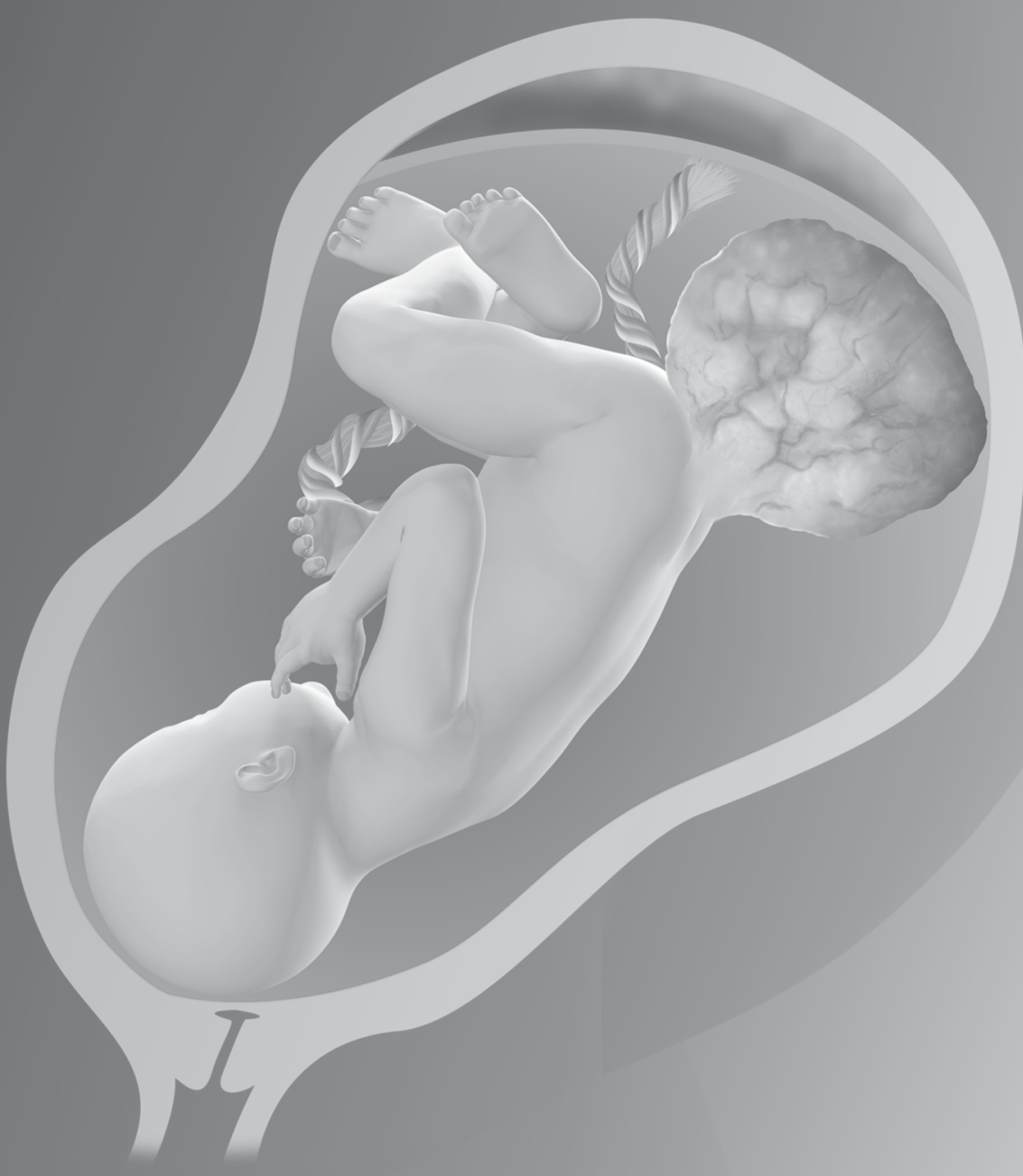


Samenvatting 


\section{Chapter 9}

Het sacrococcygeaal teratoom (SCT) is een meestal goedaardige kiemceltumor die bij ongeveer zes pasgeborenen per jaar in Nederland voorkomt. Sinds de eerste beschrijving van de chirurgische resectie van SCT in 1841 is uitgebreid onderzoek gedaan naar de beste behandeling van deze tumor, die vroeg in de zwangerschap ontstaat en tijdens de zwangerschap verder uitgroeit. De standaard behandeling van patiënten met een SCT is resectie met aanvullende chemotherapie indien het een maligne tumor met metastasen betreft. Ondanks de goed gestandaardiseerde behandeling voor SCT is nog weinig bekend over de lange termijn gevolgen van de behandeling van patiënten met deze tumor, vooral met betrekking tot de functionele uitkomsten en de kwaliteit van leven. Tegenwoordig worden pasgeborenen na de operatie ongeveer drie jaar gevolgd om een eventueel recidief tijdig te ontdekken. Bij de huidige follow-up wordt echter geen aandacht besteed aan mogelijke functionele klachten, mede omdat er weinig over bekend is.

In dit proefschrift worden nieuw-verkregen inzichten in de vroege mortaliteit rondom de operatie van kinderen die geboren zijn met een SCT en het optreden van simultane andere aangeboren afwijkingen bij deze kinderen beschreven. Verder worden verschillende functionele uitkomsten op volwassen leeftijd zoals seksuele functie, zwangerschapsuitkomsten en defecatie- en mictieproblemen na de behandeling van SCT op kinderleeftijd beschreven. Daarnaast is de levenskwaliteit van volwassen patiënten die op kinderleeftijd behandeld zijn aan deze tumor geëvalueerd en vergeleken met de kwaliteit van leven van de normale Nederlandse populatie.

In hoofdstuk een wordt de embryologische ontwikkeling van SCT besproken en worden de klinische en pathologische classificaties van deze kiemceltumor beschreven. Enkele belangrijke aspecten van snelle maligne ontaarding en de consequenties daarvan voor de (chirurgische) behandeling zijn hierin verder toegelicht. Tenslotte wordt een kort overzicht gegeven over de mechanismen die mogelijk verantwoordelijk zijn voor het optreden van functionele klachten na de behandeling van patiënten met een SCT.

In hoofdstuk twee is in een nationaal cohort van 235 kinderen die in Nederland geboren zijn met een SCT tussen 1970 en 2010, de incidentie en aard van de aangeboren afwijkingen beschreven. Tevens zijn patiënt- en ziekte gebonden kenmerken geïdentificeerd die het risico op optreden van deze afwijkingen kunnen 
voorspellen. Onze analyses toonden dat bij ongeveer 32\% van de kinderen minimaal één afwijking voorkomt waarvan hydronefrose met ca. $16 \%$ het meest voorkomend was. Hydronefrose bleek gerelateerd aan de ligging van de tumor, met een vier keer verhoogd risico hierop bij kinderen met een inwendig gelegen tumor vergeleken met kinderen bij wie de tumor geheel of grotendeels uitwendig gelegen was. Verder vonden wij een verhoogde incidentie van heupdysplasie bij kinderen met SCT. Hiervoor was de tumorligging echter geen directe risicofactor. Naast afwijkingen die een relatie hebben met de massawerking van de tumor, waren er een aantal afwijkingen zoals hart- of longafwijkingen die niet direct aan de ziekte zelf gerelateerd waren, maar mogelijk verklaard kunnen worden door de vroeggeboorte van deze kinderen. Echter liet onze analyse in dit hoofdstuk ook zien, dat het optreden van afwijkingen zoals aanlegstoornis van de slokdarm of sluitingsdefecten van de buikwand vaker voorkomen bij patiënten met SCT in vergelijking met de algemene Europese populatie. Dit is belangrijke informatie voor ouders die tijdens de zwangerschap geconfronteerd worden met de diagnose SCT. Het is derhalve noodzakelijk om kinderen met SCT vroegtijdig te screenen op aangeboren afwijkingen, in het bijzonder kinderen met een inwendig gelegen tumor. Door middel van echografie van de nieren en de heupen kunnen hydronefrose en heupdysplasie relatief eenvoudig opgespoord worden en zo kan lange termijnschade voorkomen worden. Deze screeningsmodaliteiten zullen derhalve opgenomen moeten worden in het screeningsprogramma van kinderen geboren met SCT.

In hoofdstuk drie is de sterfte van pasgeborenen met SCT onderzocht. Dit hoofdstuk laat zien dat van alle kinderen die levend geboren werden met SCT ongeveer $4 \%$ kort na de geboorte overlijdt. Tumorbloeding blijkt de belangrijkste doodsoorzaak in deze periode te zijn (ca. 80\%). Van diegenen die op de kinderleeftijd sterven, overlijdt zelfs $40 \%$ ten gevolge van tumorbloeding of een hieraan gerelateerde complicatie. Het geslacht van het kind, de anatomische ligging van de tumor en maligne transformatie verhoogden het risico op bloeding-gerelateerde sterfte niet. Er werd wel een significante risicoverhoging op bloeding-gerelateerde sterfte gezien bij pasgeborenen bij wie het tumorvolume meer dan $1000 \mathrm{~cm}^{3}$ is. Ook vroeggeboorte verhoogde het risico op bloeding-gerelateerde mortaliteit, meest waarschijnlijk doordat prematuren de cardiale belasting die ontstaat door zowel de verhoogde cardiale output als ook de hemodynamische instabiliteit door bloedverlies minder goed tolereren. 


\section{Chapter 9}

De resultaten besproken in hoofdstuk drie leidden tot de discussie of standaard een keizersnede toegepast moet worden bij een SCT zwangerschap om tumorbloeding tijdens de bevalling te voorkomen. Onze analyses lieten geen duidelijk bewijs zien die deze theorie bevestigde, echter bij kinderen met hemodynamische problemen in utero of aanwijzingen voor tumorbloeding zou een keizersnede wel kunnen leiden tot een kortere bevallingstijd mogelijk resulterend in een betere overleving. Gezien de aanwijzingen voor een relatie tussen tumorgrootte en mortaliteit door tumorbloeding dient men in de praktijk te overwegen om alvorens de tumor te reseceren eerst de vascularisatie van de tumor, welke voornamelijk door de arteria sacralis media voorzien is, te onderbinden. Dit kan door het (laparoscopisch) clippen van dit bloedvat; een techniek die al bekend is, maar niet routinematig toegepast wordt bij de chirurgische behandeling van het SCT.

In het tweede gedeelte van dit proefschrift zijn de functionele uitkomsten op lange termijn geanalyseerd bij patiënten die op kinderleeftijd werden behandeld voor SCT. Er werd aangenomen dat bij deze kinderen regelmatig functionele klachten voorkomen. Om meer inzicht in het optreden en het beloop van deze klachten te verkrijgen, analyseerden we in hoofdstuk vier de functionele uitkomsten van volwassenen die op kinderleeftijd geopereerd werden aan een SCT. Patiënten beoordeelden middels vragenlijsten welke klachten zij hadden, hoe vaak deze klachten optraden maar ook hoe ernstig ze deze klachten ervoeren. Bijna de helft van alle patiënten had als volwassene mictie- of defecatie klachten. Deze traden bij de meesten niet dagelijks op. Onvoldoende controle over defecatie werd door 4\% van de patiënten gerapporteerd, $23 \%$ van de patiënten rapporteerde soiling en $22 \%$ van de patiënten gaf aan last te hebben van obstipatie. Verder was ongeveer $30 \%$ van de patiënten op volwassen leeftijd in wisselende mate incontinent voor urine. Opvallend was dat functionele klachten over het algemeen door patiënten niet als storend werden ervaren; echter gaf urine-incontinentie voor patiënten een grotere belasting dan incontinentie voor feces. Dit kan mogelijk verklaard worden door het feit dat urineincontinentie veel regelmatiger optreedt vergeleken met defecatie problemen.

In deze studie werden geen risicofactoren gevonden die het optreden van functionele klachten in het algemeen voorspelden. De resultaten benadrukken, dat het nodig is om het huidige follow-up programma uit te breiden. De vanuit oncologisch standpunt gekozen drie jaar follow-up termijn is te kort om deze functionele klachten 
op te sporen en zo nodig verder onderzoek in te zetten, omdat driejarigen vaak nog niet zindelijk zijn en klachten ook pas op oudere leeftijd kunnen optreden.

In hoofdstuk vijf werd de seksuele functie van patiënten met SCT onderzocht: met gevalideerde vragenlijsten over seksuele functie werden de patiënten vergeleken met de normale Nederlandse populatie. Vrouwelijke patiënten bleken in deze vergelijking een slechtere seksuele functie te hebben dan de gemiddelde Nederlandse vrouw. De kleine groep mannelijke patiënten die in deze studie onderzocht werd, rapporteerde goede erectiele functie zonder aanwijzingen voor verdere seksuele dysfunctie. De verminderde seksuele functie bij vrouwelijke patiënten bleek te berusten op een verminderd verlangen en een afgenomen opwinding en niet op dyspareunie. Een mogelijke verklaring voor deze bevindingen is een negatief zelfbeeld ten gevolge van de operatie en de daarmee verbonden cosmetische veranderingen. Vrouwelijke patiënten hadden op volwassen leeftijd een significant lager zelfbeeld dan mannelijke patiënten. Analyse naar de relatie van zelfbeeld en vrouwelijke seksuele functie liet maar een gering verband zien tussen deze twee parameters en kon derhalve niet de enige verklaring voor de verminderde seksuele functie zijn. Mogelijke invloed van chirurgische schade aan neuronale en vasculaire structuren in het kleine bekken die een rol spelen bij normaal seksueel functioneren is nog niet geheel duidelijk. Derhalve dient schade aan deze structuren tijdens de chirurgische resectie zo veel mogelijk voorkomen te worden.

In hoofdstuk zes werd de invloed van SCT-behandeling op de zwangerschap en bevalling geëvalueerd. Er wordt aangenomen dat de veranderingen in het bekken en bekkenbodem leiden tot onvermogen om vaginaal te bevallen, met de discussie of deze vrouwen standaard een keizersnede zouden moeten ondergaan. De uitkomsten van in totaal 26 zwangerschappen en 20 bevallingen bij dertien vrouwen zijn verder geanalyseerd. Vaginale bevalling was in de grote meerderheid van de bevallingen veilig en verliep ongecompliceerd. Er werden drie keizersneden verricht, waarvan één gepland, in verband met de eerdere operatieve behandeling voor SCT; de overige twee waren spoedprocedures bij verslechtering van de conditie van het kind. Het wordt niet aanbevolen een keizersnede als standaard bevallingsmethode voor deze patiëntengroep te beschouwen. Een vaginale bevalling is veilig mits het behandelend team van de medische voorgeschiedenis op de hoogte is en op mogelijke complicaties kan anticiperen. 


\section{Chapter 9}

In hoofdstuk zeven werd de algemene kwaliteit van leven van de patiënten ouder dan 18 jaar vergeleken met de kwaliteit van leven van de algemene Nederlandse populatie. Patiënten behandeld voor SCT op kinderleeftijd hadden later een vergelijkbare kwaliteit van leven als Nederlanders van vergelijkbare leeftijd. Er waren geen aanwijzingen voor beperkingen in sociaal, emotioneel of fysisch functioneren op de volwassen leeftijd. Ook na correctie voor verdelingsverschillen van geslacht, leeftijd en levensvorm (alleen of met partner) tussen de twee groepen bleven de resultaten hetzelfde.

De resultaten uit deze analyse bevestigen de bevindingen uit hoofdstuk vijf, namelijk dat functionele klachten niet noodzakelijk leiden tot een beperking in de algemene kwaliteit van leven.

Hoofdstuk acht behelst de kwaliteit van leven van patiënten die behandeld werden voor een maligne SCT. Deze patiënten ondergingen naast de chirurgische behandeling in bijna alle gevallen ook chemotherapeutische therapie, wat gepaard gaat met chemotherapeutische toxiciteit. Bij meer dan de helft van de patiënten die behandeld werden voor een maligne SCT, werden chemotherapie-gerelateerd functieverlies of orgaanschade vastgesteld, waarbij gehoorverlies het meest voorkwam. Vergelijkingen tussen patiënten die voor een maligne versus een benigne SCT werden behandeld, toonden allemaal een verminderd lichamelijk functioneren in de voor maligniteit behandelde groep, zonder dat deze fysieke beperkingen leidden tot vermindering van de algemene kwaliteit van leven. 


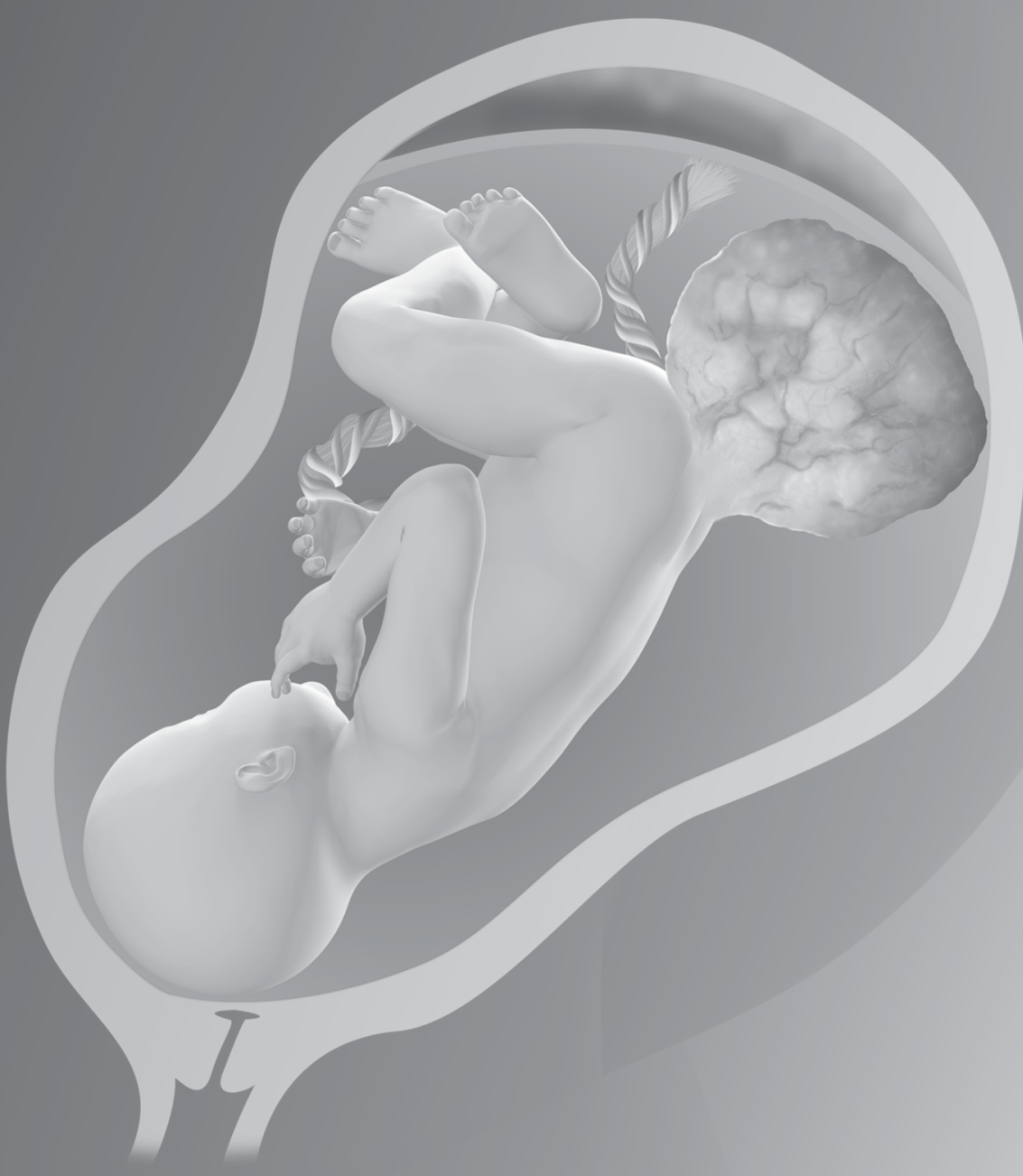


Valorization 


\section{Chapter 9}

\section{INTRODUCTION AND RELEVANCE OF THE SCIENTIFIC RESULTS}

Sacrococcygeal teratoma (SCT) is a rare condition affecting merely six children annually in the Netherlands. This poses the question if it is worth to investigate long-term complaints and to set up a national follow-up guideline for children with SCT. If we widen our perspective from the national to the international situation, we see that worldwide approximately 133 million children are born annually, which potentially increases the number of children born with SCT to approximately 4,700 children annually. This calculation is based on the incidence of one in 27,000 live births in the Netherlands, which might even be an underestimation. Except for the oncological follow-up of these patients no guidelines are available that give recommendations on screening for associated anomalies or defining the long-term follow-up. However, as the majority of patients treated for SCT nowadays survive, attention must be shifted from achieving survival towards improving functional outcomes. Nationally and internationally there is a need for a standardized early screening program to detect associated anomalies and for an evidence based long-term follow-up program that can be implanted in clinical practice.

\section{TARGET GROUP}

So far, little information concerning the long-term sequelae of SCT was available until now. Parents and patients suffering from SCT therefore could not be informed adequately about the expected sequelae resulting from treatment and the disease itself. Results and consequences of the present thesis are therefore relevant and applicable in daily life of patients with SCT and their parents. In addition, our results are relevant for a wide range of health professionals. Paediatric surgeons and neonatologists are obviously involved in the care of patients with SCT, but also more specialists in related fields might benefit from the present results. Obstetricians and gynaecologists play an important role in the prenatal diagnosis of SCT. They counsel affected parents during pregnancy and probably need to discuss abortion requests. Knowledge of pre- and postnatal complications as well as information on the long-term course of the disease is therefore essential. In 
addition, obstetricians and midwifes possibly will be consulted by women previously treated for SCT who want to become pregnant or those previously treated for SCT needing medical assistance during pregnancy and delivery. Patients who suffer from buttock deformation might consult plastic surgeons. Urologists, nephrologists and gastroenterologists might be consulted because of functional sequelae at different ages. Beside the various specialists involved in the care of patients treated for SCT, our results are also relevant for general practitioners, who might be the first health professional contacted by patients who have been dismissed from outpatient follow-up.

\section{IMPLEMENTATION AND INNOVATION}

Centralization of care and standardization of treatment guidelines have shown to be the cornerstones of improvement care of patients with rare diseases. We showed in this thesis, that standardized care for patients born with SCT should also include preoperative preparations considering the laparoscopic clipping of blood supplying vessels in greater tumours or hemodynamic instable patients. In addition, focused screening for associated anomalies including hip dysplasia and hydronephrosis should be performed early. Furthermore special attention should be paid to oncological, functional and cosmetically long-term complaints. Implementation of all these aspects in a standardized care program for patients with SCT will be easy to apply in the Netherlands and also internationally. 


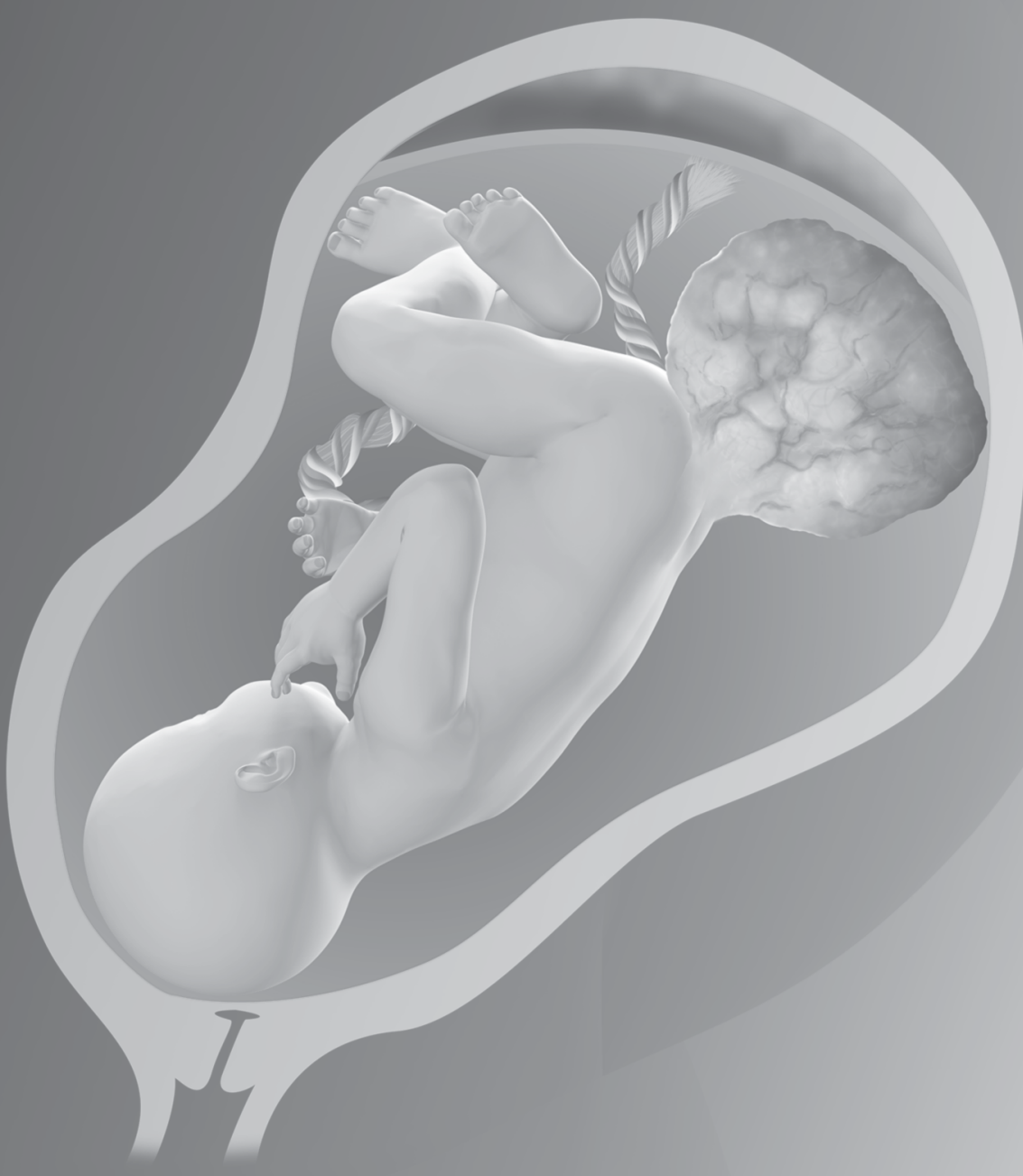


Dankwoord 
"Like to the moon am I that cannot shine alone"

Michelangelo

Ook al sta ik als enige voorop dit boekje, uiteindelijk is dit proefschrift het resultaat van het werk en de ondersteuning van velen. Daarom is het ook ontzettend leuk om nu iedereen die mij geholpen heeft om te kunnen "shinen" te danken. Hopelijk ben ik niemand vergeten.

Allereerst was dit proefschrift nooit tot stand gekomen zonder de bereidheid van alle patiënten om mee te doen aan dit onderzoek, de tijd te nemen om alle vragenlijsten in te vullen en vooral om open en eerlijk problemen te rapporteren. Hiervoor oprecht mijn dank en ik hoop dat de resultaten voor $u$ en uw lotgenoten iets betekenen.

Ik had het geluk een ontzettend betrokken promotor te hebben, die mij van begin af aan heeft begeleid. Beste prof. dr. van Heurn, beste Ernst: al tijdens mijn semistage gaf je mij de vrijheid om verantwoordelijkheden te nemen en hiervan te leren. De mogelijkheid om het werk waar ik toen mee ben begonnen af te maken was voor mij een enorm cadeau en ik realiseer me dat ik wel op het juiste moment op de juiste plek was om hier de kans voor te krijgen. Ondanks jouw enorm drukke agenda als professor heb je altijd tijd voor mij genomen om vragen te beantwoorden en problemen te bespreken. Ik hoefde bij jou nooit officiële afspraken te maken en kon gewoon langs lopen, jouw deur stond letterlijk altijd open. Dit samen met het razend snel corrigeren van mijn stukken heeft ertoe geleid dat wij samen dit boekje zo snel hebben kunnen afmaken. Ook voor mijn aanstelling als ANIOS in Maastricht heb jij je ingezet en uiteindelijk was dit de basis voor mijn opleidingsplek. Ik heb inmiddels zelf kunnen zien hoe veel mogelijkheden en uitdagingen jouw nieuwe baan in Amsterdam jou biedt en ik wens jou hier heel veel plezier en succes. Ik hoop toch ooit nog de mogelijkheid te krijgen om binnen de (kinder-) chirurgie van jou te mogen leren. 
De tweede drijvende kracht bij het ontstaan van dit boekje was mijn co-promotor, Joep Derikx. Joep, je hebt ontzettend veel tijd en werk geïnvesteerd en daarom is het tot stand komen van dit boekje voor een groot deel aan jou te danken. Jouw kennis heeft mij op alle vlakken enorm geholpen. Hoe jij als arts, onderzoeker en collega (inmiddels baas) bent, is voor mij een voorbeeld. Jouw motiverende manier van supervisie op wetenschappelijk en chirurgisch werk is fantastisch. Wat hebben we veel gelachen op de EUPSA congressen; altijd belangrijk om ook even goede koffie te drinken en goed te eten. Lachen hoe ik in Dublin opeens zo ziek was en wonderbaarlijk toch weer opknapte zodat je toch niet de hele fles wijn alleen hoefde te drinken. Ik mis ook de vrijdagmiddag-brownies met een "bestuurstoren cappuccino". Joep, ik hoop dat ik ooit nog met jou mag samenwerken en wat chirurgische handigheid van jou mag leren. Hopelijk tot een keer in Amsterdam.

Prof. dr. Zimmermann bedankt voor het optreden als voorzitter van de beoordelingscommissie van dit proefschrift. En ook alle andere leden van de beoordelingscommissie, hartelijk dank voor de tijd en moeite die jullie hebben genomen om mijn proefschrift te beoordelen. Dear prof. dr. Rintala, dear Risto, it is a great honour that you took the effort to join the review committee of my thesis.

Daarnaast ook dank aan de leden van de promotiecommissie die als opponent zijn opgetreden tijdens mijn verdediging.

Dank ook aan alle co-auteurs, jullie hebben er niet alleen voor gezorgd dat wij de data van alle kinderchiurgische centra hebben kunnen verzamelen, maar jullie hebben ook met een kritisch blik de artikelen verbeterd.

Een bijzonder dank ook aan Ko Hagoort. Beste Ko, jouw werk was heel essentieel, je hebt met veel inzet alle stukken gereviseerd en de puntjes op de i gezet.

Beste Marc, ook jij hoort natuurlijk bij "het kinder-team" en hebt mij tijdens mijn tijd in het MUMC veel geleerd. Jouw rust en handigheid zijn inspirerend. Leuk dat we elkaar wel nog op de EUPSA tegen komen en binnenkort mag ik dan in het MUMC ook nog van jou opereren leren. 


\section{Chapter 9}

Mijn paranimfen Mechteld en Greg.

Mechteld, hoe moet ik jou in een paar alinea's danken en zeggen hoe veel je betekent voor mij. Ik begon als semi bij jou en inmiddels hebben wij ook een tijdje als collega's samen mogen werken. Maar veel belangrijker is dat we inmiddels ook echt vriendinnen zijn. Ondanks dat alles niet altijd even makkelijk voor jou gaat sta je altijd voor mij klaar. Door jouw eerlijkheid en oprechtheid heb je mij altijd geholpen het beste eruit te halen... Ik hoop dat wij de Cambodia-Vietnam experience nog eens kunnen herhalen, er staan nog genoeg plekken in de top 500 lonely planet destinations waar wij uit kunnen kiezen. Ook zien we elkaar een stuk minder, echter hebben wij toch vaak genoeg tasty thai dates om elkaar even weer een update te geven. Dank je dat jij er altijd voor mij bent en heden naast mij staat.

Greg. Wat moet ik lachen om jouw imitaties in het Duits over jouw leven bij de chirurgie. Je begreep altijd mijn frustraties, maar ook enthousiasme op het werk en ik kon hiermee altijd bij jou terecht. Bedankt ook voor alle sterren diners! Aan tafel bij goed eten en een goed wijntje was altijd een hele fijne calm down: hoe jij kookt en ik er naast zit (omdat ik niks mag doen.... en ik weet hoe irritant je het vindt als ik met mijn vingers uit de pan proef....), slow dancing in a burning room met Taylor en inderdaad goede wijn. Trouwens, je weet wel dat ik veel beter ben in theedoekfighten dan jij ...

Ik ben blij en trots dat je vandaag naast mij staat als mijn paranimf. Wat fijn dat wij vrienden zijn en ondanks de drukte van het werk elkaar toch vaak genoeg blijven zien.

Assistenten van het MUMC: jullie hebben destijds voor mijn eerste baan gezorgd en tevens hebben jullie mij bij de eerste stapjes binnen de chirurgie ondersteund. Ik zal altijd jullie Kremertje blijven....bedankt voor jullie steun.

Dan Meindert Sosef en de Heerlens chirurgen club... Knipogend had ik beloofd jou en de maatschap chirurgie in Heerlen te noemen en te bedanken voor de financiële ondersteuning voor mijn congresbezoek toen ik net bij jullie was begonnen en wel meteen geld wilde. Bij deze: jullie hebben dus oprecht een bijdrage aan dit boekje geleverd, waarvoor dank! Beste Meindert, jou dank ik voor de kans die je mij hebt gegeven toen ik bij jou binnenliep om te zeggen dat ik wilde 
beginnen in Heerlen, maar ook direct mee wilde solliciteren. Bedankt voor jouw steun tijdens mijn sollicitatie. Ik was graag gebleven, maar soms lopen dingen niet zo als gehoopt en toch komt uiteindelijk alles wel goed.

Lieve assistenten uit het Zuyderland, bedankt voor jullie steun tijdens mijn sollicitatie en in de helaas korte periode die ik bij jullie heb mogen werken. Bedankt voor een leuke tijd, het was top: druk druk druk, maar super gezellig. En gelukkig weten jullie nu allemaal wat een sacrococcygeaal teratoom is.

Mijn nieuwe buddies, Venluuuuse collega's, Marlies, Rene, Bart, Aniek, Hilco, Johanne, Thomas, Arthur, Eva, Meghan, Marjolein, Luuk, Maarten en Freek: jullie hebben mij met open armen ontvangen toen ik net een beetje depri was om het feit dat ik niet in Heerlen mocht blijven en bij jullie begon. Ik ben uiteindelijk blij hoe alles is gelopen, want jullie zijn daadwerkelijk topcollega's en mijn dagelijks werk met jullie wil ik niet missen. Ilse en Ruth, ook al zijn jullie maar tijdelijke collega's, jullie horen er net zo bij als de rest.

Ik hoop dat jullie mijn gekke en drukke manier wel nog even aan kunnen en hoop nog vaker met jullie te kunnen gaan stappen en uiteraard achteraf te mogen genieten van de gastvrijheid van het VieCuri: altijd een zorgzame collega beschikbaar die even wat primperan regelt. In het bijzonder Marlies en Bart: jullie zijn wel echt mijn meest relaxte Vaccation \& Party crew geworden. Zwitserland, Mexico, wat wordt ons volgende trip?

Naast de assistenten in Venlo, wil ik natuurlijk ook mijn bazen in het VieCuri danken voor alle hulp en adviezen. Inmiddels heb ik helemaal mijn plekje bij jullie gevonden en verheug mij erop nog meer van jullie te mogen leren.

"Te gekke etentjes girls": jullie horen bij de collega's en toch zijn jullie een bijzonder groepje. Jullie zijn fantastische meiden en ik hoop onze etenstraditie nog lang voort te kunnen zetten. Bedankt voor alle goede adviezen en support. 


\section{Chapter 9}

Jessica en Lianne: bedankt voor alle tijd die jullie in dit onderzoek hebben gestoken en jullie enthousiasme hierbij. Jullie stonden altijd klaar om meteen weer aan de slag te gaan als ik weer een keertje zo ver was en tijd had. Jullie hebben fantastisch werk geleverd. Heel veel succes met jullie carrières!

Meine liebe alte (und einzige) WG. Es ist so schade, dass wir nicht mehr zusammen wohnen... Ihr habt die Arbeit an dieser Doktorarbeit natürlich live mitbekommen und mir mit Rat und Tat zur Seite gestanden (auch bei der Kleiderauswahl für diverse Konferenzen). Tina, deine Geduld, Sorgfältigkeit und dein unglaubliches Vermögen einfach zuzuhören ist wunderbar und macht dich sehr besonders. Ich bin stolz auf dich, dass du deine Doktorarbeit trotz Gegenwind gemeistert hast und auch auf deine Entscheidung nochmal neu anzufangen in Itzehoe, du wirst eine sehr, sehr gute Therapeutin, da bin ich fest von überzeugt.

Stephielein du bist straight und chaotisch in einer Person, deine Energie um nach der Arbeit noch sämtlichen Verabredungen oder Aktivitäten nachzukommen war beneidenswert, während Tina und ich nur noch in der Lage waren "Bauer sucht Frau" zu schauen. Ich bin sehr froh, dass deine Entscheidung aus Aachen wegzugehen belohnt wurde und hoffe demnächst auf deiner Doktorparty mit dir anzustoßen.

Meine lieben Emashty Mädels Esther, Anni, Steffi, Hanna, Tina und Yassi. Wie besonders es ist, dass wir uns noch so nah sind. Obwohl sich jedes einzelne Leben weiterdreht bleiben wir trotzdem beieinander, mal mehr, mal weniger. Ich bin euch unendlich dankbar für eure Freundschaft und bin stolz so unglaublich tolle, selbständige und hübsche Freundinnen zu haben. Vielen Dank für euer Interesse an meiner Arbeit und eure Unterstützung bei allem. Ihr bedeutet mir sehr viel.

Meine lieben Woogles und Woogle-Männer. Danke, dass ihr es mir nie übel genommen habt, wenn ich mal wieder viel zu spät gekommen bin, oder wegen der Arbeit absagen musste. Vielen Dank für Euer Verständnis und Euer Interesse an meiner Arbeit. 
Meine lieben Geschwister, Verena und Philipp. Unsere Lebenswege sind ganz unterschiedlich und doch haben wir bei näherer Betrachtung viele Gemeinsamkeiten. Und obwohl ich eure kleine Schwester bin, bin ich sehr stolz auf euch und auf das, was ihr aus eurem Leben macht. Ich danke euch für euer Interesse und alle Anerkennung.

Thomas, du gehörst natürlich auch dazu! Ich schätze deine Meinung sehr und staune immer wieder über dein enormes Wissen und dein unglaubliches Diskussions-und Argumentationsvermögen. Schön, dass ihr bald wieder in der Nähe seid.

JoniPoni ich muss dich einfach hier nennen. Du bist mein größter Sonnenschein und ich liebe dich wirklich über alles. Es ist fantastisch wie du uns die Welt erklärst.

Toto, du hast in dieser ganzen Zeit die größte Ausdauer bewiesen. Du hast dich nie beschwert, wenn ich mich am Wochenende wieder an den Schreibtisch gesetzt habe, wieder nicht mitgekommen bin, weil ich arbeiten musste, oder dich versetzt habe, weil ich noch länger auf der Arbeit bleiben wollte. Kein einziges Mal hast du mir das zum Vorwurf gemacht, sondern immer geschaut wo du mir noch Arbeit abnehmen kannst. Ich weiß, dass das nicht selbstverständlich ist und danke dir von ganzem Herzen für alles, was du für mich getan hast. Jetzt ist es endlich fertig.

Mama und Papa. Euch gilt unumstritten der größte Dank. Schon immer habt ihr mich unterstützt und mir alles ermöglicht und dabei nie an mir gezweifelt. Ohne eure Ausdauer in all den Diskussionen, aber auch das Vertrauen, das ihr mir entgegen gebracht habt, würde ich heute nicht hier stehen. Ich kann mir vorstellen, dass es nicht immer leicht war mich auf dem rechten Weg zu halten mit meinem enormen Dickkopf und Temperament und doch habt ihr es geschafft. Dafür danke ich euch von ganzem Herzen. 
